\title{
Review of low-temperature vapour power cycle engines with quasi- isothermal expansion
}

\author{
Opubo N. Igobo, Philip A. Davies
}

\begin{abstract}
Sustainable Environment Research Group, School of Engineering and Applied Science, Aston University,
\end{abstract} Birmingham, B4 7ET, UK email: p.a.davies@aston.ac.uk

\begin{abstract}
External combustion heat cycle engines convert thermal energy into useful work. Thermal energy resources include solar, geothermal, bioenergy, and waste heat. To harness these and maximize work output, there has been a renaissance of interest in the investigation of vapour power cycles for quasiisothermal (near constant temperature) instead of adiabatic expansion. Quasi-isothermal expansion has the advantage of bringing the cycle efficiency closer to the ideal Carnot efficiency, but it requires heat to be transferred to the working fluid as it expands. This paper reviews various low-temperature vapour power cycle heat engines with quasi-isothermal expansion, including the methods employed to realize the heat transfer. The heat engines take the form of the Rankine cycle with continuous heat addition during the expansion process, or the Stirling cycle with a condensable vapour as working fluid. Compared to more standard Stirling engines using gas, the specific work output is higher. Cryogenic heat engines based on the Rankine cycle have also been enhanced with quasi-isothermal expansion. Liquid flooded expansion and expander surface heating are the two main heat transfer methods employed. Liquid flooded expansion has been applied mainly in rotary expanders, including scroll turbines; whereas surface heating has been applied mainly in reciprocating expanders.
\end{abstract}

Keywords:
Vapour power cycle
Quasi-isothermal expansion
Renewable energy
Waste heat utilisation

\section{Contents}

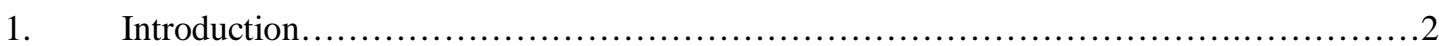

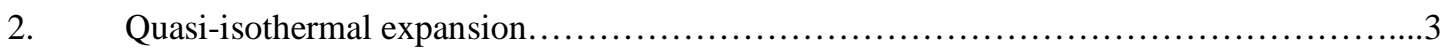

2.1. Methods of effecting quasi-isothermal expansion............................... 3

2.1.1. Expander surface heating........................................

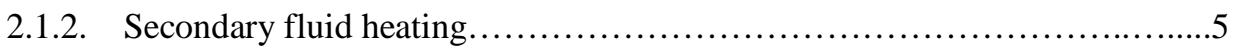

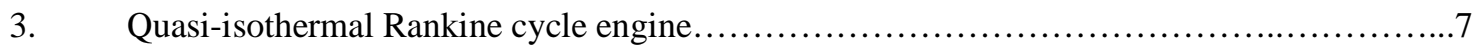

3.1. Liquid flooded Rankine cycle engine......................................

3.2. Surface heated Rankine cycle engine......................................... 8

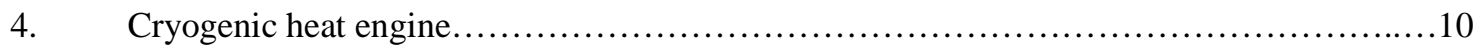

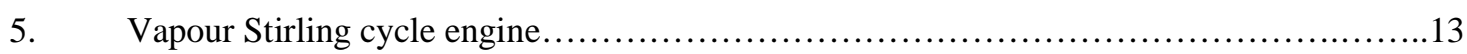

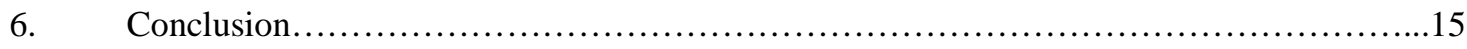

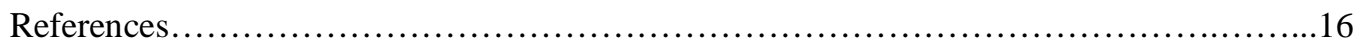




\section{Introduction}

Owing to the global energy challenges associated with fossil fuel - rising cost, energy security and climate change - there has been growing interest into sustainable alternatives or renewable energy sources such as: wind, solar, geothermal, biomass and waste heat. Presently, renewable energy sources account for less than $15 \%$ of the global energy supply [1], of which biomass is a major contributor. However, solar has recorded the fastest growth, and renewables have been projected to become the world's second largest source of power generation by 2015 [2]. Studies have already shown that the renewable heat sources have the potential of meeting the global energy demand several times over [3]. As a means of encouraging the exploitation of the renewable heat sources, 'heat policies' (including incentives) have been introduced in some countries [4]. Globally, solar, biomass and waste heat are readily available in distributed form as low-grade $\left(<250^{\circ} \mathrm{C}\right)$ heat, and are well suited for decentralized small-scale $(<100 \mathrm{~kW})$ applications. Thus there has been a renaissance of interest in small-scale external combustion heat engines (gas and vapour power cycles) to convert the thermal energy into useful work, with particular emphasis on improving performance. Isothermal expansion is one technique for achieving such improvement.

Ideally, certain gas power cycles (such as Stirling and Ericsson cycles) perform work by the isothermal (constant temperature) expansion of a compressed and heated gas working fluid (which remains gaseous throughout the entire cycle). They are noted for having the high theoretical efficiencies of the Carnot cycle - which is the maximum obtainable efficiency for given temperature limits [5]. On the other hand, for vapour power cycles (typically the Rankine cycle), the working fluid is a condensable vapour, and is intermittently vaporised and condensed; the expansion process is adiabatic (i.e. the fluid expands without experiencing heat transfer during the process) and produces less work than its isothermal counterpart [6]. Nevertheless, in comparison to the gas compression work of the gas power cycles, less input work is required to pressurize the condensed liquid of the vapour power cycles, and the total cycle pressure-volume characteristics exhibit greater work output than the gas cycles. Thus the vapour cycle engines have higher specific work output [7]. The vapour power cycles can also have advantages over gas cycle equivalents because the phase change allows smaller surface areas and temperature differences to drive the boiling/condensation required by the cycle. This inference arises from the higher heat transfer coefficients associated with phase change (by orders of magnitude) relative to that of forced convection for gas [8]. The smaller surface areas lead to compact heat exchangers and engine size [9]; this together with the higher work output gives the vapour cycle engines higher power density; and the low temperature differences aid better performance (relative to the gas cycles) in low-grade heat applications. This has been demonstrated in a study that showed the Rankine cycle to be more efficient than Stirling cycle for temperature range of $150-300^{\circ} \mathrm{C}[10]$.

In power plants operating on the Rankine cycle, reheating is a practical approach to improve the cycle efficiency and specific work output. As the number of stages of reheating increases, the expansion and reheat processes approximate an average isothermal process and the cycle efficiency increases [11]. But in the reheating process, the steam must be returned back to the boiler for each reheat, which, besides requiring many additional components, inevitably adds complexity to the plant layout and geometry, and results to heat and pressure losses [12]. Alternatively, the vapour cycle engine could be designed in such a way that (like the Stirling or Ericsson engines) heat is continuously transferred to the working fluid during the expansion process thus resulting in isothermal expansion, or more realistically, quasi-isothermal expansion - which may be somewhere between the adiabatic and ideal isothermal processes.

In this paper, relevant research works with emphasis on low temperature vapour power cycles with quasi-isothermal expansion will be presented. Various methods employed to effect quasi-isothermal operation, including concepts, studies and results, will be reviewed to provide an insight into their practicality, system performance and energy efficiency. The first part (section 2) of the paper presents 
the general theoretical advantage of quasi-isothermal expansion, including the various heat transfer methods used to achieve it. The second part (section 3-5) of the work covers the power cycles to which the methods are applied. For each power cycle, the theory and principle of operation is explained, and then specific studies are reviewed in which these cycles have been implemented. Fig. 1 classifies the methods and vapour power cycles for quasi-isothermal operation according to the approach used in this review.

\section{Quasi-Isothermal expansion}

The paths of both the isothermal and adiabatic expansion processes can be illustrated graphically on a pressure-volume (P-v) plane as shown in Fig. 2, using the gas equation $P_{1} v_{1}^{n}=P_{2} v_{2}^{n}$. The expansion index $\mathrm{n}$ is equal to 1 and $\mathrm{k}$ for isothermal and adiabatic processes respectively [13], where $\mathrm{k}$ is the ratio of the specific heats $\left(\mathrm{C}_{\mathrm{p}} / \mathrm{C}_{\mathrm{v}}\right)$ of the gas, and is always $>1[14]$. For example, under a substantial range of operating conditions, $\mathrm{k}$ is about 1.4 for nitrogen gas and steam [15].

The work output is simply the integral $\left(\int P d V\right)$ between the two end states (1 and 2), as is represented by the area under the path curves. Hence, from the figure it can be seen that the area under the curve (i.e. the expansion work output) for the adiabatic expansion is less than that of an isothermal expansion having the same initial operating conditions. This can also be seen numerically from the integration of both curves from state 1 (start of expansion) to state 2 (end of expansion).

The work done by isothermal expansion can be given as [16]:

$$
W_{i s o}=\int P d V=P_{1} v_{1} \ln \left(\frac{P_{1}}{P_{2}}\right)
$$

Similarly, the work done by adiabatic expansion can be expressed as:

$$
W_{a d}=\int P d V=P_{1} v_{1} \frac{1-\left(\frac{P_{1}}{P_{2}}\right)^{\frac{1-n}{n}}}{n-1}
$$

Hence, from the above equations, the relative improvement of the isothermal expansion work over the adiabatic work can be expressed in terms of the expansion index and pressure ratio $r_{p}=P_{1} / P_{2}$ as:

$$
\text { Relative improvement }=\frac{W_{i s o}}{W_{a d}}-1=\left[\frac{(n-1) \ln \left(r_{p}\right)}{\left(1-r_{p}\right)^{\frac{1-n}{n}}}\right]-1
$$

For example, with $r_{p}=7$ and $\mathrm{n}=1.4$, eq. 3 shows that the isothermal expansion gives $83 \%$ more work than the adiabatic.

The expansion process of conventional vapour power cycles is generally assumed adiabatic, and as such is subject to this reduced work output [6]. The adiabatic expansion process is also characterised by drop in temperature from $\mathrm{T}_{1}$ to $\mathrm{T}_{2}$ '. Hence, modifying an adiabatic expansion to an isothermal one would ideally require the addition of heat to the expanding fluid to maintain its temperature constant.

In reality, when the heat absorbed by the vapour is not sufficient to maintain isothermal expansion, the result is termed quasi-isothermal expansion. In this case, the heat absorbed shifts the expansion 
process from adiabatic behaviour towards the ideal isothermal behaviour. Consequently, the work output will be more than the adiabatic work, but less than the isothermal work available, in proportion to the extent to which the expansion approaches the isothermal case. This extent has been termed isothermality, $\gamma$, defined as the ratio of actual work output to the ideal isothermal work [17].

$$
\gamma=\frac{w_{a c}}{W_{i s o}}
$$

Thus it determines the work output as a fraction of the isothermal work available. On the other hand, for rotary expanders some authors have described the extent of isothermal behaviour as the ratio of discharge temperature to supply temperature [18].

\subsection{Methods of effecting quasi-isothermal expansion}

Over the years, a number of methods have been developed, by which a vapour power cycle's working fluid can continuously gain heat during the expansion process to effect quasi-isothermal expansion; often times this result in variants of the traditional power cycles. The identified methods can be generally grouped on the basis of the means of heat transfer as: secondary fluid heating and expander surface heating. The methods and the power cycles (including the variants) to which it is applied are shown in Table 1.

\subsubsection{Expander surface heating}

A simple approach to achieve heat transfer to the working fluid during the expansion process is to provide a means of heating the expander sufficiently above the fluid temperature; such that during the expansion process, heat could be effectively transferred from the surface of the expansion chamber to the fluid, as illustrated in Fig. 3a. This is quite popular for reciprocating expanders as found in conventional Stirling engines, and steam-jacketed steam engines. The extent of isothermal operation achievable here will depend on the rate of heat transfer, which is a function of the overall heat transfer coefficient and temperature differential between the engine wall and the fluid, and the surface area of the wall exposed to the fluid [19]. As such, geometries giving high surface to volume ratios such as tubes and fins are generally utilised to increase the total heat transfer area as found in conventional Stirling engines [20].

\subsubsection{Secondary fluid heating}

The heat transfer required to effect quasi-isothermal expansion could be provided by means of a secondary fluid which co-exists with the working fluid in the expander during the expansion process (Fig. 3b). In this case, the secondary fluid - which will ideally be of a high thermal content - is dispersed into the working fluid such that during the expansion process, the temperature dropped by the expanding working fluid is quickly recovered from the secondary fluid. The heating fluid could ideally be a vapour - as with direct steam injection; or more practically, a liquid - as with liquid flooded expansion.

\subsubsection{Direct steam injection}

The concept of achieving isothermal expansion by direct steam injection entails injecting small amount of relatively very high temperature steam (secondary fluid) into the expanding steam [21]. The secondary steam transfers heat to the working steam by virtue of its higher temperature thermal content, as such requires the secondary steam to be continuously injected with appropriate amount and temperature in such a way as to keep the expansion temperature constant. 


\subsubsection{Liquid flooding}

The liquid flooding process involves literally flooding a screw or scroll machine with a large quantity of liquid simultaneously as the working fluid passes through the device, such that the liquid provides a medium of heat exchange with the working fluid whilst in transit through the device. Unlike with steam injection, the secondary fluid is normally different from the working fluid, and is immiscible with it. This concept can ideally be applied to compression and expansion processes (its application to expansion processes will be covered in section 3.2.1). Over the last two decades, there have been a significant number of studies on the application of liquid flooding to compressors. Researchers have studied oil-flooding in screw compressors [22] and scroll compressors [23] primarily to improve sealing and lubrication, but without much emphasis on heat transfer [24]. In recent years, conventional screw [25] and scroll [26] compressors have been effectively used in reverse as expanders (with minor modifications), thus widening the scope for liquid-flooded expansion. The combinations of the different working fluids and flooding liquid considered in the literature are shown in Table 2.

The concept of flooded expansion (and compression) was studied by Hugenroth [27] in a liquid flooded Ericson cycle cooler, which used liquid flooding of both the compressor and the expander (to achieve nearly isothermal compression and expansion) to overcome the practical difficulties of achieving isothermal conditions in the basic reverse Ericson cycle. In a later experimental work [28], off-the-shelf automotive scrolls were used as the compressor and expander, nitrogen as the working fluid and alkyl-benzene as the flooding liquid. The performance of the off-the-shelf scroll machine was not sufficient to achieve high cycle efficiency. For increasing operating pressure ratios, the expander adiabatic efficiency was seen first to increase and then to decrease. This effect was partly attributed to the limitation of the expander not being designed for liquid flooded operation

To optimize the design of the compressor and the expander, Bell et al. [29] developed comprehensive models of both machines. Validation of the models and optimization of the design were also carried out [30]. The model developed was an extension of earlier models that were developed by Halm [31], and Chen et al [32] for scroll compressors without liquid flooding. The important contribution of the work was said to be the treatment of a mixture of gas and large fraction of oil. Also, Lemort et al. [33] further studied the performance of liquid flooded expansion using scroll expander and developed a detailed model of the flooded scroll expander, to facilitate predictions of the performance over a wide range of operating conditions and design changes. The model was able to predict the shaft power to about $6.7 \%$ maximum deviation from measured experimental value.

\subsection{Summary}

In summary, quasi-isothermal expansion has been identified as a realistic alternative to adiabatic expansion to improve the work output of vapour power cycle engines. This can be achieved by further heat addition to the working fluid during the expansion process. The heat can be transferred by means of heating the expander external surface, or by means of a secondary heating (flooding) fluid. The expander surface heating is found to be more popular with reciprocating engines, whereas the secondary fluid heating is more popular with rotary engines. 


\section{Quasi-isothermal Rankine cycle engines}

\subsection{Theory and principle of operation}

The quasi-isothermal Rankine cycle is simply a Rankine cycle whose working fluid gains significant amount of heat during the expansion process of the cycle, such that it is somewhere between adiabatic and isothermal, but its reference limit is ideally isothermal, as depicted on the temperature entropy (Ts) diagrams in Fig. 4. Fig 4a shows a case where the expansion starts from a super-heated state [34]; while in Fig 4b, the expansion starts from a saturated state [35]. As a result of the heat addition during the expansion process, the spent vapour becomes significantly superheated at the end of expansion, thus necessitating regeneration (utilising the heat available at the end of expansion to preheat the feed working fluid) to improve the thermal efficiency. Studies have shown that the efficiency of the ideal cycle (with isothermal expansion and regeneration) can be up to $93 \%$ of the efficiency of a Carnot cycle operating with the same temperatures limits [21]. Where isothermal expansion is not fully achieved, the resulting quasi-isothermal cycle's performance will depend on the quantity of heat successfully absorbed during expansion, which of course is dependent on the heat transfer technique employed.

\subsection{Studies and performance}

Using the thermodynamic cycles of Fig 4, researchers have proposed and studied different versions of the quasi-isothermal Rankine cycle using different modes of heat transfer. Thus, both liquid flooded and external heated surface machines have been reported. These implementations will now be reviewed.

\subsubsection{Liquid-flooded Rankine cycle}

The idea of liquid flooded expansion can be applied to Rankine cycle, as patented by Woodland [36]. A schematic of the system is depicted in Fig. 5. The working fluid and the flooding liquid are both pressurised and heated to the required high side pressure and temperature (via separate pumps and heat exchangers). The fluids are then mixed and fed to the expander where they flow together to do work. During the expansion process, temperature drop of the working fluid (vapour) is inhibited by heat gain from the liquid (because the liquid has a relatively higher heat capacity), thus resulting in a near isothermal expansion. At the end of expansion, the superheated working fluid is then separated from the liquid and passed through a regenerator (before being condensed) to preheat the condensed fluid pumped for the next cycle, as the flooding liquid is simultaneously re-pressurized and heated back to the high side conditions.

Woodland [37] also carried out theoretical study of the application of liquid flooding to organic Rankine cycle (ORC) with regeneration, for different working fluids (ammonia, carbon dioxide, R410a and dry fluids such as iso-butane, n-pentane and R245fa ). The analysis showed that, working fluids ammonia and R410a exhibited higher performance improvement due to the flooded expansion. For ammonia, the addition of the liquid flooding offered about $20 \%$ more improvement in thermal efficiency. A later study [38] that featured water as a working fluid in the liquid flooded ORC, showed a relative improvement of $10 \%$ due to the flooded expansion; the improvement increased with the source temperature. In contrast, the improvement for the dry fluids was significantly less (only about $5 \%)$, and approaches zero at higher $\left(>250^{\circ} \mathrm{C}\right)$ operating temperatures. Higher work output was expected from the more isothermal flooded expansion than from ordinary expansion process. However, for these dry fluids, the improvement in work output is not high enough to significantly outweigh the additional energy inputs (pump work and heat input) required for the flooding process. 
Lemort et al. [39] developed a prototype of a flooded Rankine cycle engine with a hermetic scroll expander and R245fa working fluid. The study was focused on investigating the impact of oil quantity on the expander performance. For operating pressure ratio of 4.2 bar, supply temperature of $92^{\circ} \mathrm{C}$ and oil mass fraction of $0.023-0.1$, the results showed that the expander overall isentropic effectiveness (ratio of the measured power output to the ideal expander power) decreased with increasing oil quantity. Further investigation was recommended to ascertain with certainty the underlying reason; nevertheless, increase of supply pressure drops (at the expander inlet) and viscous losses were mentioned as likely reasons for the decrease in performance. This is in agreement with the results of a previous study on the performance of liquid flooded expansion using scroll expander [33]. For a given pressure level, in the experiment, the measured power output reportedly decreased with the oil flow rate as a result of increasing pressure drops due of the oil suction process at the expander inlet. The study also analysed the variation of exhaust temperature with oil fraction for different operating speeds. As would be expected, the result further showed that the expansion tends to approach isothermal behaviour for higher oil fractions. The range of isothermal expansion (in this case defined as the ratio of discharge temperature to supply temperature) achieved was about 0.93 to 0.99 for oil fractions of 0.2 to 0.8 respectively. This shows that, although the liquid flooding facilitated sufficient heat transfer, such that isothermal behaviour is approached, there are practical challenges in translating it to net performance improvement. Another practical issue worth noting is that the separation of the refrigerant from the oil in the oil separator is not generally perfect, as such some amount of refrigerant usually remain entrained in the oil [28]. This entrainment may pose a durability issue in the long run, as higher oil flow rate will result to larger amount of refrigerant entrained, thus it can result in the need for frequent servicing, as has been observed with oil flooded compressor [40].

For the purpose of increasing the efficiency of a trans-critical $\mathrm{CO}_{2}$ Rankine cycle thermo-electric energy storage (TEES) system, Kim et al. [41] proposed the application of a variant of the liquid flooded concept to achieve isothermal expansion (and compression) for the discharging (and charging) process of the TEES system. The discharging process is basically the retrieval of mechanical-electrical energy from the stored thermal energy by means of a heat engine (Rankine cycle, in this case). Fig. 6 depicts the discharging process of the proposed isothermal TEES system.

The system is somewhat like a double cylinder engine. On operation, pressurised $\mathrm{CO}_{2}$ is heated in the evaporator and fed via valve ' $\mathrm{A}$ ' into the first cylinder which is initially filled with hot liquid. The vapour then exerts pressure and expands against the hot liquid (serving as a liquid piston) which flows through the 4-way valve and the hydraulic motor (wherein the flow and pressure of the liquid is converted into rotary work). During the expansion, the circulation pump continually sprays a portion of the hot liquid unto the expanding vapour, thus providing a means of heating the vapour to effect isothermal expansion. The expended liquid continuous in flow, through the heat exchanger in the hot storage tank and back through the 4-way valve into the second cylinder, thus exhausting the hot expanded vapour in the second cylinder via valve ' $\mathrm{D}$ ' and the regenerator to the condenser. As the stroke ends, the 4-way valve switches to reverse the flow (between the two cylinders), without changing the hydraulic pump's direction of rotation. An analysis of the system performance for the operating conditions of 160 bar and $122^{\circ} \mathrm{C}$ showed that the isothermal expansion can result in a $46 \%$ increase in work output.

\subsubsection{Expander surface heated engines}

\subsubsection{Steam jacketed reciprocating steam engine}

The steam engine with steam jacket is a classic approach to quasi-isothermal expansion. Nevertheless, certain features and observations are interesting in the modern context where steam or other (organic) working fluids may be used.

In steam engines, there tends to be heat transfer between the steam and the cylinder wall, in such a way that heat is rejected by the steam to the cylinder during the admission and early expansion 
process, while heat is transferred from the cylinder to the steam in the later part of the expansion and exhaust. This phenomenon is most pronounced for dry steam (relative to superheated steam) as the heat rejection and gain respectively leads to steam condensation on the cylinder wall and reevaporation of some of the condensate during the rest of the expansion process thus leaving behind some amount of condensate-water in the cylinder. The condensation of steam in the cylinder results in a very rapid drop in maximum pressure and thus decrease in work output, which implies an increase in steam consumption (quantity of steam) required to achieve a given power output. This consequently results to reduced efficiency, since not all the admitted steam is available to produce work for a given amount of heat energy input to generate the steam [42].

Besides the use of sufficiently superheated steam, or protecting the cylinder with lagging (insulation), steam jacketing the cylinder can be effectively utilised to mitigate the heat loss from the steam. Various Experiments carried out by a number of researchers, as recorded by Clark [43] in the 1800s, have showed that the alternate condensation and re-evaporation in steam jacketed cylinders are much less than that in unprotected cylinder. The steam jacketed cylinders results to economy in the steam consumption and displayed a greater degree of efficiency than the cylinder with superheated steam, whilst both of them are clearly superior to an unprotected cylinder with saturated steam. The steam jackets have reportedly resulted to economy of $14-25 \%$ in steam consumption rate per power output, net specific work output increase of $42 \%$ (from 224 to $318 \mathrm{~kJ} / \mathrm{kg}$ ) and efficiency (in terms of the total heat passed into the cylinder and the work output) increase of $28 \%$ (from 8.65 to $11.05 \%$ ). Further results showed that better performance was recorded for higher working pressure - this could be explained by the fact that heat transfer is facilitated by higher pressure. It was also demonstrated that by the utilisation of the steam jacket with high temperature, heat can be supplied (from the cylinder to the working steam) in quantity sufficient to prevent (or mitigate) the initial condensation in the cylinder and to re-evaporate the whole of such that may have been condensed.

\subsubsection{Surface heated boiler-less Rankine engine}

The speed of heat transfer is a limiting factor in the steam jacket design, but for certain applications speed is not considered critical. Igobo and Davies [44] proposed to use a slow-moving machine to drive a high pressure reverse osmosis process for desalination that works on a cycle time of the order of minutes. In this case, it was proposed to eliminate the traditional boiler (evaporator) of the steam engine and rely on the jacket (which may be thermal oil fed) alone for heat transfer to vaporise the working fluid and to maintain quasi-isothermal expansion. Fig. 7 shows a schematic layout for the cycle, its corresponding temperature-entropy $(T-s)$ is similar to that depicted in Fig $4 \mathrm{~b}$; on operation, water injected into the heated cylinder vaporises on contact with the hot walls, and exerts pressure on the piston to perform work while expanding. Given the relatively higher temperature of the cylinder wall, further heat is transferred to the steam during the expansion process. At the end of expansion, the superheated exhaust steam could be passed through a heat exchanger - prior to been condenser, to preheat the condensed fluid pumped for the next cycle.

Parametric analysis of the engine showed that, the heat transfer rate and thus speed of operation will increase with increasing wall temperature and with decreasing cylinder size. Preliminary experiment carried out on a $100 \mathrm{~mm}$ bore cylinder at $250^{\circ} \mathrm{C}$ wall temperature, showed that engine performance increased with the volume of water injected $(0.8-1.6 \mathrm{ml})$. A maximum pressure of about $18 \mathrm{bar}$ and $336 \mathrm{KJ} / \mathrm{kg}$ of specific work output was achieved for $1.6 \mathrm{ml}$ of injected water. The cycle efficiency also increased with the injected water volume, as efficiency range of $14-16 \%$ was achieved, which is about a half of the ideal cycle efficiency. The less-than-ideal performance was attributed mainly to non-isothermal operation as a result of insufficient surface area (of the expansion space) for heat transfer. This assertion is expected, as it has been noted in literature that: in reality, isothermal operation cannot be carried out in reciprocating engine, due to limited heat transfer area [45]. 


\subsubsection{Surface heated Rankine cycle scroll engine}

The scroll expander is a compact device with few moving parts compared to the reciprocating engine. Scroll expanders and compressors are widely used in refrigeration cycles and have become popular for use in small scale ORC heat engines [46]. Among these, engines using isothermal expansion are an interesting option.

Kim et.al. [47] proposed a scroll expander with external heating structure which included external fins attached on the scroll casing and a heating jacket (as depicted in Fig. 8); such that heat could be effectively transferred from an external source, through the scroll casing into the scroll interior. In the expansion process of the system, the transfer of heat from the scroll interior to the working fluid will reduce the temperature drop that would have otherwise resulted, thus effecting a quasi-isothermal expansion, and consequently contributing to improvement in specific work and thermal efficiency. For air as the working fluid, the isothermal process can result in a potential $34 \%$ increase in the expansion work. The system was suggested to be applicable to Ericsson cycle, refrigeration cycle and Rankine cycle.

For use in Rankine cycle, they also highlighted the possibility of the system acting as an expander and partially as a boiler, such that a very wet vapour could be employed as the working fluid at the point of entry into the expander, since the scroll machines are noted for tolerating substantial quantities of liquid fraction. In that case, given that sufficient heat is available from the scroll, the liquid fraction will vaporise during the expansion process, thus tending to reduce the rate of fall in pressure that would have otherwise resulted, and permitting higher volumetric expansion ratio and thereby enhancing the extraction of more work.

\subsection{Summary}

To summarise with regard to the Rankine cycle engine and its implementation with quasi-isothermal expansion, the expander surface heating can achieve significant improvement in performance even though the expansion chamber surface area available for heat transfer may not be sufficient to approach the level of isothermal behaviour reported with the liquid flooding system. On the other hand, the liquid flooding may experience deteriorating performance in reality, mainly because, unlike the expander surface heating, the liquid flooding incurs additional pumping energy input (for the liquid loop) and increased suction pressure drop, which (together with other associated losses) can eventually outweigh the expected performance improvements. From the perspective of technology availability, liquid flooding can be easily implemented, since its main components (scroll compressor, pump and heat exchanger) are readily commercially available. Nevertheless, it is a relatively new technology (that is yet to be fully developed), in comparison to steam jacketing, which can be regarded as a mature technology that has been proven effective and operational. However, for practical consideration for both technologies, proper insulation is recommended, to ensure that the heat loss (from the engine and piping) to the ambient is greatly minimised, so as not to result to a detrimental effect on the overall performance. In addition, further research work should be carried out on modelling of complex, unsteady multi-phase heat transfer with liquid flooding devices; and development of efficient separation mechanism for the flooding liquid separator. 


\section{Cryogenic heat engine}

\subsection{Theory and principle of operation}

Cryogenic engines are another example where quasi-isothermal expansion is used. It is interesting to review the works in this area for possible application of similar features to heat powered engines working at higher temperatures.

Cryogenic heat engines utilize the thermodynamic potential between the ambient atmosphere and a cryogenic fluid, which is generally regarded as energy storage medium. The basic concept of the cryogenic heat engine is to utilize ambient heat from the atmosphere as heat source to heat a pressurised cryogenic fluid which can be used to drive a prime mover. This is in contrast with typical heat engines which utilize an energy source at temperature significantly above ambient and use the atmosphere as a heat sink [48]. As with conventional heat engines, the performance of the cryogenic engine is strongly dependent on the cryogenic working fluid employed. A study pointed out the benefits of using low-mass gases (like $\mathrm{H}_{2}, \mathrm{He}, \mathrm{Ne}, \mathrm{N}_{2}$, and air) in two-phase system, as having large maximum specific work values [49], with $\mathrm{H}_{2}$ having the largest value. Other common cryogens are hydrocarbons, including liquefied natural gas $(\mathrm{LNG})$, of which methane $\left(\mathrm{CH}_{4}\right)$ is noted for having high specific work output potential [50]. Nevertheless, liquid nitrogen and liquid air are considered most attractive because they are essentially inexhaustible resource (that can be effectively produced from air) with considerable safety and environmental benefits.

Standard thermodynamic power cycles can be employed to produce useful work from the cryogenic fluid. For instance, cryogenic gas Stirling cycle could utilise seawater (ambient temperature) as the heat source to heat nitrogen gas in the expander, while liquefied natural gas (LNG) serves as the heat sink to cool the gas during compression [51]. Similarly, ambient evaporation of a cryogenic fluid and condensation by means of LNG as heat sink, can be employed for cryogenic Rankine cycle (Fig. 9a); and multiple cryogenic cycles can be cascaded to yield better cold energy recovery (Fig. 9b and c) [52]. For these closed cycles, propane $\left(\mathrm{C}_{3} \mathrm{H}_{8}\right)$ and ethane $\left(\mathrm{C}_{2} \mathrm{H}_{6}\right)$ are commonly considered as the working fluids; nevertheless, other low boiling point substances can be employed. The cryogenic power cycle can also be used as the bottom cycle in combined (or hybrid) cycles with other relatively higher temperature power cycles [53]. However, the simplest and most applicable power cycle is the open system (direct expansion) Rankine cycle [54], where the spent exhaust gas is released into the atmosphere. In this case the principle of operation is similar to that of a typical open cycle steam engine.

A schematic of a typical cryogenic heat engine is depicted in Fig. 10. The cryogenic liquid stored in a tank (which may be vacuum jacketed) is pumped to the required working pressure; the pressurised liquid is then vaporised and heated in an appropriate ambient heat exchanger system, and then fed to an expander, where it expands to do work. Since the rapid expansion process of the cryogen fluid results in the temperature of the fluid always being less than ambient, the expander will be at a relatively higher temperature than the expanding fluid, thus during the expansion process, further heat may be transferred from the expander to the fluid, resulting to a possible quasi-isothermal expansion process [48]. The T-s diagram of the ideal cycle at critical pressure operation is shown in Fig. 10b. Process 1-2 indicates the pumping process, process $2-3$ is the heating process in the heat exchanger, and process 3-0 is the isothermal expansion. Process 0-4-1 is the condensation stage (for closed loop system), or the liquefaction process which takes place remotely in an air processing plant [55] (for open system). 
Over the years, there have been investigations on the application of cryogenic heat engine for power generation, and also as an automotive propulsion for non-polluting zero emission vehicles; concept and technical feasibility have been evaluated [56], flow simulations in the engine have been carried out [57], and demonstration models have been built to test its practicality [58]. Key for practical realisation of the engine is the heat exchanger. Considering the low temperature of the cryogenic fluid, it will be essential for the liquid to be vaporized without the accumulation of frost, so as to avoid deteriorating performance. William et al., [59] developed a frost free heat exchanger for using atmospheric air to vaporize and superheat relatively large quantities of liquid nitrogen without the adverse building up of frost. Amrit et al. [60] also developed a cryogenic heat exchanger and presented analytical model for turbulent flows.

Research work carried out at the University of Washington highlighted substantial benefits in the overall energy efficiency for isothermal expander over an adiabatic one in liquid nitrogen cryogenic engines [61]. The study investigated the specific work output as a function of peak cycle pressure for adiabatic and isothermal expansions and showed that the isothermal work increases monotonically with increasing pressure, while that for the adiabatic process is found to be only weakly dependent on peak cycle pressure above $4 \mathrm{MPa}$. For pressure range of 10 to 300 bar at $300 \mathrm{~K}$, the net specific work is 190 to $420 \mathrm{~kJ} / \mathrm{kg}$ and 140 to $190 \mathrm{~kJ} / \mathrm{kg}$ for isothermal and adiabatic conditions respectively.

Knowlen [62] studied the performance of two other cryogens (namely $\mathrm{CH}_{4}$ and $\mathrm{C}_{2} \mathrm{H}_{6}$ ) alongside $\mathrm{N}_{2}$ for both isothermal and adiabatic expansion, and also showed that for all the working fluids, at a given injection pressure, the specific work obtainable from isothermal expansion exceeded that of the adiabatic expansion, with the difference greater as pressure is increased. The study also examined the use of $\mathrm{N}_{2}$ as a heat sink for different closed loop $\mathrm{CH}_{4}$ and $\mathrm{C}_{2} \mathrm{H}_{6}$ topping cycles, and found that for binary $\left(\mathrm{N}_{2}-\mathrm{CH}_{4}\right)$ and ternary $\left(\mathrm{N}_{2}-\mathrm{CH}_{4}-\mathrm{C}_{2} \mathrm{H}_{6}\right)$ cascaded cycles, specific energies in the range of 200$380 \mathrm{~kJ} / \mathrm{kg}$ and $300-450 \mathrm{~kJ} / \mathrm{kg}$ can be realized respectively, depending on the extent of isothermal operation achievable. Yuanwei et al. [63] proposed a Temperature-Energy level-Energy (T- $\Omega-H)$ diagram method for analysing the performance of two different configurations of three-loop cascaded cycles with seawater and LNG respectively as the heat source and heat sink. They claimed that the proposed method facilitates quick optimisation process on a base case design. A number of authors have also explored different closed cycles that use seawater and LNG respectively as the heat source and heat sink. Choi et al. [64] compared the performance of different configurations of two and three loop cascaded cycles and combined (closed-open) cycles in comparison with the conventional single closed or open cycles. The study showed that the cascaded cycles exhibited better performance than the conventional single closed or open cycles; it also showed that, $\mathrm{C}_{3} \mathrm{H}_{8}-\mathrm{C}_{2} \mathrm{H}_{6}$ cascaded cycle exhibited 51\%, 49\% and $89 \%$ more work output than $\mathrm{C}_{2} \mathrm{H}_{6}-\mathrm{C}_{3} \mathrm{H}_{8}$ cascade, $\mathrm{C}_{3} \mathrm{H}_{8}$ and $\mathrm{C}_{2} \mathrm{H}_{6}$ cycles respectively; while the $\mathrm{C}_{3} \mathrm{H}_{8}$ cycle gave $27 \%$ more work than $\mathrm{C}_{2} \mathrm{H}_{6}$. Liu and Guo [65] studied a variant of the cascaded cycle combined with vapour absorption process, the cycle employed a binary mixture of Tetrafluoromethane $\left(\mathrm{CF}_{4}\right)$ and $\mathrm{C}_{3} \mathrm{H}_{8}$ as the working fluid. The study showed that, the proposed cycle can achieve $206 \mathrm{~kJ} / \mathrm{kg}$ specific work output, which is $63 \%$ higher than that of $\mathrm{C}_{3} \mathrm{H}_{8}$ cycle $(124 \mathrm{~kJ} / \mathrm{kg})$. In a study by $\mathrm{Li}$ et al. [54], an open cycle with two-stage expansion was shown to exhibit $326 \mathrm{~kJ} / \mathrm{kg}$ work output. This compares reasonably with the performance reported for other two-loop cascaded cycles. Hence, although cascading closed cycles can significantly improve performance, it is also possible to achieve reasonable performance improvement with the relative simpler open system, with the aid of multiple expansion stages.

In a bid to avoid drop in expander wall temperature, which could result to deteriorating performance, Knowlen [48] suggested the use of "warmant" anti-freeze liquid (as a heat transfer fluid) to be pumped through the wall, so as to maintain it at near ambient temperature. Also, a parametric analysis on engine (reciprocating expander) geometry showed that long strokes, small bore and low RPM enhances heat transfer during the expansion process. Nevertheless, the transferable heat will be limited by the expander's surface area exposed to the fluid, which will limit the degree of isothermal operation achieved. For standard engine (without modifications to cylinder piston geometry), 
isothermality is typically about 0.75 and can be improved further by enhancing heat transfer during expansion. Further analysis showed that finned piston and cylinder head geometries (Fig. 11) having high surface-to-volume ratios can be used to facilitate further heat transfer during the expansion, resulting in potential net work output of 0.85 of the ideal isothermal work.

Liquid air has similar properties to those of liquid nitrogen since air is composed of $78 \%$ nitrogen. Chen et al. [17] studied the performance of a liquid air engine for a range of working conditions and reported that, for a properly designed and manufactured engine with operating conditions of $100 \mathrm{bar}$ and $300 \mathrm{~K}$, the practical (taking into account the losses associated with conventional engines) net work outputs of the liquid air engine for isothermalities of $\gamma=0.90$ and 0.75 were respectively 200 $\mathrm{kJ} / \mathrm{kg}$ and $150 \mathrm{~kJ} / \mathrm{kg}$, i.e. respectively about 122 and $66 \%$ higher than that for an adiabatic engine (about $90 \mathrm{~kJ} / \mathrm{kg}$ ). Given that the energy consumption for liquid air production is about $1080 \mathrm{~kJ} / \mathrm{kg}$ [55], the efficiency of the cryogenic engine (in terms of energy in and energy out) for the above stated isothermalites will be about $18.5 \%$ and $13.9 \%$, while that for the adiabatic condition will be $8.3 \%$. However, Ameel et al. [66] indicated that the efficiency of the isothermal cycle can be improved by about $17 \%$, if the liquefaction process is combined with the heat engine.

Dearman [67] developed a variant of the cryogenic engine, whereby the cryogenic liquid is directly injected into a heat exchange liquid (water) in a reciprocating expander, thus the heat exchange takes place inside the engine, consequently eliminating the need for the relatively complicated, heavier and expensive heat exchanger as required previously. The principle of operation is such that, when the piston is at the top of the cylinder, water is admitted into the cylinder dead space, and then a little amount of the cryogen is injected into the water. Since the water temperature (ambient) is substantially higher than that of the cryogen, the cryogen rapidly vaporises, builds up pressure, becomes superheated and pushes the piston as it expands to do work. At the return stroke, the spent gaseous cryogen and the water are exhaust out. The water can be recovered, reheated and pumped back to the cylinder for another cycle [68].

Wen et al [69] studied the heat transfer behaviour between liquid nitrogen and water (as the heat transfer fluid) in Dearman's engine, and reported a much stronger heat transfer than that obtained from boiling on smooth surfaces and flow boiling through pipes, but comparable to that of rough surfaces and pipes with porous inserts. The pressure was seen to develop very rapidly (up to 500 $\mathrm{kPa} / \mathrm{s}$ ) and increased approximately linearly with the injection pressure; thus indicating that high pressure could be effectively developed to run the engine. Morse and Kytomaa [70] also carried out experimental study of the vaporisation of liquid nitrogen and LNG in water, and found that, the evaporation rate is significantly dependent on both the turbulence intensity of the water surface, and the thickness of the cryogenic liquid layer. However, vaporising LNG in water may require safety precautions against possible ignition of the vapour, as has been reported with incidents of LNG spills on sea [71].

\subsection{Summary}

In summary, the cryogenic engine provides an inherent means of effecting quasi-isothermal expansion with ambient temperature. The potential isothermal performance increases with increasing pressure and could be as much as twice that of the adiabatic case. Cascading multiple cycles would give better energy recovery than single closed or open cycles; however, the open cycle is the most applicable. For an operating pressure of $10 \mathrm{bar}$, the potential performance of the liquid nitrogen open cycle cryogenic engine can have an ideal efficiency of $19 \%$ and specific work of $200 \mathrm{~kJ} / \mathrm{kg}$; but this performance is quite low in comparison to the $27 \%$ ideal efficiency predicted for a surface heated engine operating on steam with similar pressure [44], and the reported $318 \mathrm{~kJ} / \mathrm{kg}$ specific work achieved for a real surface heated (steam jacketed) engine operated at 5 bar [43]. Furthermore, unlike the surface heated engine, although the cryogenic engine has the advantage of not losing heat to the ambient (since it can be at the same or even lower temperature potential with the ambient), it could suffer evaporative losses and 

result to excessive pressure rise [72].

\section{Vapour Stirling cycle engine}

\subsection{Theory and principle of operation}

The ideal Stirling cycle is a classical implementation of isothermal expansion. Though ideally efficient, it suffers from low specific power output at moderate temperatures and pressures [73]. As a means of increasing the specific power output, the use of condensable working fluid has been investigated in prior arts - the vaporisation of liquid at the hot side of the Stirling engine followed by condensation at the cold side has been identified as a viable solution [74], the use of refrigerants as working fluid has also been considered [75]. Prior arts (including a number of patents) have investigated various means of employing vapour as the working fluid in the Stirling cycle engine (including liquid-piston variants).

The concept of liquid-piston Stirling (fluidyne) engine is to replace the conventional solid-pistons of Stirling engine with columns of liquid (typically water) in U-tubed cylinder. Unless the liquid in the expansion cylinder has a low vapour pressure at the operating temperature or is separated from the hot gas by some kind of insulating float (generally referred to as dry fluidyne), ample evaporation will take place from the liquid surface and wetted cylinder walls to effect a mixture of gas and vapour working fluid [76]. As such the fluidyne engine can provide both gas and vapour power cycle. One critical design parameter in the fluidyne engine is the frictional losses in the oscillating liquid columns [77]. Studies have shown large dry fluidynes to be quite successful, but on the other hand, small dry fluidynes (which generally suffer from the large transient heat-transfer and flow losses associated with small-diameter tubes) have been reported to be impractical in the absence of evaporation [76]. The evaporation tends to raise the pressure during the expansion phase and thus increases the indicated power in the fluidyne engine. Owing to the fact that the power output is available in the form of pulsating pressure/movement of liquid in a tube, the most obvious application was as a pumping engine [78]. However, a rotating shaft power output option have also been identified, via the use of hydraulic motor [79] or solid pistons [80]; with the former, as shown if Fig. 12, the solid piston converts the pressure in the liquid piston into a force which can then be applied to a shaft, like conventional engines.

Since liquids can conform to irregular shapes, unlike solid-piston, liquid pistons have the advantage of possibly allowing the adoption of working chambers with very large surface area to volume ratios such as wire matrix, tube bundle, metal foam, etc. (Fig. 12), to substantially improve heat transfer to the working fluid and consequently bring the working fluid behaviour into the nearly isothermal regime (which will result to improved power output and efficiency). However, the high area to volume ratio will result to smaller size of flow passages, increased flow restrictions and thus, increased viscous losses. As such the heat transfer area and the viscous frictional losses must be adjusted to maximize the efficiency of the liquid piston engine [81]. Besides the increased viscous losses, the liquid piston also suffers operating stroke and frequency limitations imposed by gravitycontrolled oscillation and by surface instability at high frequency; and the need to keep a more or less constant orientation of the engine [80].

Various concepts involving the conventional solid-piston Stirling engines variants with modifications on operational configurations have also been recorded. Redderson [82] patented a vapour Stirling machine based on the alpha Stirling configuration. It featured heating and cooling chambers on the hot and cold cylinder tops respectively, and with a regenerator interconnecting the two chambers (Fig. 13). But in contrast, the working fluid in the cooling chamber is substantially in the liquid phase as such resulting to a significantly larger swept volume ratio than a conventional Stirling engine. On 
operation, the upward motion of the cold cylinder piston pumps the fluid through the regenerator into the hot chamber where it gets completely vaporised and superheated and then expands to perform work against the hot piston while gaining further heat from the hot chamber, thus tending to approach isothermal expansion. At the end of expansion, the upward motion of the hot piston pushes the spent vapour through the regenerator and into the condenser where it condenses back to water. As a means of providing output control, a control cylinder is included at the cold section to vary the effective mass of the working fluid within the engine.

Davoud and Burke [83] patented a condensing vapour Stirling engine, in which at the end of expansion, a portion of the spent vapour is expelled (via a receiver cylinder) and condensed, while the remaining portion is compressed in the power cylinder, during which the weight equivalent of the condensed portion is pump and injected back into the cylinder as a fine spray of water. This was said to lower the entropy and enthalpy of the steam in the cylinder, and thus lower the compression work that would have been required. The compressed steam gets superheated in the heater tubes arrangement at the top dead centre of the cylinder, and then expands against the piston to do work. They later went further to patent a simpler version (with only one cylinder), in which bulk of the spent steam is expelled directly to the condenser. The condensed water is then pumped and injected into the cylinder top dead volume containing the heater tubes where it gets vaporised and superheated [84].

\subsection{Studies and performance}

West [74] developed a two-phase, two component working fluid system for an alpha Stirling engine configuration (Fig. 14), in which, the working fluid consists of both a condensable vapour (steam) and permanent gas (air), such that the air is contained in the cold section, and prevented from passing into the hot section by means of controlled evaporation (i.e. steam pressure) in the hot section. Water injected into the evaporator vaporises into the hot cylinder where it expands to do work. The expended vapour then passes into the cold end where it condenses and is subsequently removed.

The analysis showed that under moderate operating conditions the engine can achieve a cyclic power output at least five times greater than a conventional Stirling-cycle machine of similar dimensions, but at the expense of significantly lower ideal cycle efficiency. Nevertheless, by controlling the rate at which the liquid is evaporated into the expansion cylinder an indicated efficiency in the range of 3 to $9 \%$ at low temperatures $\left(110^{\circ} \mathrm{C}\right.$ to $\left.130^{\circ} \mathrm{C}\right)$ may be achievable even without regeneration.

Isshiki et.al. [85], developed a steam Stirling engine which operates as a hybrid of Stirling and Rankine systems, such that the engine featured a power cylinder (with heating tube at the cylinder top), displacer cylinder and a regenerator in between, as with Stirling; but also has injection/exhaust port, thus spent steam could be ejected, condensed, pump and re-vaporised externally just like Rankine. On operation, when the power piston comes near its top dead centre, saturated steam from the external boiler injected into the displacer cylinder, passes through the regenerator and heater, and then expands into power cylinder at near constant high temperature. On the return stroke, the spent steam passes through the regenerator and is exhausted to a condenser where it gets condensed and then pumped back to the boiler. Experiment carried out on a mini scale prototype operated at $0.2 \mathrm{Mpa}$ (gauge) and $250^{\circ} \mathrm{C}$ showed that output power of about 12 watt was achieved at $400 \mathrm{rpm}$. This is significantly higher (approximately five times) than the reported 2.6 watt achieved for a conventional gas Stirling engine operated at $320^{\circ} \mathrm{C}[86]$.

\subsection{Summary}

In summary, the use of vapour as the working fluid in Stirling engines can result in power outputs about five times larger compared to conventional non-condensable gas working fluid. To facilitate more heat transfer to the fluid to approach a more isothermal behaviour, liquid pistons could be employed to allow the expansion space to be enhanced with high surface area geometries like wire matrix. However, it introduces practical issues that will need to be further investigated. As such it is 
recommended that further research be carried out on: modelling the behaviour of the oscillating liquid in liquid piston devices with particular attention to viscous forces and inertia effect of the liquid oscillation. Since the various technologies presented are still in the concept or early development stage, further experimental studies should be carried to give a better insight on their practical realisations; and optimization of the various full engine dynamics to maximize efficiency and power density for specific applications.

\section{Conclusion}

To convert low-grade thermal energy into useful work, external combustion engines using vapour cycles (though relatively less efficient) have been preferred over those using gas powered cycles due to the former's higher specific work output and smaller engine size. Relative to the traditional ideal adiabatic expansion process in the vapour power cycle engines, quasi-isothermal expansion has been found to improve the specific work output and cycle efficiency of the engines.

Two main methods of effecting the quasi-isothermal expansion have been identified - liquid flooding and expander surface heating. The expander surface heating has been studied for both reciprocating and rotary expanders; however there are more references in the literature for its use with reciprocating expanders. Liquid flooding is referenced more for use with rotary expanders.

In practical performance of the quasi-isothermal expansion, studies have showed that liquid flooded expansion approaches isothermal behaviour with increasing oil fraction; but at the expense of deteriorating overall performance, that was partly attributed to the resulting increased suction pressure drop and viscous losses. On the other hand, the expander surface heating has been shown to achieve significant improvement in performance (over $40 \%$ and $20 \%$ increase in specific work output and efficiency respectively). Here, a relatively slower operating speed is required to enable significant heat transfer during the expansion process as the cylinder wall surface area available for heat transfer limits the isothermal operation. However expander geometries with high surface-to-volume ratios (such as fins) could be employed to facilitate heat transfer and further improve performance, as has been demonstrated with cryogenic engine. Furthermore, much higher surface area to volume ratios (such as wire matrix) could be easily realized with the adoption of liquid pistons.

With regards technology availability, it can be seen that the expander surface heating has been ready for many decades in the form of steam jacketing, whereas liquid flooding is a relatively new technology that is yet to be fully developed. Nevertheless, it can be easily implemented with commercially available parts.

This paper concludes that, while quasi-isothermal vapour power cycle engines have the potential to significantly improve the performance in a number of applications (e.g. desalination, transport and heat recovery), there are research areas to be further examined. As such, it is recommended that further research be carried out on: modelling of complex, unsteady multi-phase heat transfer with liquid flooding devices to predict performance and tailor to applications; modelling the behaviour of the oscillating liquid in liquid piston devices with particular attention to inertia and viscous losses; and the investigation (selection) of other appropriate liquids and working fluids for a range of low temperature operations. Further experimental studies are also recommended to give better insights on the practical realisations and optimisations of the technologies presented as concepts or early developmental stages.

\section{Acknowledgement}

We acknowledge support from the School of Engineering and Applied Science, Aston University, in the form of a PhD scholarship for O. N. Igobo 
[1] International Energy Agency (IEA). Key world energy statistics. 2012 ed. Paris, France: OECD/IEA; 2012.

[2] Internal Energy Agency (IEA). World energy outlook, Executive summary. 2012 ed. Paris, France: OECD/IEA; 2012.

[3] Jacobson MZ, Delucchi MA. Providing all global energy with wind, water, and solar power, Part I: Technologies, energy resources, quantities and areas of infrastructure, and materials. Energy Policy. 2011;39(3):1154-69.

[4] KPMG International. Taxes and incentives for renewable energy. Toronto, Canada: KPMG; June 2012.

[5] Campos MC, Vargas JVC, Ordonez JC. Thermodynamic optimization of a Stirling engine. Energy. 2012;44(1):902-10.

[6] Park Jk, Ro PI, Lim SD, Mazzoleni AP, Quinlan B. Analysis and optimization of a quasiisothermal compression and expansion cycle for ocean compressed air energy storage (OCAES). Oceans, 2012: IEEE; 2012. p. 1-8.

[7] Redderson RH. Vapor stirling heat machine. US Patents; 1989.

[8] Alanne K, Saari K, Kuosa M, Jokisalo J, Martin AR. Thermo-economic analysis of a microcogeneration system based on a rotary steam engine (RSE). Applied Thermal Engineering. 2012;44(0):11-20.

[9] Markides CN. The role of pumped and waste heat technologies in a high-efficiency sustainable energy future for the UK. Applied Thermal Engineering. 2012;53:197-209.

[10] Bianchi M, De Pascale A. Bottoming cycles for electric energy generation: Parametric investigation of available and innovative solutions for the exploitation of low and medium temperature heat sources. Applied Energy. 2011;88(5):1500-9.

[11] Cengel YA, Boles MA. Thermodynamics, an engineering approach. 7th ed. NewYork, USA: McGraw-Hill, 2011.

[12] Cengel YA, Cimbala JM, Turner RH, Kanoglu M. Fundamentals of thermal-fluid sciences. 4th ed. NewYork, USA: McGraw-Hill, 2012.

[13] Rajput RK. Engineering thermodynamics. 3rd ed. Massachusetts, USA: Jones and Bartlett, 2010.

[14] O'Kelly P. Computer Simulation of Thermal Plant Operations. New York, USA: Springer; 2012.

[15] NIST Standard Reference Database. Thermophysical Properties of Fluid Systems.

webbook.nist.gov; accessed 1/11/2013.

[16] Moran MJ, Shapiro HN, Boettner DD, Bailey M. Fundamentals of engineering thermodynamics. 7th ed. New Jersey, USA: John Wiley \& Sons, 2010.

[17] Chen H, Ding Y, Li Y, Zhang X, Tan C. Air fuelled zero emission road transportation: A comparative study. Applied Energy. 2011;88(1):337-42. 
[18] Bell IH, Lemort V, Groll EA, Braun JE, King GB, Horton WT. Liquid flooded compression and expansion in scroll machines-Part II: Experimental testing and model validation. International Journal of Refrigeration. 2012;35(7):1890-900.

[19] Couper JR, Penney WR, Fair JR, Walas SM. 8 - Heat Transfer and Heat Exchangers. In: Couper JR, Penney WR, Fair JR, Walas SM, editors. Chemical Process Equipment (Third Edition). Boston, USA: Butterworth-Heinemann; 2012. p. 161-221.

[20] Cheng C-H, Yang H-S, Keong L. Theoretical and experimental study of a 300-W beta-type Stirling engine. Energy. 2013;59:590-9.

[21] Cicconardi S, Jannelli E, Perna A, Spazzafumo G. A steam cycle with an isothermal expansion: the effect of flowvariation. International journal of hydrogen energy. 1999;24(1):53-7.

[22] Stosic N, Milutinovic L, Hanjalic K, Kovacevic A. Experimental investigation of the influence of oil injection upon the screw compressor working process. International Compressor Engineering Conference. Purdue University: paper 687; 1990.

[23] Sakuda A, Sawai K, Iida N, Hiwata A, Morimoto T, Ishii N. Performance improvement of scroll compressor with new sealing-oil supply mechanism. International Conference on Compressors and their Systems: No. C591/019; 2001.

[24] Hugenroth J, Braun J, Groll E, King G. Liquid-flooded Ericsson cycle cooler: Part 1Thermodynamic analysis. International Refrigeration and Air conditioning Conference. Purdue University: Paper 823; 2006.

[25] Wang W, Wu Y-t, Ma C-f, Xia G-d, Wang J-f. Experimental study on the performance of single screw expanders by gap adjustment. Energy. 2013;62(0):379-84.

[26] Declaye S, Quoilin S, Guillaume L, Lemort V. Experimental study on an open-drive scroll expander integrated into an ORC (Organic Rankine Cycle) system with R245fa as working fluid. Energy. 2013;55:173-83.

[27] Hugenroth J, Braun J, Groll E, King G. Thermodynamic analysis of a liquid-flooded Ericsson cycle cooler. International Journal of Refrigeration. 2007;30(7):1176-86.

[28] Hugenroth J, Braun J, Groll E, King G. Experimental investigation of a liquid-flooded Ericsson cycle cooler. International Journal of Refrigeration. 2008;31(7):1241-52.

[29] Bell IH, Lemort V, Groll EA, Braun JE, King GB, Horton WT. Liquid-flooded compression and expansion in scroll machines - Part I: Model development. International Journal of Refrigeration. 2012;35(7):1878-89.

[30] Bell IH, Groll EA, Braun JE, King GB, Horton WT. Optimization of a scroll compressor for liquid flooding. International Journal of Refrigeration. 2012;35(7):1901-13.

[31] Halm NP. Mathematical modeling of scroll compressors [Master Thesis]. Indiana, USA: Purdue University, 1997.

[32] Chen Y, Braun JE, Groll EA. Modeling of hermetic scroll compressors: model development. HVAC\&R Research. 2004;10(2):129-52.

[33] Lemort V, Bell I, Groll EA, Braun J. Analysis of liquid-flooded expansion using a scroll expander. International compressor engineering conference at Purdue: Paper 1323; 2008. 
[34] Williams JD. Design of a liquid nitrogen vaporization system for automotive propulsion [PhD Thesis]. Washington, USA: University of Washington 1997.

[35] Cicconardi S, Jannelli E, Perna A, Spazzafumo G. Parametric analysis of a steam cycle with a quasi-isothermal expansion. International journal of hydrogen energy. 2001;26(3):275-9.

[36] Woodland BJ, Braun JE, Groll EA, Horton WT. Organic Rankine cycle with flooded expansion and internal regeneration. US Patents; 2011.

[37] Woodland BJ, Groll EA, Braun JE, Horton WT. Performance benefits for organic Rankine cycles with flooded expansion and internal regeneration. International refrigeration and air conditioning conference. Purdue University: Paper 1134; 2010.

[38] Woodland BJ, Krishna A, Groll E, Braun JE. Thermodynamic comparison of organic Rankine cycles employing liquid-flooded expansion or a solution circuit. Applied Thermal Engineering. 2013;61(2):859-65.

[39] Lemort V, Declaye S, Quoilin S. Experimental characterization of a hermetic scroll expander for use in a micro-scale Rankine cycle. Proceedings of the Institution of Mechanical Engineers, Part A: Journal of Power and Energy. 2012;226(1):126-36.

[40] Bell I, Groll E, Braun J, Horton WT. Experimental testing of an oil-flooded hermetic scroll compressor. International Journal of Refrigeration. 2013;36(7):1866-73.

[41] Kim Y-M, Shin D-G, Lee S-Y, Favrat D. Isothermal transcritical CO< sub $>2</$ sub $>$ cycles with TES (thermal energy storage) for electricity storage. Energy. 2013;49:484-501.

[42] Rogers GFC, Mayhew YR. Engineering thermodynamics work and heat transfer. London, UK: Longmans, 1965.

[43] Clark DK. The Steam engine: A treaties on steam engines and boilers. London, UK: Blackie and Sons limited, 1890.

[44] Igobo ON, Davies PA. A high-efficiency solar Rankine engine with isothermal expansion. International Journal of Low-Carbon Technologies. 2013;8(suppl 1):i27-i33.

[45] Kim H, Kim W, Kim H, Kim S. Applicability of scroll expander and compressor to an external power engine: Conceptual design and performance analysis. International Journal of Energy Research. 2012;36(3):385-96.

[46] Cho S-Y, Cho C-H, Ahn K-Y, Lee YD. A study of the optimal operating conditions in the organic Rankine cycle using a turbo-expander for fluctuations of the available thermal energy. Energy 2013;64:900-11.

[47] Kim YM, Shin D, Lee J. A scroll expander with heating structure and their systems. International compressor engineering conference, Purdue: paper 1635; 2004.

[48] Knowlen C, Williams J, Mattick A, Deparis H, Hertzberg A. Quasi-isothermal expansion engines for liquid nitrogen automotive propulsion. SAE paper 972649. 1997.

[49] Ordonez C, Plummer M. Cold thermal storage and cryogenic heat engines for energy storage applications. Energy Sources. 1997;19(4):389-96.

[50] Li Y, Chen H, Ding Y. Fundamentals and applications of cryogen as a thermal energy carrier: A critical assessment. International Journal of Thermal Sciences. 2010;49(6):941-9. 
[51] Dong H, Zhao L, Zhang S, Wang A, Cai J. Using cryogenic exergy of liquefied natural gas for electricity production with the Stirling cycle. Energy. 2013;63:10-8.

[52] Zhu HM, Liu HW, Sun H. Exergy Analysis of Cascade Ethylene-Propane Rankine Cycle with Cold Energy Recovery of LNG. Applied Mechanics and Materials. 2012;170:2489-93.

[53] Xia G, Sun Q, Cao X, Wang J, Yu Y, Wang L. Thermodynamic analysis and optimization of a solar-powered transcritical CO2 (carbon dioxide) power cycle for reverse osmosis desalination based on the recovery of cryogenic energy of LNG (liquefied natural gas). Energy. 2014;66:643-53.

[54] Li Y, Wang X, Jin Y, Ding Y. An integrated solar-cryogen hybrid power system. Renewable Energy. 2012;37(1):76-81.

[55] Castle W. Air separation and liquefaction: recent developments and prospects for the beginning of the new millennium. International Journal of Refrigeration. 2002;25(1):158-72.

[56] Dooley J, Hammond R. Concept evaluation of automotive propulsion using liquid air/nitrogen. Final report. R and D Associates, Marina del Rey, California, USA; 1982.

[57] Tian CZ, Yuan GJ, Chen GJ. Cylinder Flow Simulation of Liquid Nitrogen Engine Based on STAR-CD. Applied Mechanics and Materials. 2013;344:31-6.

[58] Plummer M, Koehler C, Flanders D, Reidy R, Ordonez C. Cryogenic heat engine experiment. Advances in cryogenic engineering. 1998;43:1245-52.

[59] Williams J. Cryogenic automobile propulsion: heat exchanger design and performance issues. Proceedings of AIAA 19th IECEC. CA, US: AIAA 97-0017; 1997.

[60] Amrit J, Douay C, Dubois F, Defresne G. Cryogenic heat exchanger with turbulent flows. European Journal of Physics. 2012;33(1):189.

[61] Knowlen C, Hertzberg A, Mattick A. Cryogenic automotive propulsion. AIAA 94-4224; 1994.

[62] Knowlen C, Mattick A, Bruckner AP, Hertzberg A. High efficiency energy conversion systems for liquid nitrogen automobiles. SAE paper 981898. 1998.

[63] Yuanwei L, Hongchang Y, Chongfang M. Analysis and optimization of the power cycle based on the cold energy of liquefied natural gas. Measuring Technology and Mechatronics Automation (ICMTMA), 2011 Third International Conference on: IEEE; 2011. p. 455-8.

[64] Choi I-H, Lee S, Seo Y, Chang D. Analysis and optimization of cascade Rankine cycle for liquefied natural gas cold energy recovery. Energy. 2013;61:179-95.

[65] Liu Y, Guo K. A novel cryogenic power cycle for LNG cold energy recovery. Energy. 2011;36(5):2828-33.

[66] Ameel B, T'Joen C, De Kerpel K, De Jaeger P, Huisseune H, Van Belleghem M, et al. Thermodynamic analysis of energy storage with a liquid air Rankine cycle. Applied Thermal Engineering. 2012;52:130-40.

[67] The Dearman Engine Company. www.dearmanengine.com/cms/liquid-air/; accessed 22/6/2013.

[68] Dearman's liquid air engine could rival battery systems. Professional Engineering; Feb 2012. p. 9. 
[69] Wen D, Chen H, Ding Y, Dearman P. Liquid nitrogen injection into water: pressure build-up and heat transfer. Cryogenics. 2006;46(10):740-8.

[70] Morse TL, Kytömaa HK. The effect of turbulence on the rate of evaporation of LNG on water. Journal of Loss Prevention in the Process Industries. 2011;24(6):791-7.

[71] Esteves AS, Reis Parise JA. Mathematical modeling of cryogenic spills onto quiescent sea waters followed by pool fires of liquefied natural gas (LNG). Applied Thermal Engineering. 2013;59(1):58798.

[72] Aceves SM, Petitpas G, Espinosa-Loza F, Matthews MJ, Ledesma-Orozco E. Safe, long range, inexpensive and rapidly refuelable hydrogen vehicles with cryogenic pressure vessels. International Journal of Hydrogen Energy. 2012;38(5):2480-9.

[73] Sripakagorn A, Srikam C. Design and performance of a moderate temperature difference Stirling engine. Renewable Energy. 2011;36(6):1728-33.

[74] West CD. Two-phase, two-component Stirling engine with controlled evaporation. Oak Ridge National Lab., Tennesse, USA; 1982.

[75] Huang D, Wu F. Research of Refrigerant Phase-Change Stirling-Cycle Heat Engines. International conference on Measuring Technology and Mechatronics Automation (ICMTMA). Shangshai: IEEE; 2011. p. 1088-91.

[76] West CD. Liquid-piston Stirling machines. 2nd International Conference on Stirling Engines. Shanghai, China1984. p. 1-10.

[77] Stevens JW. Low Capital Cost Renewable Energy Conversion With Liquid Piston Stirling Engines. ASME 2010 4th International Conference on Energy Sustainability: American Society of Mechanical Engineers; 2010. p. 479-84.

[78] West CD. Stirling engines and irrigation pumping. Tennessee, USA: Oak Ridge national laboratory; 1987.

[79] Mauran S, Martins M, Stitou D, Semmari H. A novel process for engines or heat pumps based on thermal-hydraulic conversion. Applied Thermal Engineering. 2012;37(0):249-57.

[80] Van de Ven J, Gaffuri P, Mies B, Cole G. Developments towards a liquid piston Stirling engine. International Energy Conversion Engineering Conference, Cleveland, Ohio: Paper 5635; 2008.

[81] Van de Ven JD. Mobile hydraulic power supply: Liquid piston Stirling engine pump. Renewable Energy. 2009;34(11):2317-22.

[82] Redderson RH. Vapor stirling heat machine. US Patents; 1989.

[83] Davoud JG, Burke Jr JA. Condensing vapor heat engine with two-phase compression and constant volume superheating. US Patents; 1977.

[84] Burke Jr JA, Davoud JG. Condensing vapor heat engine with constant volume superheating and evaporating. US Patents; 1978.

[85] Isshiki N, KOJiMA H, Ushiyama I, Isshiki S. Report on the developments of steam super Stirling engine. Energy Conversion Engineering Conference and Exhibit, 2000(IECEC) 35th Intersociety: IEEE; 2000. p. 111-9. 
[86] Çinar C, Aksoy F, Erol D. The effect of displacer material on the performance of a low temperature differential Stirling engine. International Journal of Energy Research. 2012;36(8):911-7. 


\title{
Review of low-temperature vapour power cycle engines with quasi- isothermal expansion
}

\author{
Opubo N. Igobo, Philip A. Davies
}

\begin{abstract}
Sustainable Environment Research Group, School of Engineering and Applied Science, Aston University, Birmingham, B4 7ET, UK email: p.a.davies@aston.ac.uk
\end{abstract}

\begin{abstract}
External combustion heat cycle engines convert thermal energy into useful work. Thermal energy resources include solar, geothermal, bioenergy, and waste heat. To harness these and maximize work output, there has been a renaissance of interest in the investigation of vapour power cycles for quasiisothermal (near constant temperature) instead of adiabatic expansion. Quasi-isothermal expansion has the advantage of bringing the cycle efficiency closer to the ideal Carnot efficiency, but it requires heat to be transferred to the working fluid as it expands. This paper reviews various low-temperature vapour power cycle heat engines with quasi-isothermal expansion, including the methods employed to realize the heat transfer. The heat engines take the form of the Rankine cycle with continuous heat addition during the expansion process, or the Stirling cycle with a condensable vapour as working fluid. Compared to more standard Stirling engines using gas, the specific work output is higher. Cryogenic heat engines based on the-open Rankine cycle have also been enhanced with quasiisothermal expansion. Liquid flooded expansion and expander surface heating are the two main heat transfer methods employed. Liquid flooded expansion has been applied mainly in rotary expanders, including scroll turbines; whereas surface heating has been applied mainly in reciprocating expanders.
\end{abstract}

\section{Keywords:}

\author{
Vapour power cycle \\ Quasi-isothermal expansion \\ Renewable energy \\ Waste heat utilisation
}

\section{Contents}

1. Introduction. .2

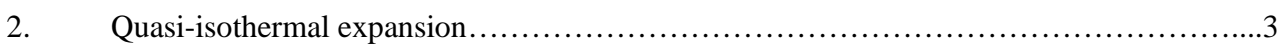

2.1. Methods of effecting quasi-isothermal expansion.................................

2.1.1. Expander surface heating...........................................

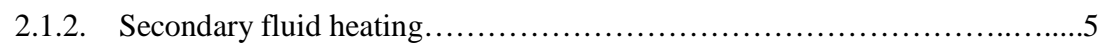

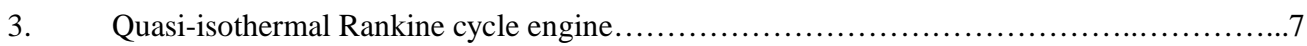

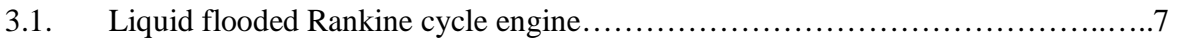

3.2. Surface heated Rankine cycle engine........................................

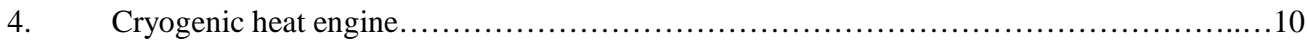

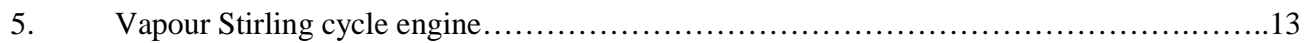

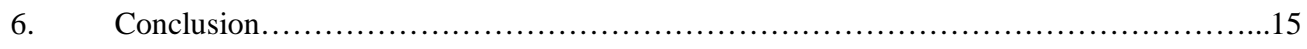

References................................................................ 16 


\section{Introduction}

Owing to the global energy challenges associated with fossil fuel - rising cost, energy security and climate change - there has been growing interest into sustainable alternatives or renewable energy sources such as: wind, solar, geothermal, biomass and waste heat. Presently, renewable energy sources account for less than $15 \%$ of the global energy supply, $[1]$, of which biomass is a major contributor, while. However, solar has recorded the fastest growth. The IEA has projected the, and renewables have been projected to become the world's second largest source of power generation by $2015[1,2][2]$. Studies have already shown that the renewable heat sources have the potential of meeting the global energy demand several times over $[3,4],[3]$. As a means of encouraging the exploitation of the renewable heat sources, 'heat policies' (including incentives) have been introduced I in some countries $[5,6] .[4]$. Globally, solar, biomass and waste heat are readily available in distributed form as low-grade $\left(<250^{\circ} \mathrm{C}\right)$ heat, and are well suited for decentralized small-scale $(<100$ $\mathrm{kW})$ applications. Thus there has been a renaissance of interest in small-scale external combustion heat engines (gas and vapour power cycles) to convert the thermal energy into useful work, with particular emphasis on improving performance. Isothermal expansion is one technique for achieving such improvement.

Ideally, certain gas power cycles (such as Stirling and Ericsson cycles) perform work by the isothermal (constant temperature) expansion of a compressed and heated gas working fluid (which remains gaseous throughout the entire cycle). They are noted for having the high theoretical efficiencies of the Carnot cycle - which is the maximum obtainable efficiency for given temperature limits [7]. On the other hand, for vapour power cycles, [5]. On the other hand, for vapour power cycles (typically the Rankine cycle), the working fluid is a condensable vapour, and is intermittently vaporised and condensed; the expansion process is adiabatic (i.e. the fluid expands without experiencing heat transfer during the process) and produces less work than its isothermal counterpart [8].6]. Nevertheless, in comparison to the gas compression work of the gas power cycles, less input work is required to pressurize the condensed liquid of the vapour power cycles, and the total cycle pressuret-volume characteristics exhibit greater work output than the gas cycles. Thus the vapour cycle engines have higher specific work output [9].[7]. The vapour power cycles can also have advantages over gas cycle equivalents because the phase change allows smaller surface areas and temperature differences to drive the heat supply/removalboiling/condensation required by the cycle. This inference arises from the higher heat transfer coefficients associated with phase change (by orders of magnitude) relative to that of forced convection between a gas and solid surface for gas [8]. The smaller surface areas lead to compact heat exchangers and engine size [10][9]; this together with the higher work output gives the vapour cycle engines higher power density; and the low temperature differences aid better performance (relative to the gas cycles) in low-grade heat applications. This has been demonstrated in a study that showed the Rankine cycle to be more efficient than Stirling cycle for temperature range of $150-300^{\circ} \mathrm{C}[10]$.

In power plants operating on tapeur cycles (typically-the Rankine cycle), reheating is a practical approach to improve the cycle efficiency and specific work output. As the number of stages of reheating increases, the expansion and reheat processes approximate an average isothermal process

| and the cycle efficiency increases- $[11]$. But in the reheating process, the steam must be returned back to the boiler for each reheat, which, besides requiring many additional components, inevitably adds | complexity to the plant layout and geometry, and results to heat and pressure losses [11, 12].[12]. Alternatively, the vapour cycle engine could be designed in such a way that (like the Stirling or Ericsson engines) heat is continuously transferred to the working fluid during the expansion process thus resulting in isothermal expansion, or more realistically, quasi-isothermal expansion - which may be somewhere between the adiabatic and ideal isothermal processes.

In this paper, relevant research works with emphasis on low temperature vapour power cycles with quasi-isothermal expansion will be presented. Various methods employed to effect quasi-isothermal 
operation, including concepts, studies and results, will be reviewed to provide an insight into their practicality, system performance and energy efficiency. The first part (section 2) of the paper presents the general theoretical advantage of quasi-isothermal expansion, including the various heat transfer methods used to achieve it. The second part (section 3-5) of the work covers the power cycles to which the methods are applied. For each power cycle, the theory and principle of operation is explained, and then specific studies are reviewed in which these cycles have been implemented. Fig. 1 classifies the methods and vapour power cycles for quasi-isothermal operation according to the approach used in this review.

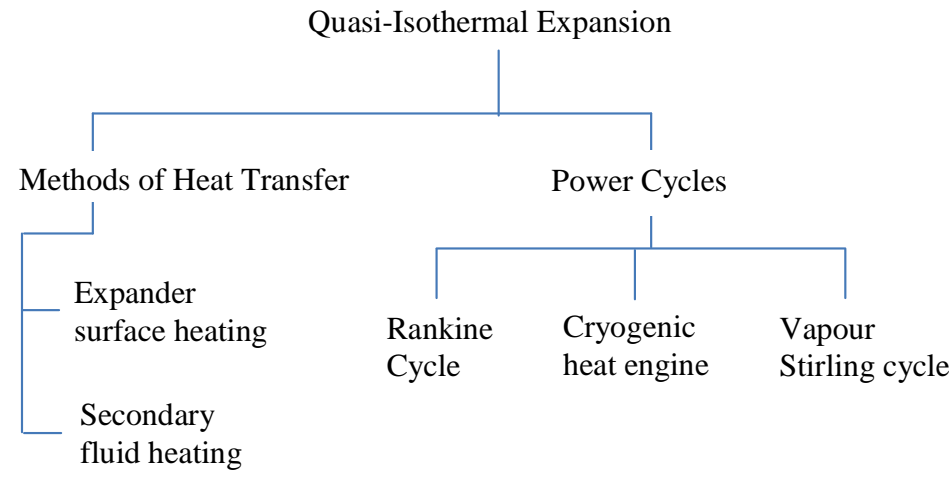

Fig. 1. Overview of the review approach

\section{Quasi-Isothermal expansion}

The paths of both the isothermal and adiabatic expansion processes can be illustrated graphically on a pressure-volume (P-v) plane as shown in figFig. 2, using the gas equation $P_{1} v_{1}^{n}=P_{2} v_{2}^{n}$. The expansion index $\mathrm{n}$ is equal to 1 and $\mathrm{k}(\rightarrow 1)$-for isothermal and adiabatic processes respectively [13, 14][13], where $\mathrm{k}$ is the ratio of the specific heats $\left(\mathrm{C}_{\mathrm{p}} / \mathrm{C}_{\mathrm{v}}\right)$ of the gas, and is always $>1[14]$. For example, under a substantial range of operating conditions, $\mathrm{k}$ is about 1.4 for nitrogen gas and steam [15]. 


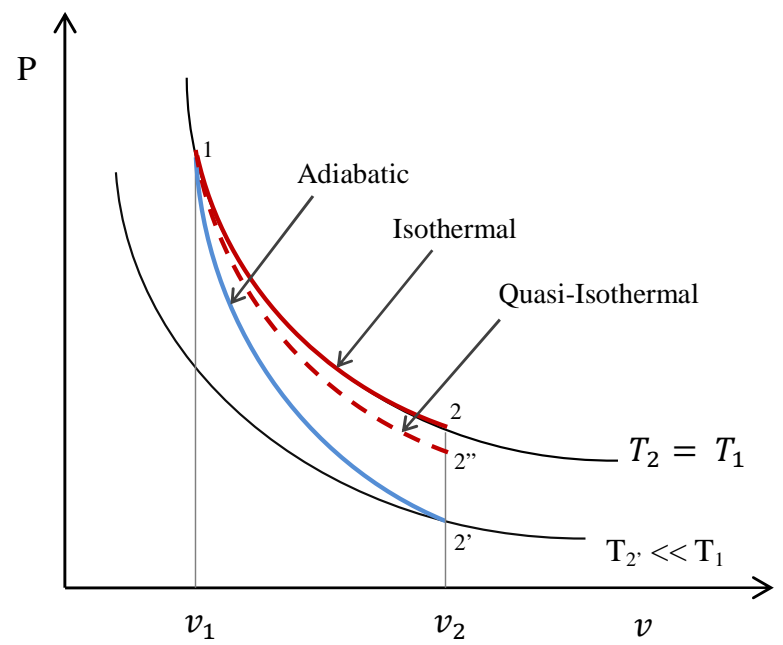

Fig. 2. Graphical representation of isothermal and adiabatic expansion processes

The work output is simply the integral $\left(\int P d V\right)$ between the two end states (1 and 2), as is represented by the area under the path curves. Hence, from the figure it can be seen that the area under the curve (i.e. the expansion work output) for the adiabatic expansion is less than that of an isothermal expansion having the same initial operating conditions. This can also be seen numerically from the integration of both curves from state 1 (start of expansion) to state 2 (end of expansion).

The work done by isothermal expansion can be given as [16]:

The work done by isothermal expansion can be given as [16]:

$$
W_{i s o}=\int P d V=P_{1} v_{1} \ln \left(\frac{P_{1}}{P_{2}}\right)
$$

Similarly, the work done by adiabatic expansion can be expressed as:

$$
W_{a d}=\int P d V=P_{1} v_{1} \frac{1-\left(\frac{P_{1}}{P_{2}}\right)^{\frac{1-n}{n}}}{n-1}
$$

Hence, from the above equations, the relative improvement of the isothermal expansion work over the adiabatic work can be expressed in terms of the expansion index and pressure ratio $r_{p}=P_{1} / P_{2}$ as:

$$
\text { Relative improvement }=\frac{W_{\text {iso }}}{W_{a d}}-1=\left[\frac{(n-1) \ln \left(r_{p}\right)}{\left(1-r_{p}\right)^{\frac{1-n}{n}}}\right]-1
$$

For example, with $r_{p}=7$ and $\mathrm{n}=1.4$, eq. 3 shows that the isothermal expansion gives $83 \%$ more work than the adiabatic.

The expansion process of conventional vapour power cycles is generally assumed adiabatic, and as | such is subject to this reduced work output [8, 17].[6]. The adiabatic expansion process is also 
characterised by drop in temperature from $\mathrm{T}_{1}$ to $\mathrm{T}_{2}$. Hence, modifying an adiabatic expansion to an isothermal one would ideally require the addition of heat to the expanding fluid to maintain its temperature constant.

In reality, when the heat absorbed by the vapour is not sufficient to maintain isothermal expansion, the result is termed quasi-isothermal expansion. In this case, the heat absorbed shifts the expansion process from adiabatic behaviour towards the ideal isothermal behaviour. Consequently, the work output will be more than the adiabatic work, but less than the isothermal work available, in proportion to the extent to which the expansion approaches the isothermal case. This extent has been termed | isothermality, $\gamma$, defined as the ratio of actual work output to the ideal isothermal work [18].[17].

$$
\gamma=\frac{w_{a c}}{w_{\text {iso }}}
$$

Thus it determines the work output as a fraction of the isothermal work available. On the other hand, for rotary expanders some authors have described the extent of isothermal behaviour as the ratio of | discharge temperature to supply temperature [19, 20].[18].

\subsection{Methods of effecting quasi-isothermal expansion}

Over the years, a number of methods have been developed, by which a vapour power cycle's working fluid can continuously gain heat during the expansion process to effect quasi-isothermal expansion; often times this result in variants of the traditional power cycles. The identified methods can be generally grouped on the basis of the means of heat transfer as: secondary fluid heating and expander surface heating. The methods and the power cycles (including the variants) to which it is applied are | shown in table Table 1.

Table 1. Heating methods and the applicable power cycles for quasi-isothermal operation, with relevant examples from the literature

\begin{tabular}{|c|c|c|}
\hline Applications & Secondary fluid heating & $\begin{array}{l}\text { Expander surface } \\
\text { heating }\end{array}$ \\
\hline $\begin{array}{l}\text { Rankine cycle engine } \\
\text { (section 3) }\end{array}$ & $\begin{array}{l}\text { Theoretical study of } \\
\text { liquid flooded scroll } \\
\text { turbine, using various } \\
\text { fluids }[21][19] \\
\text { Experimental study of the } \\
\text { effect of flooding liquid } \\
\text { quantity in scroll turbine } \\
\text { [2220] }\end{array}$ & $\begin{array}{l}\text { Theoreticalstudy of } \\
\text { surface heated seroll } \\
\text { turbine [12] } \\
\text { Experimental study of } \\
\text { surface heated } \\
\text { reciprecating cylinder } \\
\text { [23]Theoretical study } \\
\text { of surface heated scroll } \\
\text { turbine [21] } \\
\text { Experimental study of } \\
\underline{\text { surface heated }} \\
\text { reciprocating cylinder } \\
{[22]}\end{array}$ \\
\hline
\end{tabular}




\begin{tabular}{|c|c|c|}
\hline $\begin{array}{l}\text { Cryogenic engine } \\
\text { (section } 4)\end{array}$ & $\begin{array}{l}\text { Experimental study of } \\
\text { evaperating eryogenic } \\
\text { liquid in water }[24,25] \\
\text { Experimental studies of } \\
\text { evaporating cryogenic } \\
\text { liquid in water }[23,24]\end{array}$ & $\begin{array}{l}\text { Theoretical study of } \\
\text { surface heated } \\
\text { reciprecating cylinder } \\
{[24,26] \text { Theoretical }} \\
\text { studies of surface } \\
\text { heated reciprocating } \\
\text { cylinder }[23,25]\end{array}$ \\
\hline $\begin{array}{l}\text { Stirling cycle engine } \\
\text { (section } 5)\end{array}$ & & $\begin{array}{l}\text { Theoretical study of } \\
\text { eentrolled evaporation } \\
\text { in Stirling engine }[27 \text {, } \\
28] \\
\text { Experimental study of } \\
\text { vapour Stirling engine } \\
\text { [28]Theoretical studies } \\
\text { of controlled } \\
\text { evaporation in Stirling } \\
\text { engine }[26,27] \\
\text { Experimental study of } \\
\text { vapour Stirling engine } \\
{[27]}\end{array}$ \\
\hline
\end{tabular}

\subsubsection{Expander surface heating}

A simple approach to achieve heat transfer to the working fluid during the expansion process is to provide a means of heating the expander sufficiently above the fluid temperature; such that during the expansion process, heat could be effectively transferred from the surface of the expansion chamber to | the fluid, as illustrated in figFig. 3a. This is quite popular for reciprocating expanders as found in conventional Stirling engines, and steam-jacketed steam engines. The extent of isothermal operation achievable here will depend on the rate of heat transfer, which is a function of the overall heat transfer coefficient and temperature differential between the engine wall and the fluid, and the surface area of

| the wall exposed to the fluid [16].[28]. As such, geometries giving high surface to volume ratios such as tubes and fins are generally utilised to increase the total heat transfer area as found in conventional Stirling engines [29]. 
Heat source

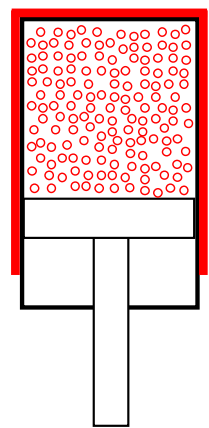

(a)

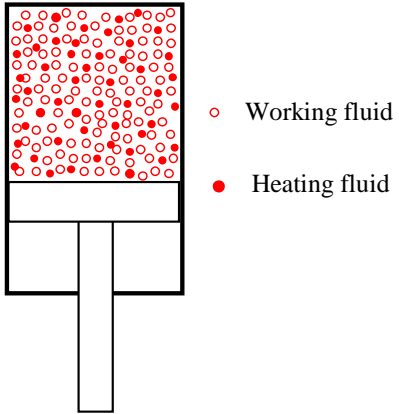

(b)

Fig. 3. The two main means of heat transfer used to achieve isothermal expansion: (a) expander surface heating; (b) secondary fluid heating system

|

\subsubsection{Secondary fluid heating}

The heat transfer required to effect quasi-isothermal expansion could be provided by means of a secondary fluid which co-exists with the working fluid in the expander during the expansion process

| (figFig. 3b). In this case, the secondary fluid - which will ideally be of a high thermal content - is dispersed into the working fluid such that during the expansion process, the temperature dropped by the expanding working fluid is quickly recovered from the secondary fluid. The heating fluid could ideally be a vapour - as with direct steam injection; or more practically, a liquid - as with liquid flooded expansion.

\subsubsection{Direct steam injection}

The concept of achieving isothermal expansion by direct steam injection entails injecting small amount of relatively very high temperature steam (secondary fluid) into the expanding steam [30]. The secondary steam transfers heat to the working steam by virtue of its higher temperature thermal content, as such requires the secondary steam to be continuously injected with appropriate amount and temperature in such a way as to keep the expansion temperature constant.

\subsubsection{Liquid flooding}

The liquid flooding process involves literally flooding a screw or scroll machine with a large quantity of liquid simultaneously as the working fluid passes through the device, such that the liquid provides a medium of heat exchange with the working fluid whilst in transit through the device. Unlike with steam injection, the secondary fluid is normally different from the working fluid, and is immiscible with it. This concept can ideally be applied to compression and expansion processes (its application to expansion processes will be covered in section 3.2.1). Over the last two decades, there have been a significant number of studies on the application of liquid flooding to compressors. Researchers have studied oil-flooding in screw compressors [31] and scroll compressors [32] primarily to improve | sealing and lubrication, but without much emphasis on heat transfer [33]. In recent years, 
eonventional serew and seroll compressers have been effectively used in reverse as expanders (with minor modifications) In recent years, conventional screw [34] and scroll $[34,35],[35]$ compressors have been effectively used in reverse as expanders (with minor modifications), thus widening the scope for liquid-flooded expansion. The combinations of the different working fluids and flooding liquid considered in the literature are shown in table Table 2.

Table 2. Combinations of different working fluids and flooding liquid

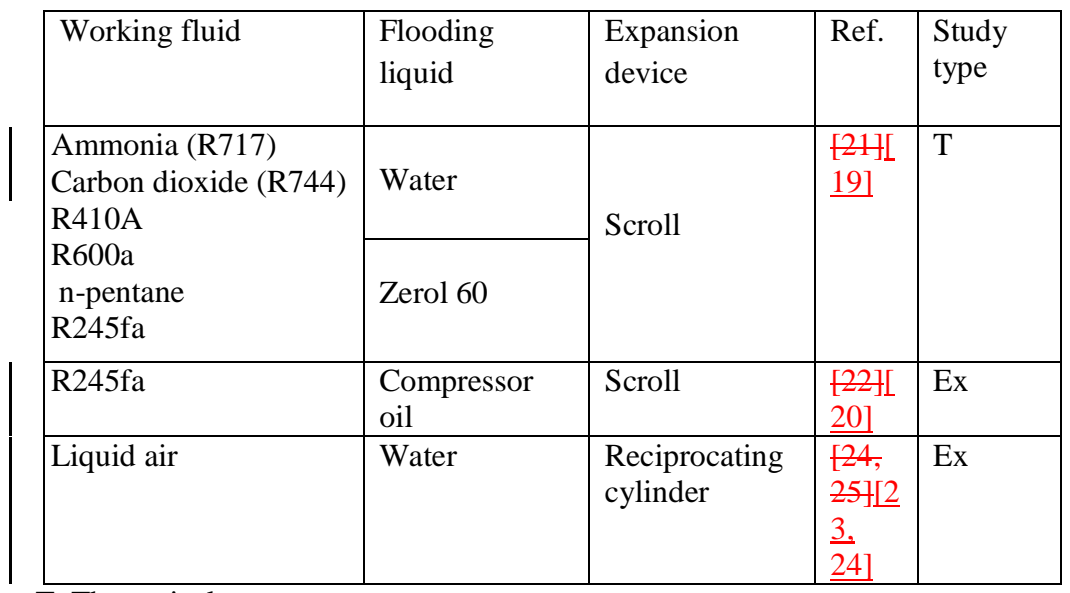

T. Theoretical

Ex. Experimental

The concept of flooded expansion (and compression) was studied by Hugenroth [36] in a liquid flooded Ericson cycle cooler, which used liquid flooding of both the compressor and the expander (to achieve nearly isothermal compression and expansion) to overcome the practical difficulties of achieving isothermal conditions in the basic reverse Ericson cycle. In a later experimental work [37], off-the-shelf automotive scrolls were used as the compressor and expander, nitrogen as the working fluid and alkyl-benzene as the flooding liquid. The performance of the off-the-shelf scroll machine was not sufficient to achieve high cycle efficiency. For increasing operating pressure ratios, the expander adiabatic efficiency was seen first to increase and then to decrease. This effect was partly attributed to the limitation of the expander not being designed for liquid flooded operation

To optimize the design of the compressor and the expander, Bell et al. [38] developed comprehensive models of both machines. Validation of the models and analysis of the machines were carried out. The model developed was an extension of earlier models that were developed by Halm [39] and Chen [40, $41]$ for scroll compressors without liquid flooding. The important contribution of the work was said to be the treatment of a mixture of gas and large fraction of oil. Also, Lemort et al. [19] further studied the performance of liquid flooded expansion using seroll expander and developed a detailed model of the flooded scroll expander, to facilitate predictions of the performance over a wide range of operating conditions and design changes.[38] developed comprehensive models of both machines. Validation of the models and optimization of the design were also carried out [39]. The model developed was an extension of earlier models that were developed by Halm [40], and Chen et al [41] for scroll compressors without liquid flooding. The important contribution of the work was said to be the treatment of a mixture of gas and large fraction of oil. Also, Lemort et al. [42] further studied the performance of liquid flooded expansion using scroll expander and developed a detailed model of the flooded scroll expander, to facilitate predictions of the performance over a wide range of operating conditions and design changes. The model was able to predict the shaft power to about $6.7 \%$ maximum deviation from measured experimental value. 


\subsection{Summary}

In summary, quasi-isothermal expansion has been identified as a realistic alternative to adiabatic expansion to improve the work output of vapour power cycle engines. This can be achieved by further heat addition to the working fluid during the expansion process. The heat can be transferred by means of heating the expander external surface, or by means of a secondary heating (flooding) fluid. The expander surface heating is found to be more popular with reciprocating engines, whereas the secondary fluid heating is more popular with rotary engines.

\section{Quasi-isothermal Rankine cycle engines}

\subsection{Theory and principle of operation}

The quasi-isothermal Rankine cycle is simply a Rankine cycle whose working fluid gains significant amount of heat during the expansion process of the cycle, such that it is somewhere between adiabatic and isothermal, but its reference limit is ideally isothermal, as depicted on the temperature entropy (Ts) diagrams in figFig. 4. Fig 4a shows a case where the expansion starts from a super-heated state [42]; while in fig [43]; while in Fig 4b, the expansion starts from a saturated state [43].[44]. As a result of the heat addition during the expansion process, the spent vapour becomes significantly superheated at the end of expansion, thus necessitating regeneration (utilising the heat available at the end of expansion to preheat the feed working fluid) to improve the thermal efficiency. Studies have shown that the efficiency of the ideal cycle (with isothermal expansion and regeneration) can be up to $93 \%$ of the efficiency of a Carnot cycle operating with the same temperatures limits $[23,30] \cdot[30]$. Where isothermal expansion is not fully achieved, the resulting quasi-isothermal cycle's performance will depend on the quantity of heat successfully absorbed during expansion, which of course is dependent on the heat transfer technique employed.

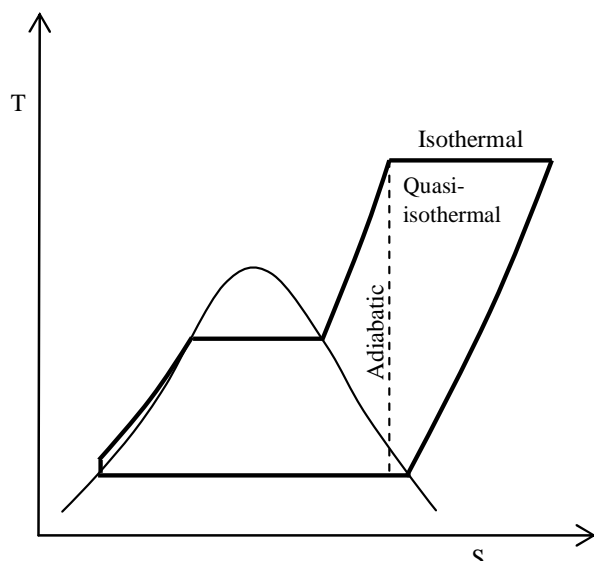

(a)

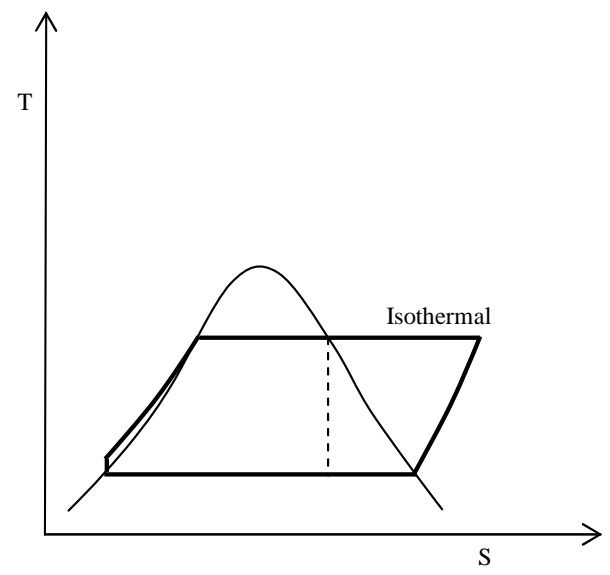

(b)

Fig. 4. Ts diagrams of Rankine cycle with isothermal expansion $[42,43]$, (a) starting from superheated state; (b) starting from saturated state.4. T-s diagrams of Rankine cycle with isothermal expansion, (a) starting from superheated state [30]; (b) starting from saturated state [44].

\subsection{Studies and performance}


Using the thermodynamic cycles of Fig 4, researchers have proposed and studied different versions of the quasi-isothermal Rankine cycle using different modes of heat transfer. Thus, both liquid flooded and external heated surface machines have been reported. These implementations will now be | reviewed.

\subsubsection{Liquid-flooded Rankine cycle}

The idea of liquid flooded expansion can be applied to Rankine cycle, as patented by Woodland [44]. A schematic of the system is depicted in fig. [45]. A schematic of the system is depicted in Fig. 5. The working fluid and the flooding liquid are both pressurised and heated to the required high side pressure and temperature (via separate pumps and heat exchangers). The fluids are then mixed and fed to the expander where they flow together to do work. During the expansion process, temperature drop of the working fluid (vapour) is inhibited by heat gain from the liquid (because the liquid has a relatively higher heat capacity), thus resulting in a near isothermal expansion. At the end of expansion, the superheated working fluid is then separated from the liquid and passed through a

| regenerator (before being condensed) to preheat the condensed fluid pumped for the next cycle, as the flooding liquid is simultaneously re-pressurized and heated back to the high side conditions.

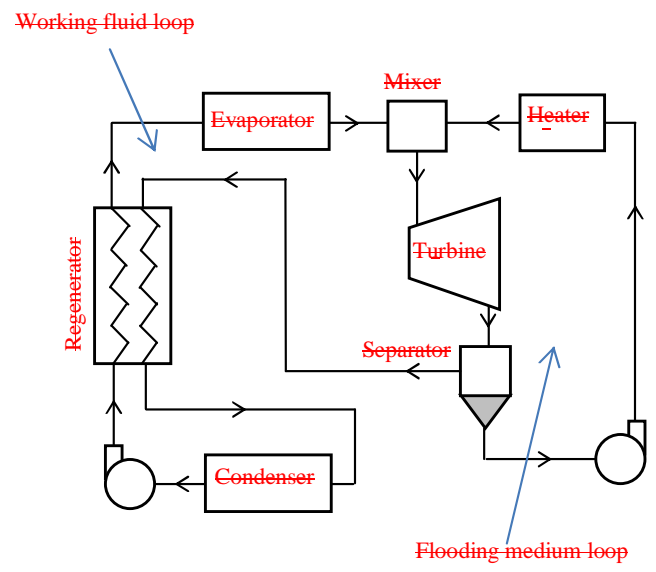

Fig. 5. Schematic of the liquid flooded ORC [21]

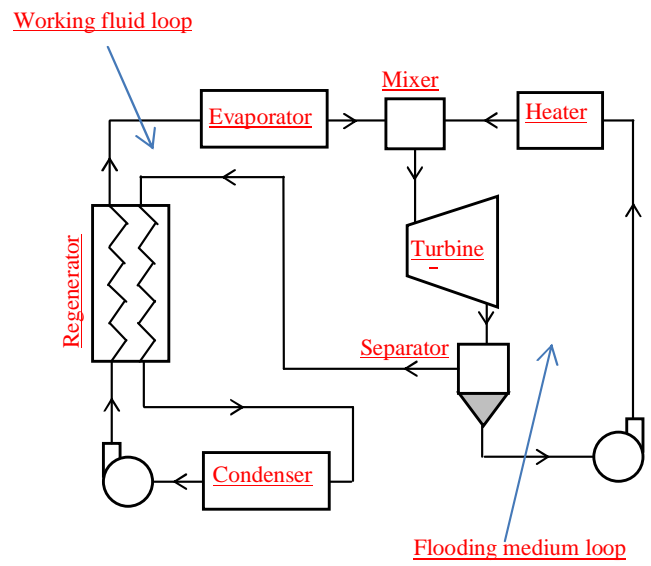

Fig. 5. Schematic of the liquid flooded ORC [19] 
Woodland [21][19] also carried out theoretical study of the application of liquid flooding to organic Rankine cycle (ORC) with regeneration, for different working fluids (ammonia, carbon dioxide, $\mathrm{R} 410 \mathrm{a}$ and dry fluids such as iso-butane, n-pentane and R245fa ). The analysis showed that, working fluids ammonia and R410a exhibited higher performance improvement due to the flooded expansion. For ammonia, the addition of the liquid flooding offered about $20 \%$ more improvement in thermal | efficiency. A later study [45]A later study [46] that featured water as a working fluid in the liquid flooded ORC, showed a relative improvement of $10 \%$ due to the flooded expansion; the improvement increased with the source temperature. In contrast, the improvement for the dry fluids was significantly less (only about $5 \%$ ), and approaches zero at higher $\left(>250^{\circ} \mathrm{C}\right)$ operating temperatures. Higher work output was expected from the more isothermal flooded expansion than from ordinary expansion process. However, for these dry fluids, the improvement in work output is not high enough to significantly outweigh the additional energy inputs (pump work and heat input) required for the flooding process.

Lemort et al. [22][20] developed a prototype of a flooded Rankine cycle engine with a hermetic scroll expander and R245fa working fluid. The study was focused on investigating the impact of oil quantity on the expander performance. For operating pressure ratio of $4.2 \mathrm{bar}$, supply temperature of $92^{\circ} \mathrm{C}$ and oil mass fraction of $0.023-0.1$, the results showed that the expander overall isentropic effectiveness (ratio of the measured power output to the ideal expander power) decreased with increasing oil quantity. Further investigation was recommended to ascertain with certainty the underlying reason; nevertheless, increase of supply pressure drops (at the expander inlet) and viscous losses were mentioned as likely reasons for the decrease in performance. This is in agreement with the results of a previous study [19] on the performance of liquid flooded expansion using scroll expander.This is in agreement with the results of a previous study on the performance of liquid flooded expansion using scroll expander [42]. For a given pressure level, in the experiment, the measured power output reportedly decreased with the oil flow rate as a result of increasing pressure drops due of the oil suction process at the expander inlet. The study also analysed the variation of exhaust temperature with oil fraction for different operating speeds. As would be expected, the result further showed that the expansion tends to approach isothermal behaviour for higher oil fractions. The range of isothermal expansion (in this case defined as the ratio of discharge temperature to supply temperature) achieved was about 0.93 to 0.99 for oil fractions of 0.2 to 0.8 respectively. This shows that, although the liquid flooding facilitated sufficient heat transfer, such that isothermal behaviour is approached, there are practical challenges in translating it to net performance improvement. Another practical issue worth noting is that the separation of the refrigerant from the oil in the oil separator is not generally perfect, as such some amount of refrigerant usually remain entrained in the oil [37]. This entrainment may pose a durability issue in the long run, as higher oil flow rate will result to larger amount of refrigerant entrained, thus it can result in the need for frequent servicing, as has been observed with oil flooded compressor [4647].

For the purpose of increasing the efficiency of a trans-critical $\mathrm{CO}_{2}$ Rankine cycle thermo-electric energy storage (TEES) system, Kim et al. [48] proposed the application of a variant of the liquid flooded concept to achieve isothermal expansion (and compression) for the discharging (and charging) process of the TEES system. The discharging process is basically the retrieval of mechanical-electrical energy from the stored thermal energy by means of a heat engine (Rankine cycle, in this case). Fig. 6 depicts the discharging process of the proposed isothermal TEES system.

The system is somewhat like a double cylinder engine. On operation, pressurised $\mathrm{CO}_{2}$ is heated in the evaporator and fed via valve ' $A$ ' into the first cylinder which is initially filled with hot liquid. The vapour then exerts pressure and expands against the hot liquid (serving as a liquid piston) which flows through the 4-way valve and the hydraulic motor (wherein the flow and pressure of the liquid is converted into rotary work). During the expansion, the circulation pump continually sprays a portion 
of the hot liquid unto the expanding vapour, thus providing a means of heating the vapour to effect isothermal expansion. The expended liquid continuous in flow, through the heat exchanger in the hot storage tank and back through the 4-way valve into the second cylinder, thus exhausting the hot expanded vapour in the second cylinder via valve ' $\mathrm{D}$ ' and the regenerator to the condenser. As the stroke ends, the 4-way valve switches to reverse the flow (between the two cylinders), without changing the hydraulic pump's direction of rotation. An analysis of the system performance for the operating conditions of 160 bar and $122^{\circ} \mathrm{C}$ showed that the isothermal expansion can result in a $46 \%$ increase in work output.

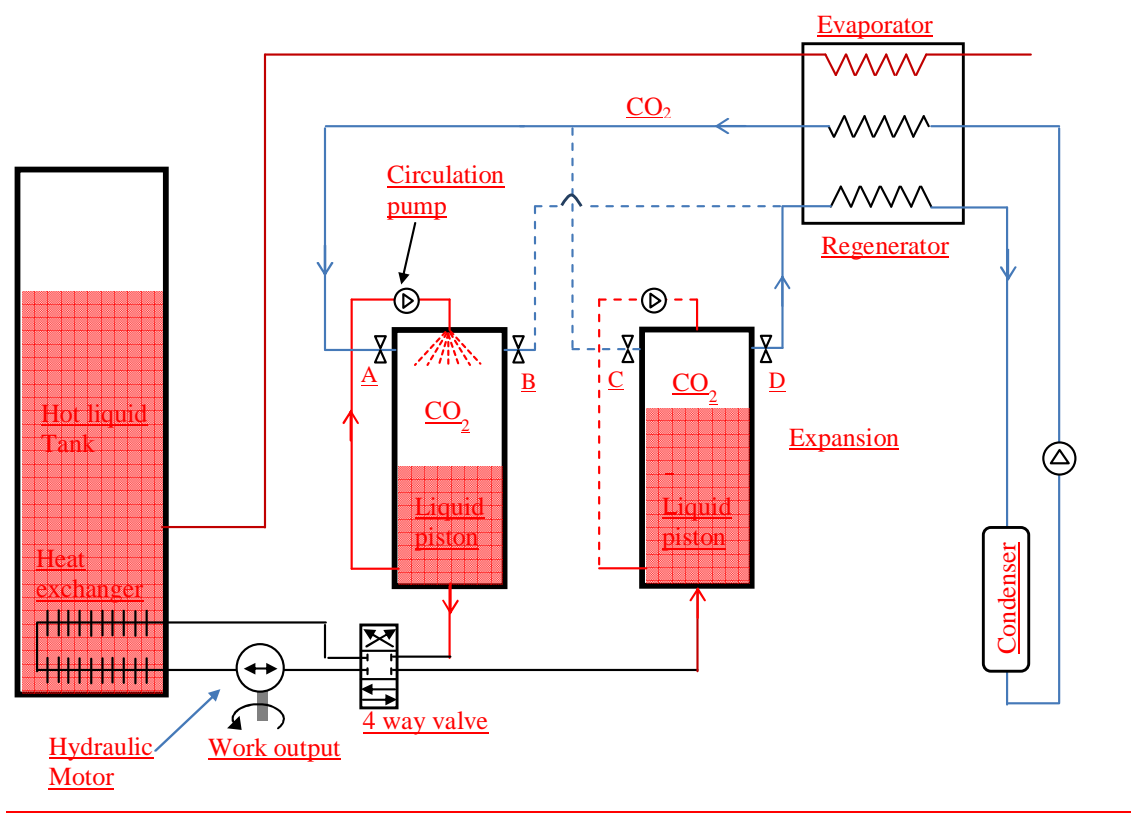

Fig. 6. Isothermal TEES system [48]

\subsubsection{Expander surface heated engines}

\subsubsection{Steam jacketed reciprocating steam engine}

The steam engine with steam jacket is a classic approach to quasi-isothermal expansion. Nevertheless, certain features and observations are interesting in the modern context where steam or other (organic) working fluids may be used.

In steam engines, there tends to be heat transfer between the steam and the cylinder wall, in such a way that heat is rejected by the steam to the cylinder during the admission and early expansion process, while heat is transferred from the cylinder to the steam in the later part of the expansion and exhaust. This phenomenon is most pronounced for dry steam (relative to superheated steam) as the heat rejection and gain respectively leads to steam condensation on the cylinder wall and reevaporation of some of the condensate during the rest of the expansion process thus leaving behind some amount of condensate-water in the cylinder. The condensation of steam in the cylinder results in a very rapid drop in maximum pressure and thus decrease in work output, which implies an increase in steam consumption (quantity of steam) required to achieve a given power output. This consequently results to reduced efficiency, since not all the admitted steam is available to produce | work for a given amount of heat energy input to generate the steam $[16,4749]$. 
Besides the use of sufficiently superheated steam, or protecting the cylinder with lagging (insulation), steam jacketing the cylinder can be effectively utilised to mitigate the heat loss from the steam.

| Various Experiments carried out by a number of researchers, as recorded by Clark [47][50] in the $1800 s$, have showed that the alternate condensation and re-evaporation in steam jacketed cylinders are much less than that in unprotected cylinder. The steam jacketed cylinders results to economy in the steam consumption and displayed a greater degree of efficiency than the cylinder with superheated steam, whilst both of them are clearly superior to an unprotected cylinder with saturated steam. The steam jackets have reportedly resulted to economy of $14-25 \%$ in steam consumption rate per power output, net specific work output increase of $42 \%$ (from 224 to $318 \mathrm{~kJ} / \mathrm{kg}$ ) and efficiency (in terms of the total heat passed into the cylinder and the work output) increase of $28 \%$ (from 8.65 to $11.05 \%$ ). Further results showed that better performance was recorded for higher working pressure - this could be explained by the fact that heat transfer is facilitated by higher pressure. It was also demonstrated that by the utilisation of the steam jacket with high temperature, heat can be supplied (from the cylinder to the working steam) in quantity sufficient to prevent (or mitigate) the initial condensation in the cylinder and to re-evaporate the whole of such that may have been condensed.

\subsubsection{Surface heated boiler-less Rankine engine}

The speed of heat transfer is a limiting factor in the steam jacket design, but for certain applications speed is not considered critical. Igobe and Davies [23] Igobo and Davies [22] proposed to use a slowmoving machine to drive a high pressure reverse osmosis process for desalination that works on a cycle time of the order of minutes. In this case, it was proposed to eliminate the traditional boiler (evaporator) of the steam engine and rely on the jacket (which may be thermal oil fed) alone for heat transfer to vaporise the working fluid and to maintain quasi-isothermal expansion. Fig. 67 shows a schematic layout for the cycle, its corresponding temperature-entropy $(T-s)$ is similar to that depicted I in figFig 4b; on operation, water injected into the heated cylinder vaporises on contact with the hot walls, and exerts pressure on the piston to perform work while expanding. Given the relatively higher temperature of the cylinder wall, further heat is transferred to the steam during the expansion process. At the end of expansion, the superheated exhaust steam could be passed through a heat exchanger prior to been condenser, to preheat the condensed fluid pumped for the next cycle. 


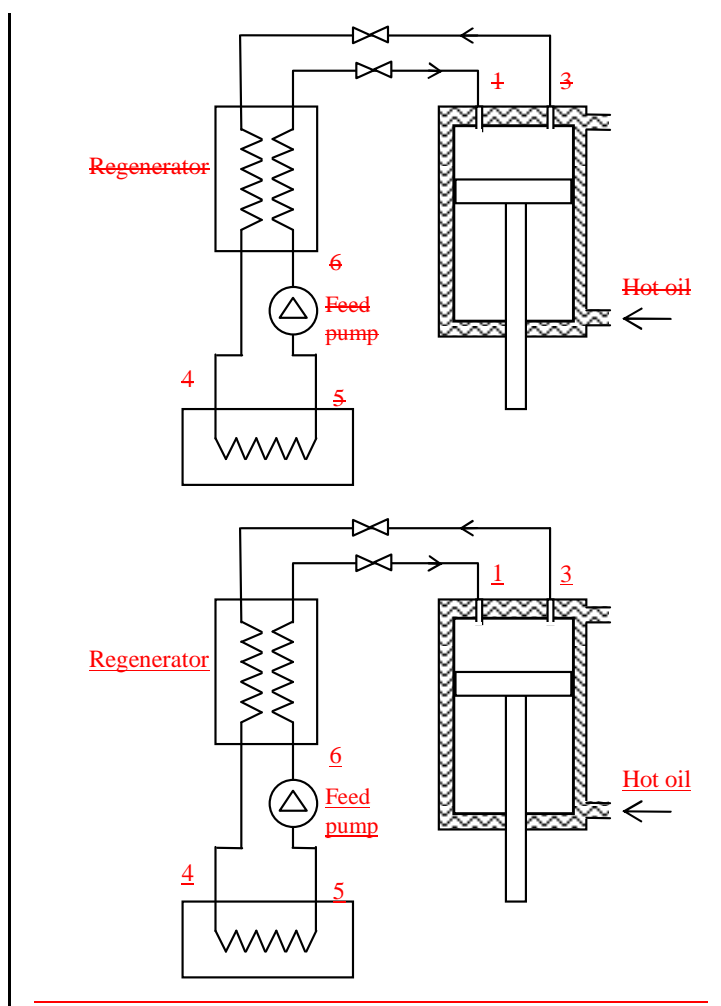

Fig. 67. Schematic of the boiler-less engine [2322]

Parametric analysis of the engine showed that, the heat transfer rate and thus speed of operation will increase with increasing wall temperature and with decreasing cylinder size. Preliminary experiment carried out on a $100 \mathrm{~mm}$ bore cylinder at $250^{\circ} \mathrm{C}$ wall temperature, showed that engine performance increased with the volume of water injected $(0.8-1.6 \mathrm{ml})$. A maximum pressure of about 18 bar and $336 \mathrm{KJ} / \mathrm{kg}$ of specific work output was achieved for $1.6 \mathrm{ml}$ of injected water. The cycle efficiency also increased with the injected water volume, as efficiency range of $14-16 \%$ was achieved, which is about a half of the ideal cycle efficiency. The less-than-ideal performance was attributed mainly to non-isothermal operation as a result of insufficient surface area (of the expansion space) for heat transfer. This assertion is expected, as it has been noted in literature that: in reality, isothermal operation cannot be carried out in reciprocating engine, due to limited heat transfer area [4851].

\subsubsection{Surface heated Rankine cycle scroll engine}

The scroll expander is a compact device with few moving parts compared to the reciprocating engine. Scroll expanders and compressors are widely used in refrigeration cycles and have become popular | for use in small scale ORC heat engines [49].[52]. Among these, engines using isothermal expansion are an interesting option.

Kim et.al. [12][21] proposed a scroll expander with external heating structure which included external fins attached on the scroll casing and a heating jacket (as depicted in fig. 7Fig. 8); such that heat could be effectively transferred from an external source, through the scroll casing into the scroll interior. In the expansion process of the system, the transfer of heat from the scroll interior to the working fluid will reduce the temperature drop that would have otherwise resulted, thus effecting a quasi-isothermal 
expansion, and consequently contributing to improvement in specific work and thermal efficiency. For air as the working fluid, the isothermal process can result in a potential $34 \%$ increase in the expansion work. The system was suggested to be applicable to Ericsson cycle, refrigeration cycle and Rankine cycle.

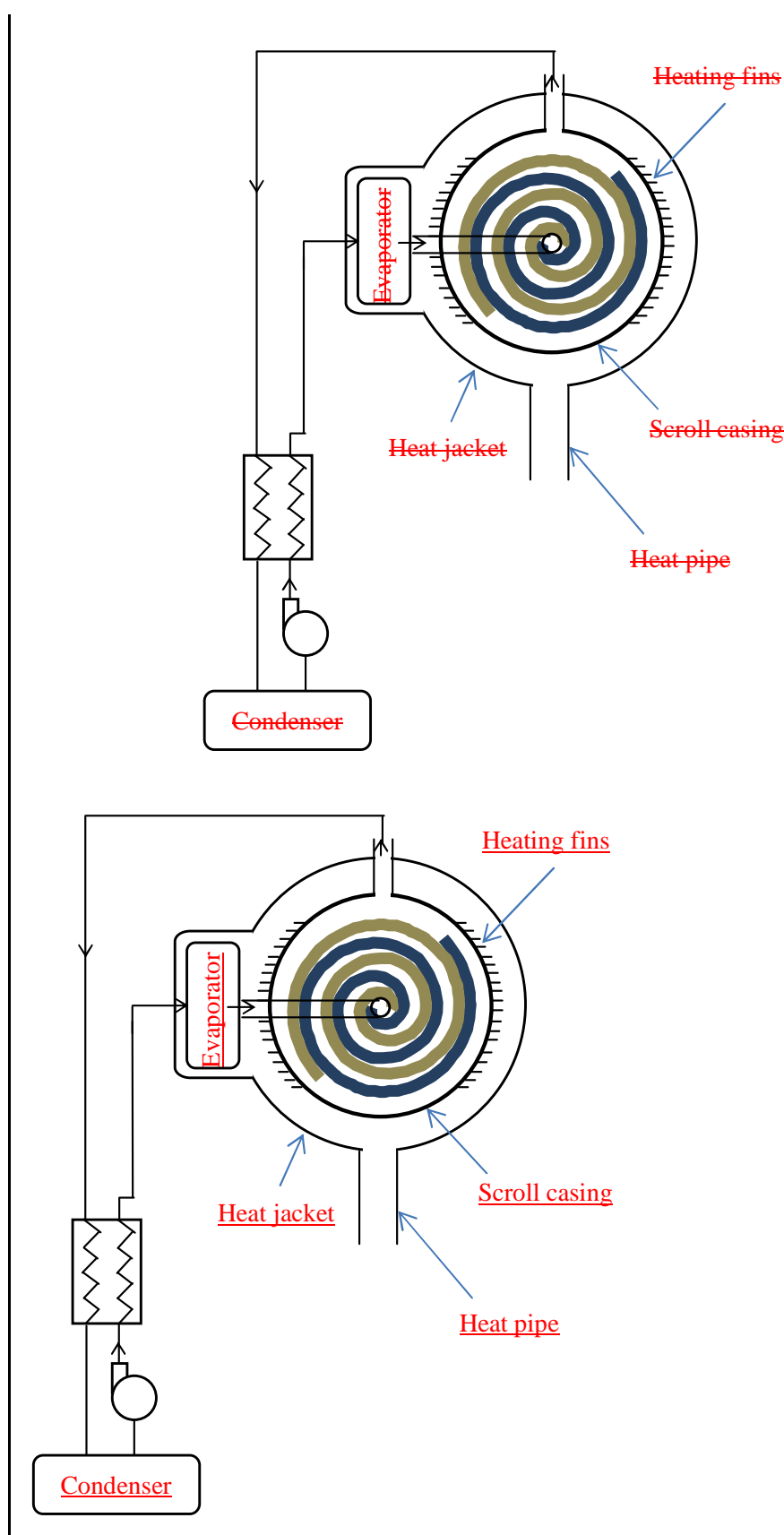

Fig. 7. Schematic of the Rankine cycle with a heated serollexpander [12]

Fig. 8. Schematic of the Rankine cycle with a heated scroll expander [21] 
For use in Rankine cycle, they also highlighted the possibility of the system acting as an expander and partially as a boiler, such that a very wet vapour could be employed as the working fluid at the point of entry into the expander, since the scroll machines are noted for tolerating substantial quantities of liquid fraction. In that case, given that sufficient heat is available from the scroll, the liquid fraction will vaporise during the expansion process, thus tending to reduce the rate of fall in pressure that would have otherwise resulted, and permitting higher volumetric expansion ratio and thereby enhancing the extraction of more work.

\subsection{Summary}

To summarise with regard to the Rankine cycle engine and its implementation with quasi-isothermal expansion, the expander surface heating can achieve significant improvement in performance even though the expansion chamber surface area available for heat transfer may not be sufficient to approach the level of isothermal behaviour reported with the liquid flooding system. On the other hand, the liquid flooding may experience deteriorating performance in reality, mainly because, unlike the expander surface heating, the liquid flooding incurs additional pumping energy input (for the liquid loop) and increased suction pressure drop, which (together with other associated losses) can eventually outweigh the expected performance improvements. From the perspective of technology availability, liquid flooding can be easily implemented, since its main components (scroll compressor, pump and heat exchanger) are readily commercially available. Nevertheless, it is a relatively new technology (that is yet to be fully developed), in comparison to steam jacketing, which can be regarded as a mature technology that has been proven effective and operational. However, for practical consideration for both technologies, proper insulation is recommended, to ensure that the heat loss (from the engine and piping) to the ambient is greatly minimised, so as not to result to a detrimental effect on the overall performance. In addition, further research work should be carried out on modelling of complex, unsteady multi-phase heat transfer with liquid flooding devices; and development of efficient separation mechanism for the flooding liquid separator.

\section{Cryogenic heat engine}

\subsection{Theory and principle of operation}

Cryogenic engines are another example where quasi-isothermal expansion is used. It is interesting to review the works in this area for possible application of similar features to heat powered engines working at higher temperatures.

Cryogenic heat engines utilize the thermodynamic potential between the ambient atmosphere and a cryogenic fluid, which is generally regarded as energy storage medium. The basic ideaconcept of the cryogenic heat engine is to utilize ambient heat from the atmosphere as atheat source to vaperize and superheat aheat a pressurised cryogenic liquid into pressurized gasfluid which can be used to drive a prime mover. This is in contrast with typical heat engines which utilize an energy source at temperature significantly above ambient and use the atmosphere as a heat sink [26, 50].[25]. As with conventional heat engines, the performance of the cryogenic engine is strongly dependent on the cryogenic working fluid employed. A study pointed out the benefits of using low-mass gases (like $\mathrm{H}_{2}$, $\mathrm{He}, \mathrm{Ne}, \mathrm{N}_{2}$, and air) in two-phase system, as having large maximum specific work values [51], with $\mathrm{H}_{2}$ having the largest value. Another cryogen reported elsewhere with high specific work value is $\mathrm{CH}_{4}$ [52].53], with $\mathrm{H}_{2}$ having the largest value. Other common cryogens are hydrocarbons, including liquefied natural gas (LNG), of which methane $\left(\mathrm{CH}_{4}\right)$ is noted for having high specific work output potential [54]. Nevertheless, liquid nitrogen and liquid air are considered most attractive because they are essentially inexhaustible resource (that can be effectively produced from air) with considerable safety and environmental benefits. 
Standard thermodynamic power cycles can be employed to produce useful work from the cryogenic fluid, but the most extensively investigated one is the open system Rankine cycle [18]. For instance, cryogenic gas Stirling cycle could utilise seawater (ambient temperature) as the heat source to heat nitrogen gas in the expander, while liquefied natural gas (LNG) serves as the heat sink to cool the gas during compression [55]. Similarly, ambient evaporation of a cryogenic fluid and condensation by means of LNG as heat sink, can be employed for cryogenic Rankine cycle (Fig. 9a); and multiple cryogenic cycles can be cascaded to yield better cold energy recovery (Fig. 9b and c) [56]. For these closed cycles, propane $\left(\mathrm{C}_{3} \underline{\mathrm{H}}_{8}\right)$ and ethane $\left(\mathrm{C}_{2} \underline{\mathrm{H}}_{6}\right)$ are commonly considered as the working fluids; nevertheless, other low boiling point substances can be employed. The cryogenic power cycle can also be used as the bottom cycle in combined (or hybrid) cycles with other relatively higher temperature power cycles [57]. However, the simplest and most applicable power cycle is the open system (direct expansion) Rankine cycle [58], where the spent exhaust gas is released into the atmosphere. In this case the principle of operation is similar to that of a typical open cycle steam engine.

A schematic of a typical cryogenic heat engine is depicted in fig. 8Fig. 10. The cryogenic liquid stored in a tank (which may be vacuum jacketed) is pumped to the required working pressure; the pressurised liquid is then vaporised and heated in an appropriate ambient heat exchanger system, and then fed to an expander, where it expands to do work. Since the rapid expansion process of the cryogen fluid results in the temperature of the fluid always being less than ambient, the expander will be at a relatively higher temperature than the expanding fluid, thus during the expansion process, further heat may be transferred from the expander to the fluid, resulting to a possible quasi-isothermal expansion process [26]. The $\mathrm{T} s$ diagram of the ideal cycle at critical pressure operation is shown in fig. 8b[25]. The T-s diagram of the ideal cycle at critical pressure operation is shown in Fig. 10b. Process 1-2 indicates the pumping process, process 2-3 is the heating process in the heat exchanger, and process 3-0 is the isothermal expansion. Process $0-4-1$ is the would-be condensation stage i.e.(for closed loop system), or the liquefaction process which takes place remotely in an air processing plant [53]. Nevertheless, the possibility of combining the liquefaction process with the Rankine cycle has been investigated [54].59] (for open system).

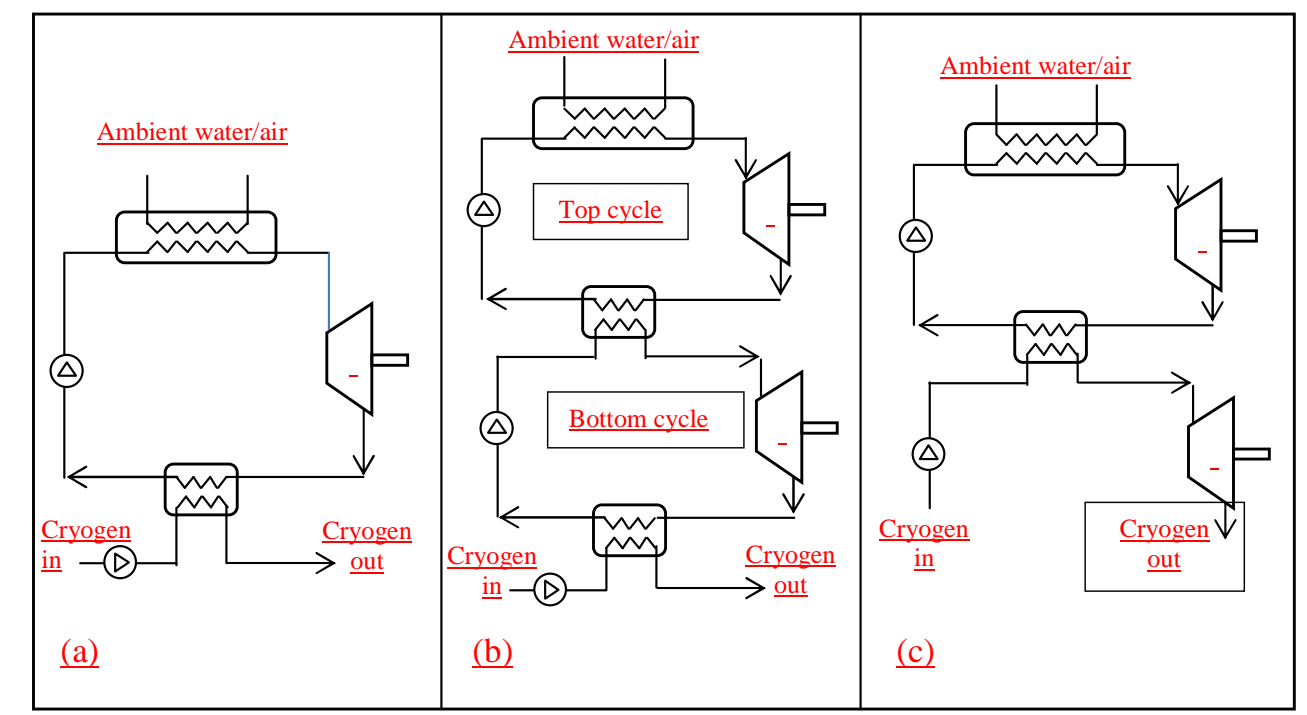

Fig. 9. Schematic configurations of cryogenic Rankine cycles [54]: (a) Rankine cycle, (b) cascaded Rankine cycle, (c) combined closed-open cycle 


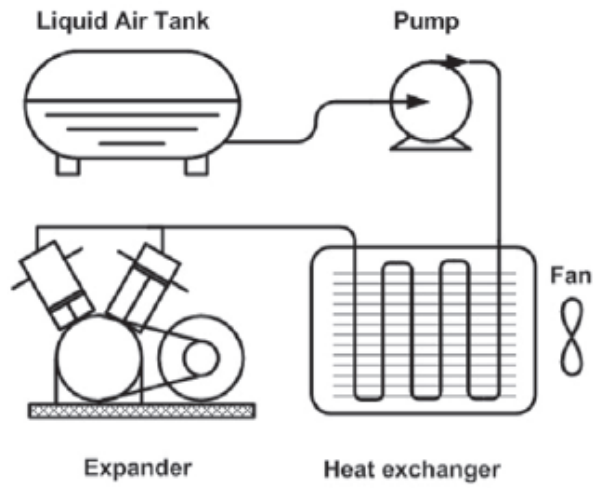

(a)

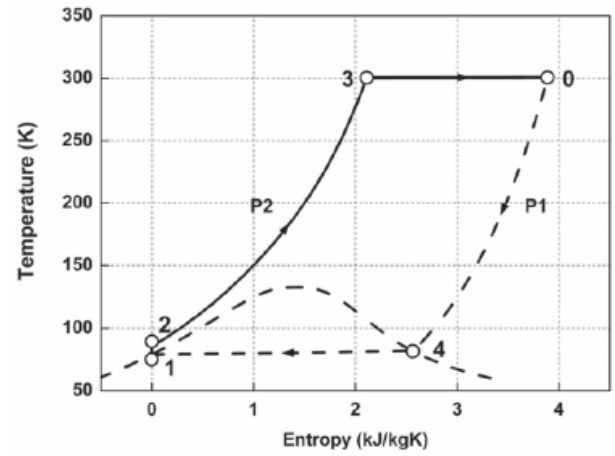

(b)

Fig. 8 10. Schematic of a direct expansion (open system) Cryogenic heat engine [1817]

Field Code Changed

Field Code Changed

\subsection{Studies and performance}

Over the years, there has been investigations on the application of cryogenic heat engine as an automotive propulsion for non-polluting zero emission vehicles, concept and technical feasibility have been evaluated [18,55], and demonstration model cars have been built to test its practicality [56, 57]. Key for practical realisation of the engine is the heat exchanger. Considering the low temperature of the cryogenic fluid, it will be essential for the liquid to be vaporized without the accumulation of frost, so as to avoid deteriorating performance. William et al., [58] developed a frost free heat exchanger for using atmospheric air to vaporize and superheat relatively large quantities of liquid nitrogen without the adverse building up of frost.

Over the years, there have been investigations on the application of cryogenic heat engine for power generation, and also as an automotive propulsion for non-polluting zero emission vehicles; concept and technical feasibility have been evaluated [60], flow simulations in the engine have been carried out [61], and demonstration models have been built to test its practicality [62]. Key for practical realisation of the engine is the heat exchanger. Considering the low temperature of the cryogenic fluid, it will be essential for the liquid to be vaporized without the accumulation of frost, so as to avoid deteriorating performance. William et al., [63] developed a frost free heat exchanger for using atmospheric air to vaporize and superheat relatively large quantities of liquid nitrogen without the adverse building up of frost. Amrit et al. [64] also developed a cryogenic heat exchanger and presented analytical model for turbulent flows.

Research work carried out at the University of Washington highlighted substantial benefits in the overall energy efficiency for isothermal expander over an adiabatic one in eryogenic engines [17].liquid nitrogen cryogenic engines [65]. The study investigated the specific work output as a function of peak cycle pressure for adiabatic and isothermal expansions and showed that the isothermal work increases monotonically with increasing pressure, while that for the adiabatic process is found to be only weakly dependent on peak cycle pressure above $4 \mathrm{MPa}$. For pressure range of 10 to $300 \mathrm{bar}$ at $300 \mathrm{~K}$, the net specific work is 190 to $420 \mathrm{~kJ} / \mathrm{kg}$ and 140 to $190 \mathrm{~kJ} / \mathrm{kg}$ for isothermal and adiabatic conditions respectively. Knowlen [52]

Knowlen [66] studied the performance of two other cryogens (namely $\mathrm{CH}_{4}$ and $\mathrm{C}_{2} \mathrm{H}_{6}$ ) alongside $\mathrm{N}_{2}$ for both isothermal and adiabatic expansion, and also showed that for all the working fluids, at a given injection pressure, the specific work obtainable from isothermal expansion exceeded that of the adiabatic expansion, with the difference greater as pressure is increased. And beyond $3 \mathrm{MPa}$, the adiabatic cycle exhibited relatively very little gain in specific work. The study also examined the use of $\mathrm{N}_{2}$ as a heat sink for different closed loop $\mathrm{CH}_{4}$ and $\mathrm{C}_{2} \mathrm{H}_{6}$ topping cycles, and found that for binary 
| $\left(\mathrm{N}_{2}-\mathrm{CH}_{4}\right)$ and ternary $\left(\mathrm{N}_{2}-\mathrm{CH}_{4}-\mathrm{C}_{2} \mathrm{H}_{6}\right)$ systemscascaded cycles, specific energies in the range of 200$380 \mathrm{~kJ} / \mathrm{kg}$ and $300-450 \mathrm{~kJ} / \mathrm{kg}$ can be realized respectively, depending on the extent of isothermal operation achievable. Yuanwei et al. [67] proposed a Temperature-Energy level-Energy (T- $\Omega-H)$ diagram method for analysing the performance of two different configurations of three-loop cascaded cycles with seawater and LNG respectively as the heat source and heat sink. They claimed that the proposed method facilitates quick optimisation process on a base case design. A number of authors have also explored different closed cycles that use seawater and LNG respectively as the heat source and heat sink. Choi et al. [68] compared the performance of different configurations of two and three loop cascaded cycles and combined (closed-open) cycles in comparison with the conventional single closed or open cycles. The study showed that the cascaded cycles exhibited better performance than the conventional single closed or open cycles; it also showed that, $\mathrm{C}_{3} \underline{H}_{8}-\mathrm{C}_{2} \underline{H}_{6}$ cascaded cycle

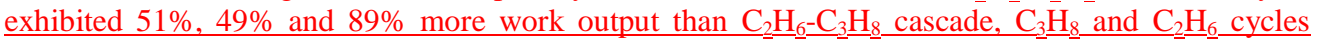
respectively; while the $\mathrm{C}_{3} \underline{H}_{8}$ cycle gave $27 \%$ more work than $\mathrm{C}_{2} \underline{\mathrm{H}}_{6}$. Liu and Guo [69] studied a variant of the cascaded cycle combined with vapour absorption process, the cycle employed a binary mixture of Tetrafluoromethane $\left(\mathrm{CF}_{4}\right)$ and $\mathrm{C}_{2} \underline{\mathrm{H}}_{8}$ as the working fluid. The study showed that, the proposed cycle can achieve $206 \mathrm{~kJ} / \mathrm{kg}$ specific work output, which is $63 \%$ higher than that of a $\mathrm{C}_{3} \underline{H}_{8}$ cycle $(124 \mathrm{~kJ} / \mathrm{kg})$. In a study by $\mathrm{Li}$ et al. [58], an open cycle with two-stage expansion was shown to exhibit $326 \mathrm{~kJ} / \mathrm{kg}$ work output. This compares reasonably with the performance reported for other two-loop cascaded cycles. Hence, although cascading closed cycles can significantly improve performance, it is also possible to achieve reasonable performance improvement with the relative simpler open system, with the aid of multiple expansion stages.

To achieve more work output by isothermal expansion, Knowlen [26] In a bid to avoid drop in expander wall temperature, which could result to deteriorating performance, Knowlen [25] suggested the use of "warmant" anti-freeze liquid (as a heat transfer fluid) to be pumped through the wall-of the expander, so as to maintain the cylinder wallit at near ambient temperature, thus enhancing heat transfer during expansion, hence effecting quasi isothermal operation.. Also, a parametric analysis on engine_(reciprocating expander) geometry showed that long strokes, small bore and low RPM enhances heat transfer during the expansion process. Nevertheless, the transferable heat will be limited by the expander's surface area exposed to the fluid, which will limit the degree of isothermal operation achieved. For standard reciprocating engine (without modifications to cylinder piston geometry), isothermality of about 0.75 has been reported $[18,26]$; and thisFor standard engine (without modifications to cylinder piston geometry), isothermality is typically about 0.75 and can be improved further by enhancing heat transfer during expansion. Further analysis showed that finned piston and cylinder head geometries (fig. 9Fig. 11) having high surface-to-volume ratios can be used to facilitate further heat transfer during the expansion, resulting in potential net work output of 0.85 of | the ideal isothermal work [26].

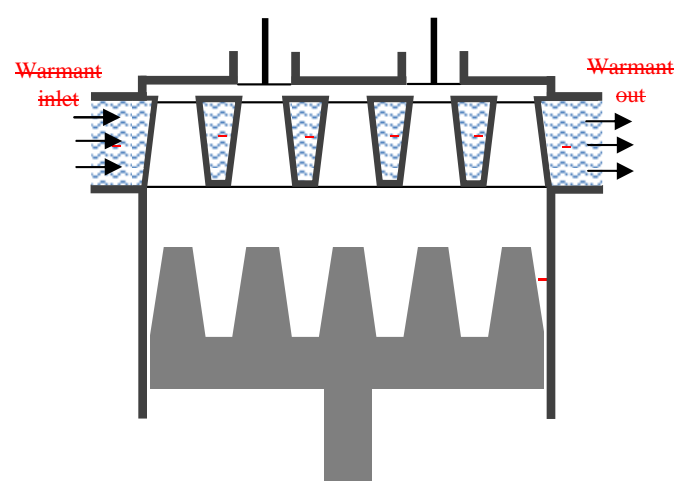

Fig. 9. Conical finned piston and heater core cylinder head [26]
Formatted: Not Highlight

Formatted: Font color: Auto 


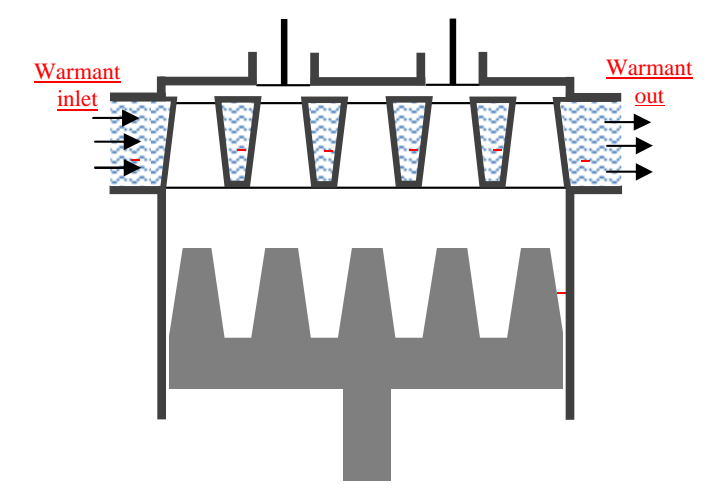

Fig. 11. Conical finned piston and heater core cylinder head [25]

Liquid air is of has similar properties thithto those of liquid nitrogen since air is composed of $78 \%$ nitrogen. Chen et al. [18] studied the performance of a liquid air engine for a range of working pressure and temperatures and reported that over the working temperatures range studied ( $270-320$ $K)$, both the theoretical total and net work output for the engine increases linearly with increasing working temperature. For a working pressure range of 50 to 400 bar, the work output was also found to increase monotonically with increasing pressure and the increase tends to level off at high pressures. ForChen et al. [17] studied the performance of a liquid air engine for a range of working conditions and reported that, for a properly designed and manufactured engine with operating conditions of 100 bar and $300 \mathrm{~K}$, the practical (taking into account the losses associated with conventional engines) net work outputs of the liquid air engine for isothermalities of $\gamma=0.90$ and 0.75 arewere respectively $200 \mathrm{~kJ} / \mathrm{kg}$ and $150 \mathrm{~kJ} / \mathrm{kg}$, which arei.e. respectively about 122 and $66 \%$ higher than that for an adiabatic engine (about $90 \mathrm{~kJ} / \mathrm{kg}$ ). Given that the energy consumption for liquid air | production is about $1080 \mathrm{~kJ} / \mathrm{kg}$ [53][59], the efficiency of the cryogenic engine (in terms of energy in and energy out) for the above stated isothermalites will be about $18.5 \%$ and $13.9 \%$, while that for the adiabatic condition will be $8.3 \%$. However, Ameel et al. [70] indicated that the efficiency of the isothermal cycle can be improved by about $17 \%$, if the liquefaction process is combined with the heat engine.

| Dearman [24, 59]Dearman [23] developed a variant of the cryogenic engine, whereby the cryogenic liquid is directly injected into a heat exchange liquid (water) in a reciprocating expander, thus the heat exchange takes place inside the engine, consequently eliminating the need for the relatively complicated, heavier and expensive heat exchanger as required previously. The principle of operation is such that, when the piston is at the top of the cylinder, water is admitted into the cylinder dead space, and then a little amount of the cryogen is injected into the water. Since the water temperature (ambient) is substantially higher than that of the cryogen, the cryogen rapidly vaporises, builds up pressure, becomes superheated and pushes the piston as it expands to do work. At the return stroke, the spent gaseous cryogen and the water are exhaust out. The water can be recovered, reheated and | pumped back to the cylinder for another cycle-[71].

Wen et al [25] studied the heat transfer behaviour between liquid cryogen and water (as the heat transfer fluid) in Dearman's engine, and reported a much stronger heat transfer than that obtained from boiling on smooth surfaces and flow boiling through pipes, but comparable to that of rough surfaces and pipes with porous inserts. The pressure was seen to develop very rapidly (up to 500 $\mathrm{KPa} / \mathrm{s}$ ) and increased approximately linearly with the injection pressure; thus indicating that high pressure could be effectively developed to run the engine. 
Wen et al [24] studied the heat transfer behaviour between liquid nitrogen and water (as the heat transfer fluid) in Dearman's engine, and reported a much stronger heat transfer than that obtained from boiling on smooth surfaces and flow boiling through pipes, but comparable to that of rough surfaces and pipes with porous inserts. The pressure was seen to develop very rapidly (up to 500 $\mathrm{kPa} / \mathrm{s}$ ) and increased approximately linearly with the injection pressure; thus indicating that high pressure could be effectively developed to run the engine. Morse and Kytomaa [72] also carried out experimental study of the vaporisation of liquid nitrogen and LNG in water, and found that, the evaporation rate is significantly dependent on both the turbulence intensity of the water surface, and the thickness of the cryogenic liquid layer. However, vaporising LNG in water may require safety precautions against possible ignition of the vapour, as has been reported with incidents of LNG spills on sea [73].

\subsection{Summary}

In summary, the cryogenic engine provides an inherent means of effecting quasi-isothermal expansion with ambient temperature. The potential isothermal performance increases with increasing pressure and could be as much as twice that of the adiabatic case. Cascading multiple cycles would give better energy recovery than single closed or open cycles; however, the open cycle is the most applicable. For an operating pressure of $10 \mathrm{bar}$, the potential performance of the liquid nitrogen open cycle cryogenic engine can have an ideal efficiency of $19 \%$ and specific work of $200 \mathrm{~kJ} / \mathrm{kg}$; but this performance is quite low in comparison to that ofthe $27 \%$ ideal efficiency predicted for a surface heated engine operating on steam with similar pressure, which can ideally have $27 \%$ efficiency [23]. Also, the ideal specific work of the cryogen is rather low compared to [22], and the reported $318 \mathrm{~kJ} / \mathrm{kg}$ specific work achieved for a real surface heated (steam jacketed) engine operated at 5 bar [47].[50]. Furthermore, unlike the surface heated engine, although the cryogenic engine has the advantage of not losing heat to the ambient (since it can be at the same or even lower temperature potential with the ambient), it could suffer evaporative losses and safety (explosion) risks at the storage tank; as it slowly absorbs heat from the ambient, which could result to excessive pressure rise [60]. [74].

\section{Vapour Stirling cycle engine}

\subsection{Theory and principle of operation}

The ideal Stirling cycle is a classical implementation of isothermal expansion. Though ideally efficient, it suffers from low specific power output at moderate temperatures and pressures [61, 62]. As a means of increasing the specific power output, the use of condensable working fluid has been investigated in prior arts the vaporisation of liquid at the hot side of the Stirling engine followed by condensation at the cold side has been identified as a viable solution $[27,63]$, the use of refrigerants as working fluid has also been considered [64]. Prior arts (including a number of patents) have investigated various means of employing vapour as the working fluid in the Stirling cycle engine (including liquid piston variants). Though ideally efficient, it suffers from low specific power output at moderate temperatures and pressures [75]. As a means of increasing the specific power output, the use of condensable working fluid has been investigated in prior arts - the vaporisation of liquid at the hot side of the Stirling engine followed by condensation at the cold side has been identified as a viable solution [26], the use of refrigerants as working fluid has also been considered [76]. Prior arts (including a number of patents) have investigated various means of employing vapour as the working fluid in the Stirling cycle engine (including liquid-piston variants). 
| The concept of liquid-piston Stirling (fluidyne) engine is to replace the conventional solid-pistons of Stirling engine with columns of liquid (typically water) in U-tubed cylinder. Unless the liquid in the expansion cylinder has a low vapour pressure at the operating temperature or is separated from the hot gas by some kind of insulating float (generally referred to as dry fluidyne), ample evaporation will take place from the liquid surface and wetted cylinder walls to effect a mixture of gas and vapour working fluid [65]. As such the fluidyne engine can provide both gas and vapour power cycle.[77]. As such the fluidyne engine can provide both gas and vapour power cycle. One critical design parameter in the fluidyne engine is the frictional losses in the oscillating liquid columns [78]. Studies have shown large dry fluidynes to be quite successful, but on the other hand, small dry fluidynes (which generally suffer from the large transient heat-transfer and flow losses associated with small-diameter tubes) have been reported to be impractical in the absence of evaporation [65].[77]. The evaporation tends to raise the pressure during the expansion phase and thus increases the indicated power in the fluidyne engine. Owing to the fact that the power output is available in the form of either pulsating pressure/movement of liquid in a tube, the most obvious application iswas as a pumping engine [66]. However, a rotating shaft power output option have also been identified lately[79]. However, a rotating shaft power output option have also been identified, via the use of hydraulic motor [80] or solid pistons [67]. Here, as shown if fig. 10, a[81]; with the former, as shown if Fig. 12, the solid piston converts the pressure in the liquid piston into a force which can then be applied to a shaft ${ }_{2}$ like conventional engines.

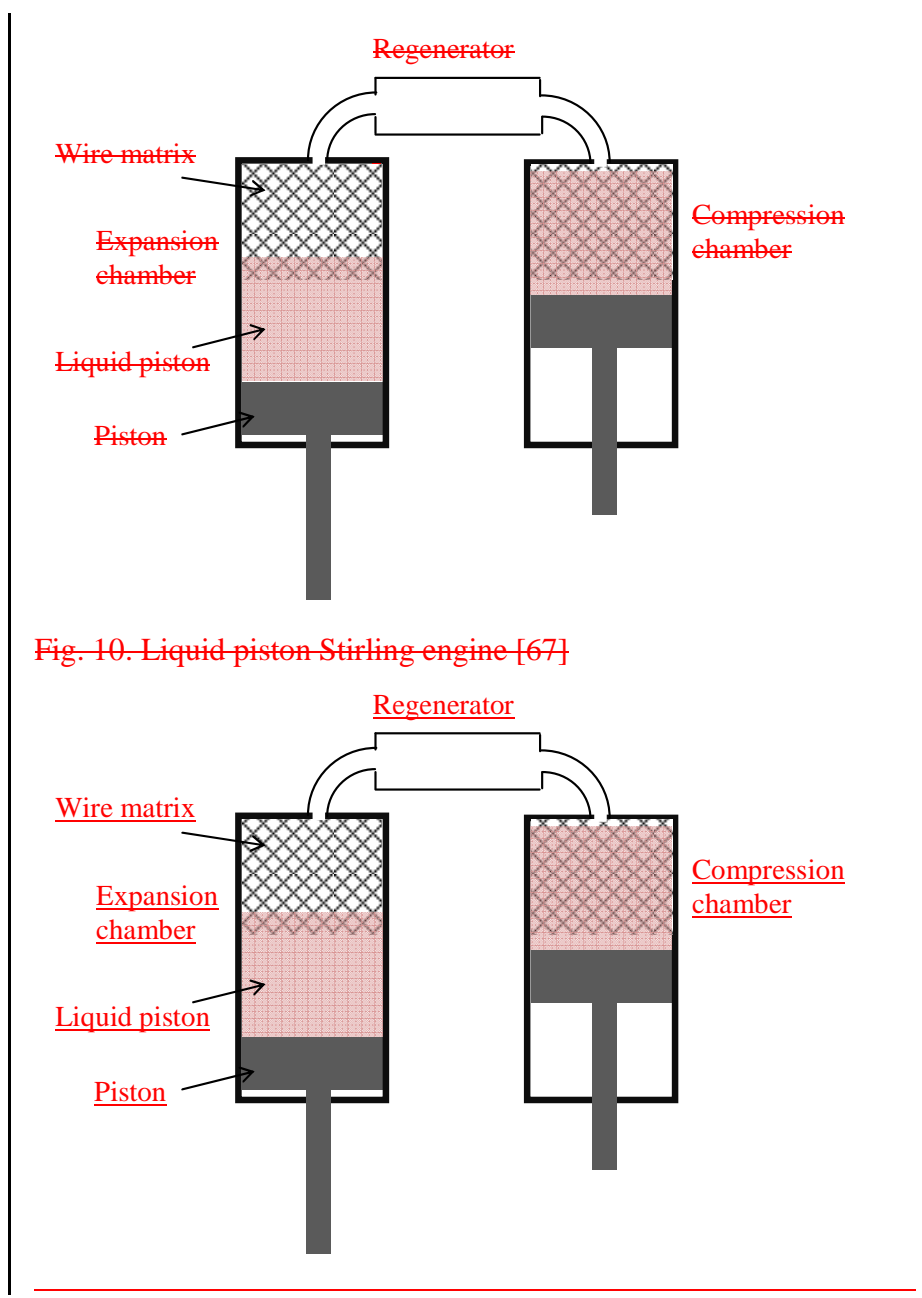


Since liquids can conform to irregular shapes, unlike solid-piston, liquid pistons have the advantage of possibly allowing the adoption of working chambers with very large surface area to volume ratios | such as wire matrix, tube bundle, metal foam, etc. (fig. 10Fig. 12), to substantially improve heat transfer to the working fluid and consequently bring the working fluid behaviour into the nearly isothermal regime (which will result to improved power output and efficiency). However, the high area to volume ratio will result to smaller size of flow passages, increased flow restrictions and thus, increased viscous losses. As such the heat transfer area and the viscous frictional losses must be $\mid$ adjusted to maximize the efficiency of the liquid piston engine $[65,68]$.[82]. Besides the increased viscous losses, the liquid piston also suffers operating stroke and frequency limitations imposed by gravity-controlled oscillation and by surface instability at high frequency; and the need to keep a more | or less constant orientation of the engine $[65,67] \cdot[81]$.

Various concepts involving the conventional solid-piston Stirling engines variants with modifications | on operational configurations have also been recorded. RedersenRedderson [69][83] patented a vapour Stirling machine based on the alpha Stirling configuration. It featured heating and cooling chambers on the hot and cold cylinder tops respectively, and with a regenerator interconnecting the two chambers (fig. 11Fig. 13). But in contrast, the working fluid in the cooling chamber is substantially in the liquid phase as such resulting to a significantly larger swept volume ratio than a conventional Stirling engine. On operation, the upward motion of the cold cylinder piston pumps the fluid through the regenerator into the hot chamber where it gets completely vaporised and superheated and then expands to perform work against the hot piston while gaining further heat from the hot chamber, thus tending to approach isothermal expansion. At the end of expansion, the upward motion of the hot piston pushes the spent vapour through the regenerator and into the condenser where it condenses back to water. As a means of providing output control, a control cylinder is included at the cold section to vary the effective mass of the working fluid within the engine.

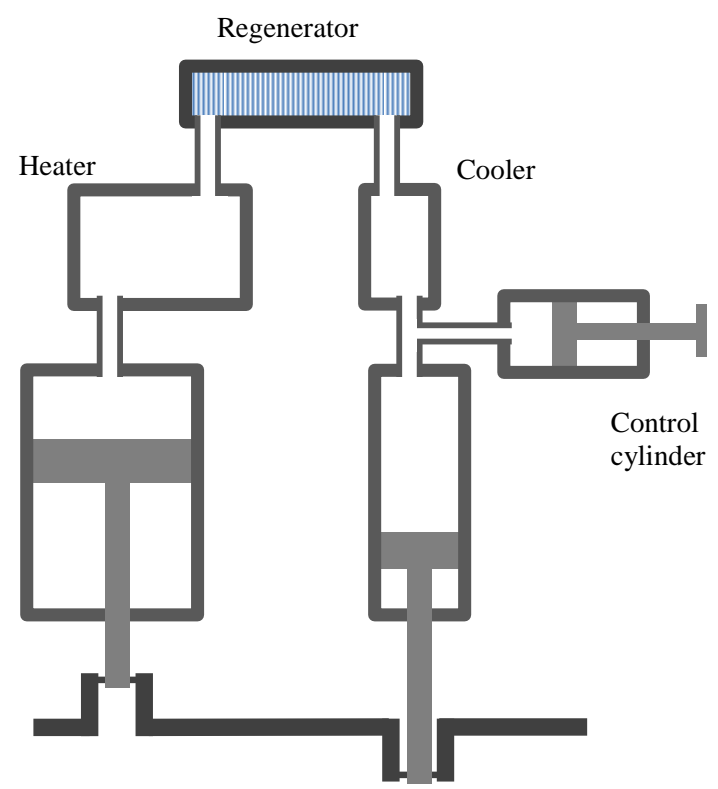

| Fig. 11․․ Vapour Stirling engine [27] 
Davoud and Burke [70][84] patented a condensing vapour Stirling engine, in which at the end of expansion, a portion of the spent vapour is expelled (via a receiver cylinder) and condensed, while the remaining portion is compressed in the power cylinder, during which the weight equivalent of the condensed portion is pump and injected back into the cylinder as a fine spray of water. This was said to lower the entropy and enthalpy of the steam in the cylinder, and thus lower the compression work that would have been required. The compressed steam gets superheated in the heater tubes arrangement at the top dead centre of the cylinder, and then expands against the piston to do work. They later went further to patent a simpler version (with only one cylinder), in which bulk of the spent steam is expelled directly to the condenser. The condensed water is then pumped and injected into the cylinder top dead volume containing the heater tubes where it gets vaporised and superheated [71]. 85$]$.

\subsection{Studies and performance}

West [27][26] developed a two-phase, two component working fluid system for an alpha Stirling engine configuration (fig. 12Fig. 14), in which, the working fluid consists of both a condensable vapour (steam) and permanent gas (air), such that the air is contained in the cold section, and prevented from passing into the hot section by means of controlled evaporation (i.e. steam pressure) in the hot section. Water injected into the evaporator vaporises into the hot cylinder where it expands to do work. The expended vapour then passes into the cold end where it condenses and is subsequently removed.

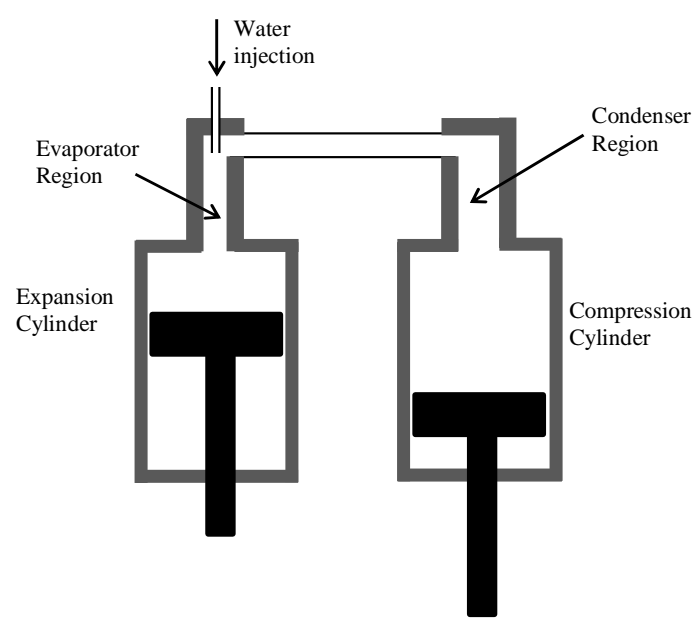

| Fig. 1214. Basic layout of the two-phase, two-component Stirling engine [2726]

The analysis showed that under moderate operating conditions the engine can achieve a cyclic power output at least five times greater than a conventional Stirling-cycle machine of similar dimensions, but at the expense of significantly lower ideal cycle efficiency. Nevertheless, by controlling the rate at which the liquid is evaporated into the expansion cylinder an indicated efficiency in the range of 3 to $9 \%$ at low temperatures $\left(110^{\circ} \mathrm{C}\right.$ to $\left.130^{\circ} \mathrm{C}\right)$ may be achievable even without regeneration.

Isshiki et.al. [28][27], developed a steam Stirling engine which operates as a hybrid of Stirling and Rankine systems, such that the engine featured a power cylinder (with heating tube at the cylinder 
top), displacer cylinder and a regenerator in between, as with Stirling; but also has injection/exhaust port, thus spent steam could be ejected, condensed, pump and re-vaporised externally just like Rankine. On operation, when the power piston comes near its top dead centre, saturated steam from the external boiler injected into the displacer cylinder, passes through the regenerator and heater, and then expands into power cylinder at near constant high temperature. On the return stroke, the spent steam passes through the regenerator and is exhausted to a condenser where it gets condensed and then pumped back to the boiler. Experiment carried out on a mini scale prototype operated at $0.2 \mathrm{Mpa}$ (gauge) and $250^{\circ} \mathrm{C}$ showed that output power of about 12 watt was achieved at $400 \mathrm{rpm}$. This is significantly higher (approximately five times) than the reported 2.6 watt achieved for a conventional gas Stirling engine operated at $320^{\circ} \mathrm{C}$ [7286].

\subsection{Summary}

In summary, the use of vapour as the working fluid in Stirling engines can result in power outputs about five times larger compared to conventional non-condensable gas working fluid. To facilitate more heat transfer to the fluid to approach a more isothermal behaviour, liquid pistons could be employed to allow the expansion space to be enhanced with high surface area geometries like wire matrix. However, it introduces practical issues that will need to be further investigated. As such it is recommended that further research be carried out on: modelling the behaviour of the oscillating liquid in liquid piston devices with particular attention to viscous forces and inertia effect of the liquid oscillation. Since the various technologies presented are still in the concept or early development stage, further experimental studies should be carried to give a better insight on their practical realisations; and optimization of the various full engine dynamics to maximize efficiency and power density for specific applications.

\section{Conclusion}

To convert low-grade thermal energy into useful work, external combustion engines using vapour cycles (though relatively less efficient) have been preferred over those using gas powered cycles due to the former's higher specific work output and smaller engine size. Relative to the traditional ideal adiabatic expansion process in the vapour power cycle engines, quasi-isothermal expansion has been found to improve the specific work output and cycle efficiency of the engines.

Two main methods of effecting the quasi-isothermal expansion have been identified - liquid flooding and expander surface heating. The expander surface heating has been studied for both reciprocating and rotary expanders; however there are more references in the literature for its use with reciprocating expanders. Liquid flooding is referenced more for use with rotary expanders.

In practical performance of the quasi-isothermal expansion, studies have showed that liquid flooded expansion approaches isothermal behaviour with increasing oil fraction; but at the expense of deteriorating overall performance, that was partly attributed to the resulting increased suction pressure drop and viscous losses. On the other hand, the expander surface heating has been shown to achieve significant improvement in performance (over $40 \%$ and $20 \%$ increase in efficiency and $40 \%$ increase in-specific work output and efficiency respectively). Here, a relatively slower operating speed is required to enable significant heat transfer during the expansion process as the cylinder wall surface area available for heat transfer limits the isothermal operation. However expander geometries with high surface-to-volume ratios (such as fins) could be employed to facilitate heat transfer and further improve performance, as has been demonstrated with cryogenic engine. Furthermore, much higher surface area to volume ratios (such as wire matrix) could be easily realized with the adoption of liquid pistons.

With regards technology availability, it can be seen that the expander surface heating has been ready for many decades in the form of steam jacketing, whereas liquid flooding is a relatively new 
technology that is yet to be fully developed. Nevertheless, it can be easily implemented with commercially available parts.

This paper concludes that, while quasi-isothermal vapour power cycle engines have the potential to significantly improve the performance in a number of applications (e.g. desalination, transport and heat recovery), there are research areas to be further examined. As such, it is recommended that further research be carried out on: modelling of complex, unsteady multi-phase heat transfer with liquid flooding devices to predict performance and tailor to applications; modelling the behaviour of the oscillating liquid in liquid piston devices with particular attention to inertia and viscous losses; and the investigation (selection) of other appropriate liquids and working fluids for a range of low temperature operations. Further experimental studies are also receommendedrecommended to give better insights on the practical realisations and optimisations of the technologies presented as concepts or early developmental stages.

$$
\text { (. }
$$

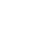

Formatted: Font: $11 \mathrm{pt}$

\section{$\underline{\text { Acknowledgement }}$}

We acknowledge support from the School of Engineering and Applied Science, Aston University, in the form of a PhD scholarship for O. N. Igobo.

\section{References}

[1] International Energy Agency (IEA). Key world energy statistics. 20112012 ed. Paris, France: OECD/IEA; 20112012.

[2] Internal Energy Agency (IEA). World energy outlook-, Executive summary. 2012 ed. Paris, France: OECD/IEA; 2012.

[3] Resch G, Held A, Faber T, Panzer C, Toro F, Haas R. Potentials and prospects for renewable energies at global scale. Energy Policy. 2008;36(11):4048-56.

[4[3] Jacobson MZ, Delucchi MA. Providing all global energy with wind, water, and solar power, Part I: Technologies, energy resources, quantities and areas of infrastructure, and materials. Energy Policy. 2011;39(3):1154-69.

[5] Department of Energy and Climate Change (DECC). Renewable Heat Incentive (RHI). https://www.gov.uk/government/policies/increasing the use of low carbon technologies/supporting pages/renewable-heat-incentive-rhi; accessed June 2013.

[6[4] KPMG-International. Taxes and incentives for renewable energy. Toronto, Canada;: KPMG; June 2012.

| [75] Campos MC, Vargas JVC, Ordonez JC. Thermodynamic optimization of a Stirling engine. Energy. 2012;44(1):902-10. 
[8ㅁ] Park Jk, Ro PI, Lim SD, Mazzoleni AP, Quinlan B. Analysis and optimization of a quasiisothermal compression and expansion cycle for ocean compressed air energy storage (OCAES). Oceans, 2012: IEEE; 2012. p. 1-8.

[97] Redderson RH. Vapor stirling heat machine. US Patents; 1989.

[10[8] Alanne K, Saari K, Kuosa M, Jokisalo J, Martin AR. Thermo-economic analysis of a microcogeneration system based on a rotary steam engine (RSE). Applied Thermal Engineering. 2012;44(0):11-20.

[9] Markides CN. The role of pumped and waste heat technologies in a high-efficiency sustainable energy future for the UK. Applied Thermal Engineering. 2012;53:197-209.

[11] Cicconardi S, Jannelli E, Perna A, Spazzafumo G. A steam cycle with direct combustion of hydrogen and oxygen and an isothermal expansion. Hydrogen Power: Theoretical and engineering selutions: Springer; 1998 . p. 50510.

[12]Kim YM, Shin $\mathrm{O}$, Le J.A $\mathrm{A}$, International compressor engineering conference, Purdue: paper 1635; 2004 .

[10] Bianchi M, De Pascale A. Bottoming cycles for electric energy generation: Parametric investigation of available and innovative solutions for the exploitation of low and medium temperature heat sources. Applied Energy. 2011;88(5):1500-9.

[11] Cengel YA, Boles MA. Thermodynamics, an engineering approach. 7th ed. NewYork, USA: McGraw-Hill, 2011.

[12] Cengel YA, Cimbala JM, Turner RH, Kanoglu M. Fundamentals of thermal-fluid sciences. 4th ed. NewYork, USA: McGraw-Hill, 2012.

[13] Cravalhe EG, Smith Jt.Rajput RK. Engineering Thermodynamies.thermodynamics. 3rd ed. Massachusetts, USA: Pitman, 1981 Jones and Bartlett, 2010.

[14] O'Kelly P. Computer Simulation of Thermal Plant Operations. New York, USA: Springer; 2012.

[15] NIST Standard Reference Database. Thermophysical Properties of Fluid Systems. http://webbook.nist.gov; accessed November-webbook.nist.gov; accessed 1/11/2013.

[16[16] Moran MJ, Shapiro HN, Boettner DD, Bailey M. Fundamentals of engineering thermodynamics. 7th ed. New Jersey, USA: John Wiley \& Sons, 2010.

[17ł Roger GFC, Maynew YR. Engineering thermolynamies and heat trafer. London, UK: 1965:

[17] Knowlen C, Hertzberg A, Mattick A. Cryogenic automotive propulsion. AIA 94 4224; 1994.

[18] Chen H, Ding Y, Li Y, Zhang X, Tan C. Air fuelled zero emission road transportation: A comparative study. Applied Energy. 2011;88(1):337-42.

[19]18] Lemon V, Bell I, Groll EA, Bratn J. Analysis of liquid-fled expansion using a seroll ex ler. In Pu Pa $1323 ; 2008$

[20] Bell IH, Lemort V, Groll EA, Braun JE, King GB, Horton WT. Liquid flooded compression and expansion in scroll machines-Part II: Experimental testing and model validation. International Journal of Refrigeration. 2012;35(7):1890-900. 
[2119] Woodland BJ, Groll EA, Braun JE, Horton WT. Performance benefits for organic Rankine cycles with flooded expansion and internal regeneration. International refrigeration and air conditioning conference. Purdue University: Paper 1134; 2010.

| [2220] Lemort V, Declaye S, Quoilin S. Experimental characterization of a hermetic scroll expander for use in a micro-scale Rankine cycle. Proceedings of the Institution of Mechanical Engineers, Part A: Journal of Power and Energy. 2012;226(1):126-36.

\section{[23[21] Kim YM, Shin D, Lee J. A scroll expander with heating structure and their systems. International compressor engineering conference, Purdue: paper 1635; 2004.}

[22] Igobo ON, Davies PA. A high-efficiency solar Rankine engine with isothermal expansion. International Journal of Low-Carbon Technologies. 2013;8(suppl 1):i27-i33.

[2423] The Dearman Engine Company. http://www.dearmanengine.com/cms/liquid-air/; accessed June-22/6/2013.

[2524] Wen D, Chen H, Ding Y, Dearman P. Liquid nitrogen injection into water: pressure build-up and heat transfer. Cryogenics. 2006;46(10):740-8.

[2625] Knowlen C, Williams J, Mattick A, Deparis H, Hertzberg A. Quasi-isothermal expansion engines for liquid nitrogen automotive propulsion. SAE paper 972649. 1997.

[2726] West CD. Two-phase, two-component Stirling engine with controlled evaporation. Oak Ridge National Lab., TN(Tennesse, USA);: 1982.

[2827] Isshiki N, KOJiMA H, Ushiyama I, Isshiki S. Report on the developments of steam super Stirling engine. Energy Conversion Engineering Conference and Exhibit, 2000(IECEC) 35th Intersociety: IEEE; 2000. p. 111-9.

[28] Couper JR, Penney WR, Fair JR, Walas SM. 8 - Heat Transfer and Heat Exchangers. In: Couper JR, Penney WR, Fair JR, Walas SM, editors. Chemical Process Equipment (Third Edition). Boston, USA: Butterworth-Heinemann; 2012. p. 161-221.

[29] Cheng C-H, Yang H-S, Keong L. Theoretical and experimental study of a 300-W beta-type Stirling engine. Energy. 2013;59:590-9.

[30] Cicconardi S, Jannelli E, Perna A, Spazzafumo G. A steam cycle with an isothermal expansion: the effect of flowvariation. International journal of hydrogen energy. 1999;24(1):53-7.

[31] Stosic N, Milutinovic L, Hanjalic K, Kovacevic A. Experimental investigation of the influence of oil injection upon the screw compressor working process. International Compressor Engineering Conference. Purdue University: paper 687; 1990.

[32] Sakuda A, Sawai K, Iida N, Hiwata A, Morimoto T, Ishii N. Performance improvement of scroll compressor with new sealing-oil supply mechanism. International Conference on Compressors and their Systems: No. C591/019; 2001.

[33] Hugenroth J, Braun J, Groll E, King G. Liquid-flooded Ericsson cycle cooler: Part 1Thermodynamic analysis. International Refrigeration and Air conditioning Conference. Purdue University: Paper 823; 2006.

[34[34] Wang W, Wu Y-t, Ma C-f, Xia G-d, Wang J-f. Experimental study on the performance of single screw expanders by gap adjustment. Energy. 2013;62(0):379-84. 
[35] Declaye S, Quoilin S, Guillaume L, Lemort V. Experimental study on an open-drive scroll expander integrated into an ORC (Organic Rankine Cycle) system with R245fa as working fluid. Energy. 2013;55:173-83.

[35] Zhou N, Wang X, Chen Z, Wang Z. Experimental study on Organic Rankine Cycle for waste heat recovery from low temperature flue gas. Energy. 2013;55:216 25 .

[36] Hugenroth J, Braun J, Groll E, King G. Thermodynamic analysis of a liquid-flooded Ericsson cycle cooler. International Journal of Refrigeration. 2007;30(7):1176-86.

[37] Hugenroth J, Braun J, Groll E, King G. Experimental investigation of a liquid-flooded Ericsson cycle cooler. International Journal of Refrigeration. 2008;31(7):1241-52.

[38] Bell $\underline{H \mathrm{H}}$, Lemort V, Groll EA, Braun J, Groll E. Development of liquidJE, King GB, Horton WT. Liquid-flooded compression and expansion in scroll machines - Part I: Model development. International Journal of Refrigeration. 2012;35(7):1878-89.

[39] Bell IH, Groll EA, Braun JE, King GB, Horton WT. Optimization of a scroll compressor and expander models.for liquid flooding. International Compresser Engineering Conference. Purdue University: Paper 1872; 2008Journal of Refrigeration. 2012;35(7):1901-13.

[3940] Halm NP. Mathematical modeling of scroll compressors [Master Thesis]:]. Indiana, USA: Purdue University, USA, 1997.

[40] Chen Y, Halm NP, Groll EA, Braun JE. Mathematical modeling of scroll compressors part I: compression process modeling. International Journal of Refrigeration. 2002;25(6):731 50.

[41] Chen Y, Braun JE, Groll EA. Modeling of hermetic scroll compressors: model development. HVAC\&R Research. 2004;10(2):129-52.

[42[42] Lemort V, Bell I, Groll EA, Braun J. Analysis of liquid-flooded expansion using a scroll expander. International compressor engineering conference at Purdue: Paper 1323; 2008.

[43] Williams JD. Design of a liquid nitrogen vaporization system for automotive propulsion [PhD Thesis]:]. Washington, USA: University of Washington, USA, 1997.

[4344] Cicconardi S, Jannelli E, Perna A, Spazzafumo G. Parametric analysis of a steam cycle with a quasi-isothermal expansion. International journal of hydrogen energy. 2001;26(3):275-9.

| [44도] Woodland BJ, Braun JE, Groll EA, Horton WT. Organic Rankine cycle with flooded expansion and internal regeneration. US Patents; 2011.

| [4546] Woodland BJ, Krishna A, Groll E, Braun JE. Thermodynamic comparison of organic Rankine cycles employing liquid-flooded expansion or a solution circuit. Applied Thermal Engineering. 2013;61(2):859-65.

| [4647] Bell I, Groll E, Braun J, Horton WT. Experimental testing of an oil-flooded hermetic scroll compressor. International Journal of Refrigeration. 2013;36(7):1866-73.

[47[48] Kim Y-M, Shin D-G, Lee S-Y, Favrat D. Isothermal transcritical CO< sub $>2</$ sub $>$ cycles with TES (thermal energy storage) for electricity storage. Energy. 2013;49:484-501.

[49] Rogers GFC, Mayhew YR. Engineering thermodynamics work and heat transfer. London, UK: Longmans, 1965. 
[50] Clark DK. The Steam engine: A treaties on steam engines and boilers. London, UK: Blackie and Sons limited, 1890.

[4851] Kim H, Kim W, Kim H, Kim S. Applicability of scroll expander and compressor to an external power engine: Conceptual design and performance analysis. International Journal of Energy Research. 2012;36(3):385-96.

[4952] Cho S-Y, Cho C-H, Ahn K-Y, Lee YD. A study of the optimal operating conditions in the organic Rankine cycle using a turbo-expander for fluctuations of the available thermal energy. Energy 2013; http://dx.doi.org/10.1016/i.energy.2013.11.013.Energy 2013;64:900-11.

[50] Ordonez C. Cryogenic heat engine. American Journal of Physies. 1996;64(4):479 81.

[51[53] Ordonez C, Plummer M. Cold thermal storage and cryogenic heat engines for energy storage applications. Energy Sources. 1997;19(4):389-96.

[52[54] Li Y, Chen H, Ding Y. Fundamentals and applications of cryogen as a thermal energy carrier: A critical assessment. International Journal of Thermal Sciences. 2010;49(6):941-9.

[55] Dong H, Zhao L, Zhang S, Wang A, Cai J. Using cryogenic exergy of liquefied natural gas for electricity production with the Stirling cycle. Energy. 2013;63:10-8.

[56] Zhu HM, Liu HW, Sun H. Exergy Analysis of Cascade Ethylene-Propane Rankine Cycle with Cold Energy Recovery of LNG. Applied Mechanics and Materials. 2012;170:2489-93.

[57] Xia G, Sun Q, Cao X, Wang J, Yu Y, Wang L. Thermodynamic analysis and optimization of a solar-powered transcritical CO2 (carbon dioxide) power cycle for reverse osmosis desalination based on the recovery of cryogenic energy of LNG (liquefied natural gas). Energy. 2014;66:643-53.

[58] Li Y, Wang X, Jin Y, Ding Y. An integrated solar-cryogen hybrid power system. Renewable Energy. 2012;37(1):76-81.

[59] Knowlen C, Mattick A, Buckner AP, Hentzberg A. High efficiency energy conversion systems for liquid nitron automobiles. SAE paper 981898.1998.

[53] Castle W. Air separation and liquefaction: recent developments and prospects for the beginning of the new millennium. International Journal of Refrigeration. 2002;25(1):158-72.

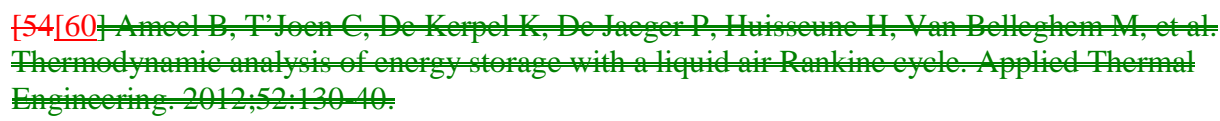

[55] Dooley J, Hammond R. Concept evaluation of automotive propulsion using liquid air/nitrogen. Final report. R and D Associates, Marina del Rey, CA (California, USA); 1982.

[56[61] Tian CZ, Yuan GJ, Chen GJ. Cylinder Flow Simulation of Liquid Nitrogen Engine Based on STAR-CD. Applied Mechanics and Materials. 2013;344:31-6.

[62] Plummer M, Koehler C, Flanders D, Reidy R, Ordonez C. Cryogenic heat engine experiment. Advances in cryogenic engineering. 1998;43:1245-52.

[57] Vitt PD. Operational characteristics of a liquid nitrogen powered automobile [Masters Thesis]: Washington University, USA, 1998.

[58[63] Williams J. Cryogenic automobile propulsion: heat exchanger design and performance issues. Proceedings of AIAA 19th IECEC. CA, US: AIAA 97-0017; 1997. 
[59664] Amrit J, Douay C, Dubois F, Defresne G. Cryogenic heat exchanger with turbulent flows. European Journal of Physics. 2012;33(1):189.

[65] Knowlen C, Hertzberg A, Mattick A. Cryogenic automotive propulsion. AIAA 94-4224; 1994.

[66] Knowlen C, Mattick A, Bruckner AP, Hertzberg A. High efficiency energy conversion systems for liquid nitrogen automobiles. SAE paper 981898. 1998.

[67] Yuanwei L, Hongchang Y, Chongfang M. Analysis and optimization of the power cycle based on the cold energy of liquefied natural gas. Measuring Technology and Mechatronics Automation (ICMTMA), 2011 Third International Conference on: IEEE; 2011. p. 455-8.

[68] Choi I-H, Lee S, Seo Y, Chang D. Analysis and optimization of cascade Rankine cycle for liquefied natural gas cold energy recovery. Energy. 2013;61:179-95.

[69] Liu Y, Guo K. A novel cryogenic power cycle for LNG cold energy recovery. Energy. 2011;36(5):2828-33.

[70] Ameel B, T'Joen C, De Kerpel K, De Jaeger P, Huisseune H, Van Belleghem M, et al. Thermodynamic analysis of energy storage with a liquid air Rankine cycle. Applied Thermal Engineering. 2012:52:130-40.

[71] Dearman's liquid air engine could rival battery systems. Professional Engineering; Feb 2012. p. 9.

[69[72] Morse TL, Kytömaa HK. The effect of turbulence on the rate of evaporation of LNG on water. Journal of Loss Prevention in the Process Industries. 2011;24(6):791-7.

[73] Esteves AS, Reis Parise JA. Mathematical modeling of cryogenic spills onto quiescent sea waters followed by pool fires of liquefied natural gas (LNG). Applied Thermal Engineering. 2013;59(1):587$\underline{98 .}$

[74] Aceves SM, Petitpas G, Espinosa-Loza F, Matthews MJ, Ledesma-Orozco E. Safe, long range, inexpensive and rapidly refuelable hydrogen vehicles with cryogenic pressure vessels. International Journal of Hydrogen Energy. 2012;38(5):2480-9.

[61] Obernberger I, Carlsen H, Biedermann F. State of the art75] Sripakagorn A, Srikam C. Design and future developments regarding small scale biomass CHP systems with-performance of a special focus on ORC andmoderate temperature difference Stirling engine-technologies. International Nordic Bioenergy Conference 2003. p. 17.

[62] Thombare D, Verma S. Technological development in the Stirling cycle engines.. Renewable and Sustainable-Energy-Reviews. 2008;12(1):1 38. 2011;36(6):1728-33.

[63] Walker G, Agbi B. Thermodynamic aspects of stirling engines with two phase, two component working fluids. Transactions of the Canadian Society for Mechanical Engineering. 1973;2(1):1-8.

[64[76] Huang D, Wu F. Research of Refrigerant Phase-Change Stirling-Cycle Heat Engines. International conference on Measuring Technology and Mechatronics Automation (ICMTMA). Shangshai: IEEE; 2011. p. 1088-91.

[6577] West CD. Liquid-piston Stirling machines. 2nd International Conference on Stirling Engines. Shanghai, China1984.p. 1-10. 
[6678] Stevens JW. Low Capital Cost Renewable Energy Conversion With Liquid Piston Stirling Engines. ASME 2010 4th International Conference on Energy Sustainability: American Society of Mechanical Engineers; 2010. p. 479-84.

[79] West CD. Stirling engines and irrigation pumping. Tennessee, USA: Oak Ridge national laboratory, USA; 1987.

[6780] Mauran S, Martins M, Stitou D, Semmari H. A novel process for engines or heat pumps based on thermal-hydraulic conversion. Applied Thermal Engineering. 2012;37(0):249-57.

[81] Van de Ven J, Gaffuri P, Mies B, Cole G. Developments towards a liquid piston Stirling engine. International Energy Conversion Engineering Conference, Cleveland, Ohio: Paper 5635; 2008.

| [6882] Van de Ven JD. Mobile hydraulic power supply: Liquid piston Stirling engine pump. Renewable Energy. 2009;34(11):2317-22.

[6983] Redderson RH. Vapor stirling heat machine. US Patents; 1989.

[7084] Davoud JG, Burke Jr JA. Condensing vapor heat engine with two-phase compression and constant volume superheating. US Patents; 1977.

[71도] Burke Jr JA, Davoud JG. Condensing vapor heat engine with constant volume superheating and evaporating. US Patents; 1978.

| [7286] Çinar C, Aksoy F, Erol D. The effect of displacer material on the performance of a low temperature differential Stirling engine. International Journal of Energy Research. 2012;36(8):911-7. 


\section{Figures}

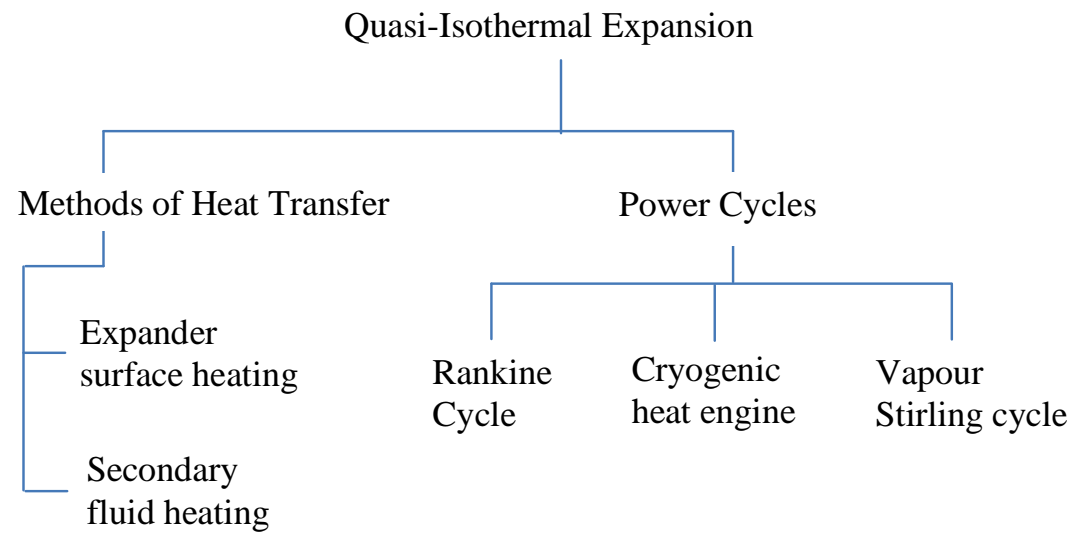

Fig. 1. Overview of the review approach

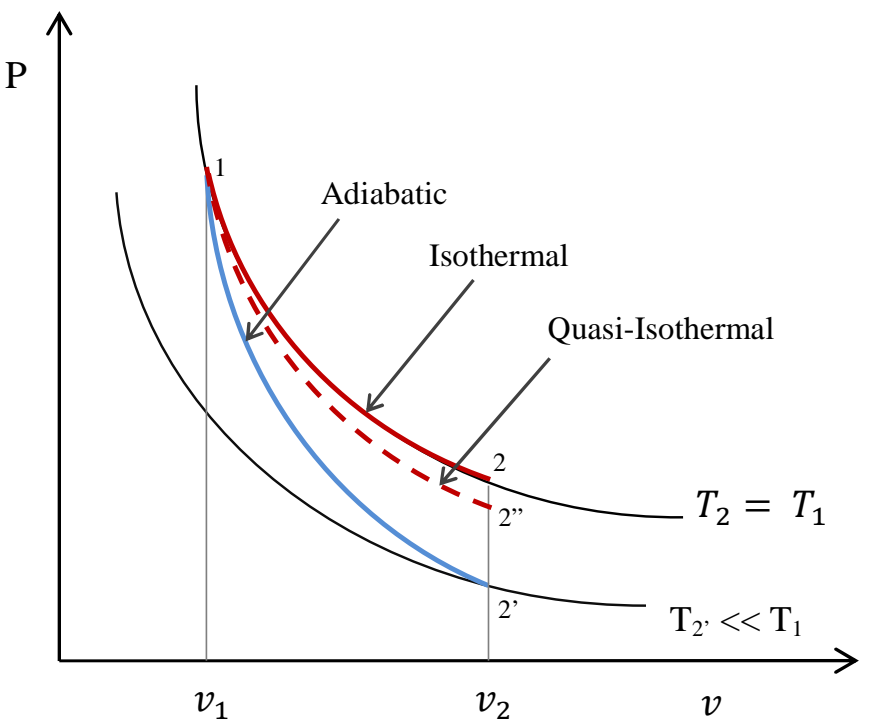

Fig. 2. Graphical representation of isothermal and adiabatic expansion processes 


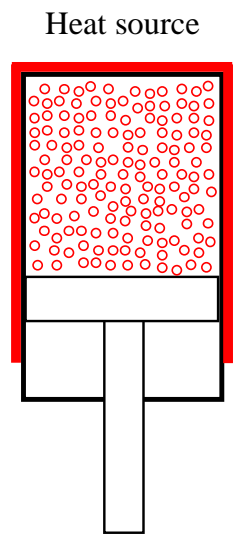

(a)

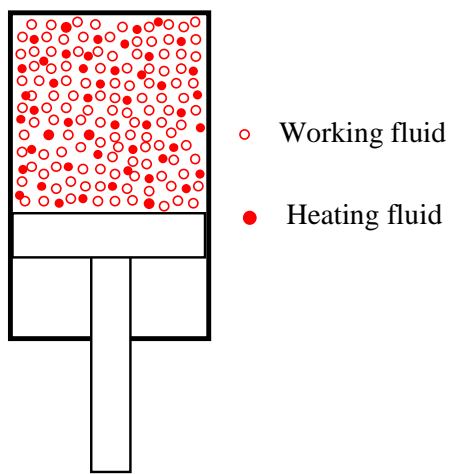

(b)

Fig. 3. The two main means of heat transfer used to achieve isothermal expansion: (a) expander surface heating; (b) secondary fluid heating system

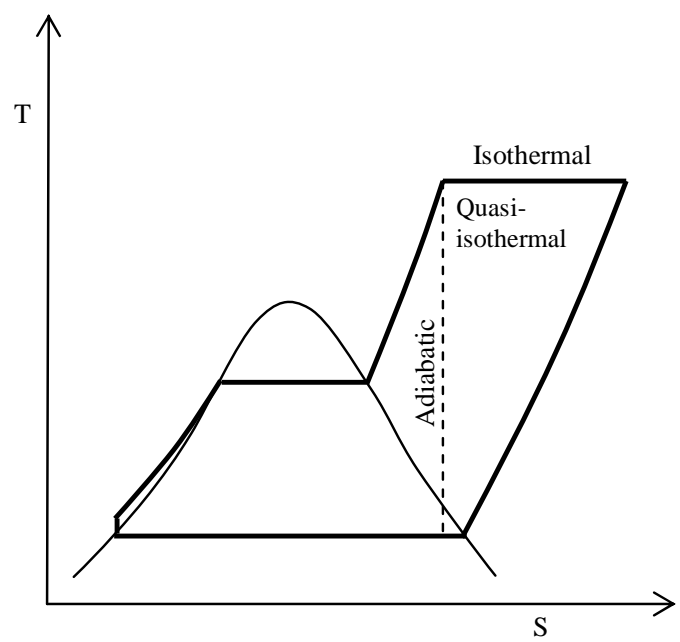

(a)

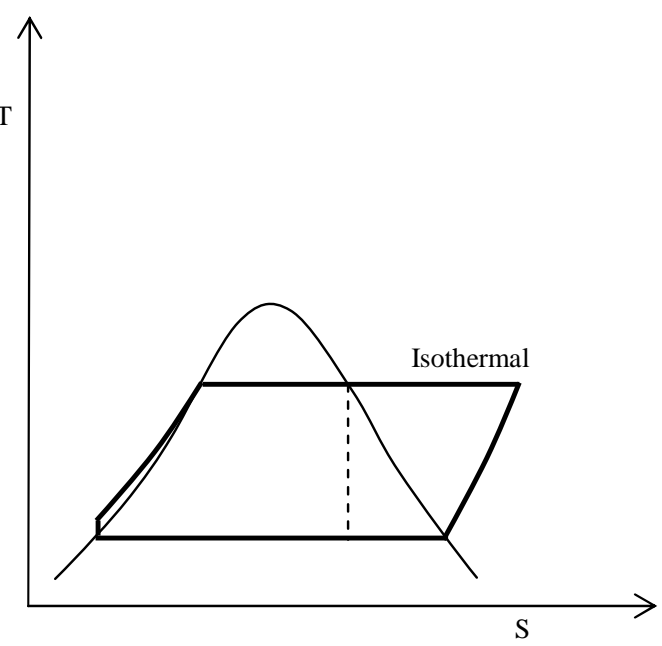

(b)

Fig. 4. T-s diagrams of Rankine cycle with isothermal expansion, (a) starting from superheated state [30]; (b) starting from saturated state [44]. 


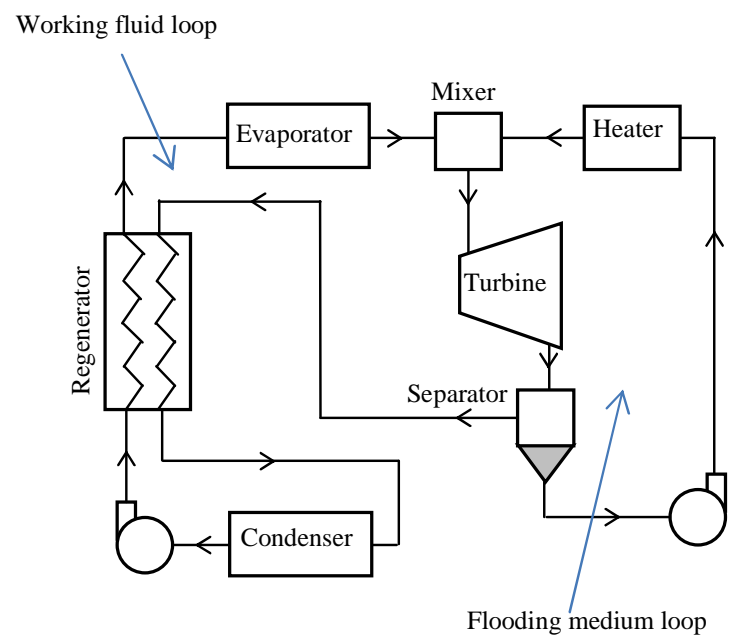

Fig. 5. Schematic of the liquid flooded ORC [19]

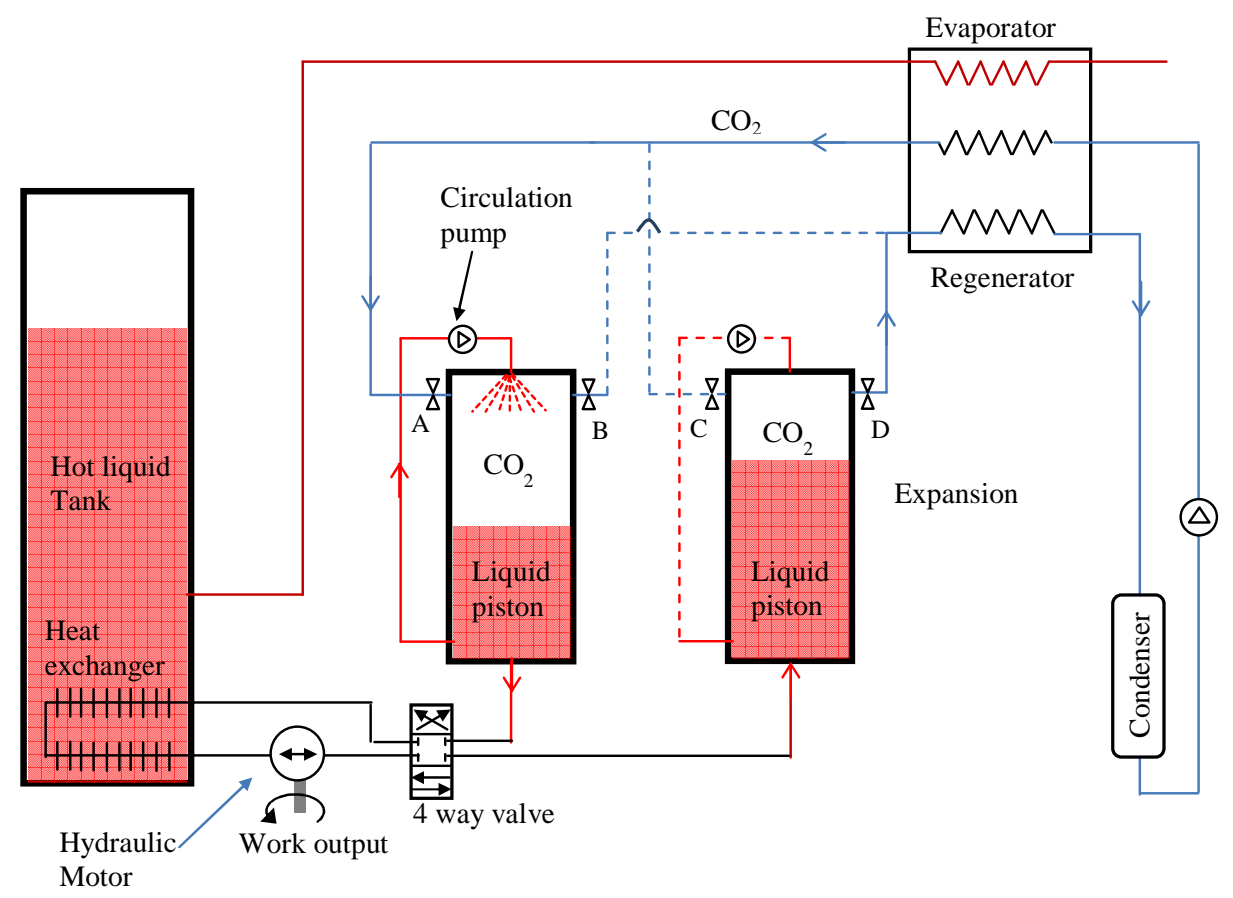

Fig. 6. Isothermal TEES system [48] 


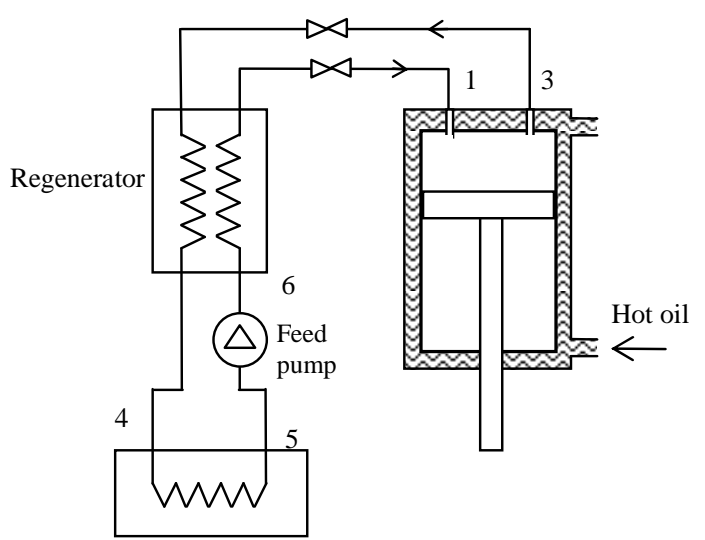

Fig. 7. Schematic of the boiler-less engine [22]

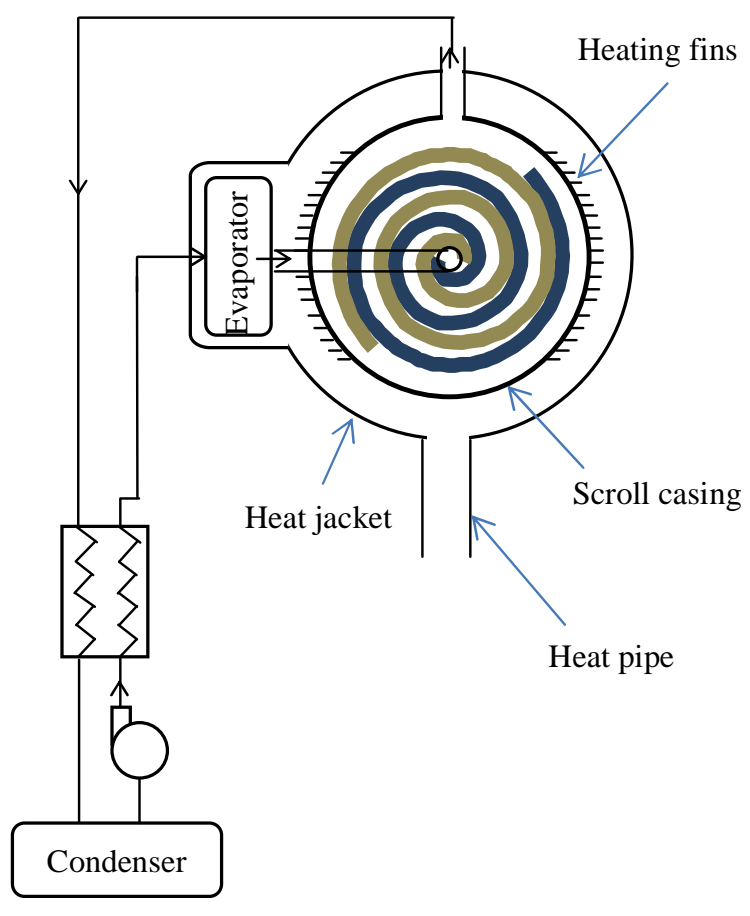

Fig. 8. Schematic of the Rankine cycle with a heated scroll expander [21] 


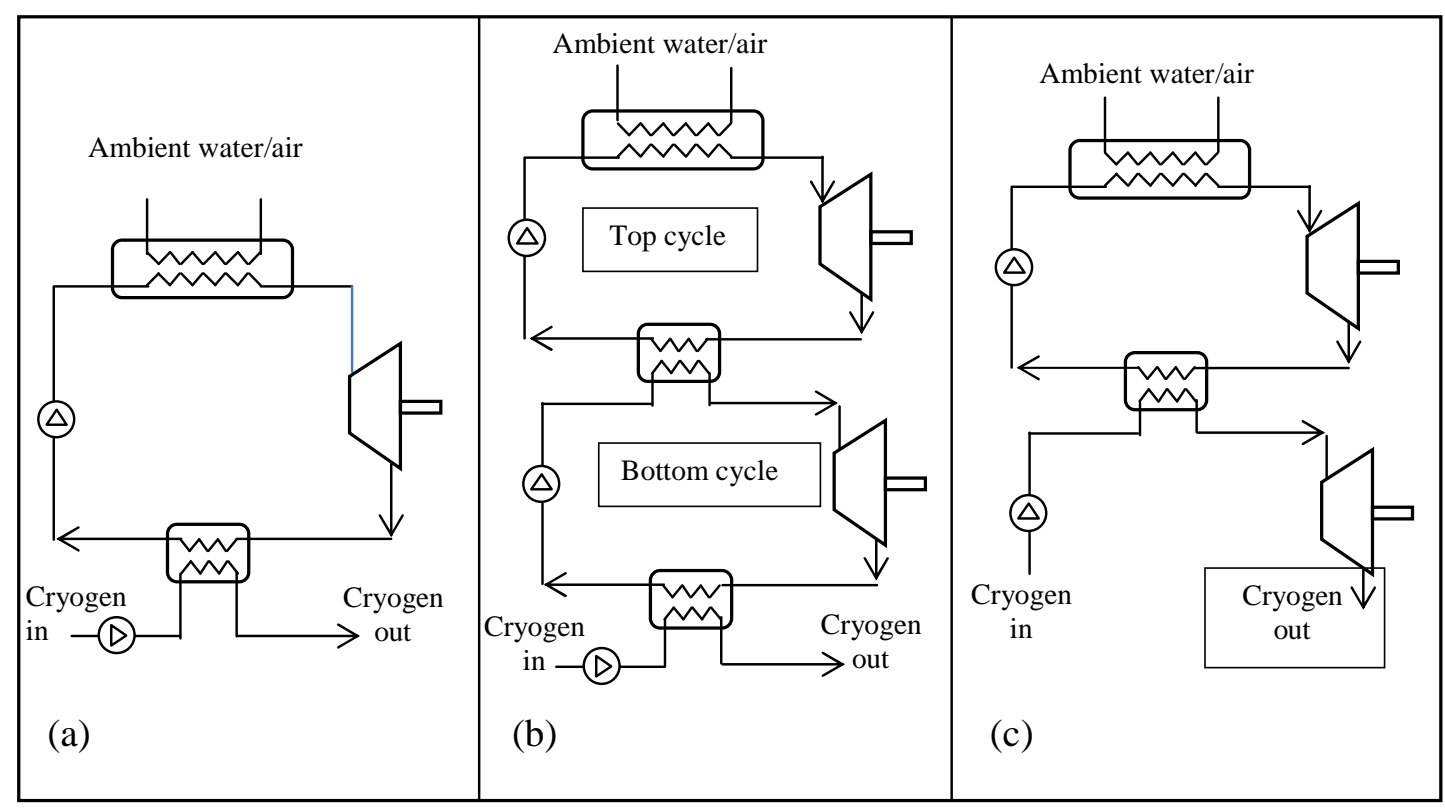

Fig. 9. Schematic configurations of cryogenic Rankine cycles [54]: (a) Rankine cycle, (b) cascaded Rankine cycle, (c) combined closed-open cycle

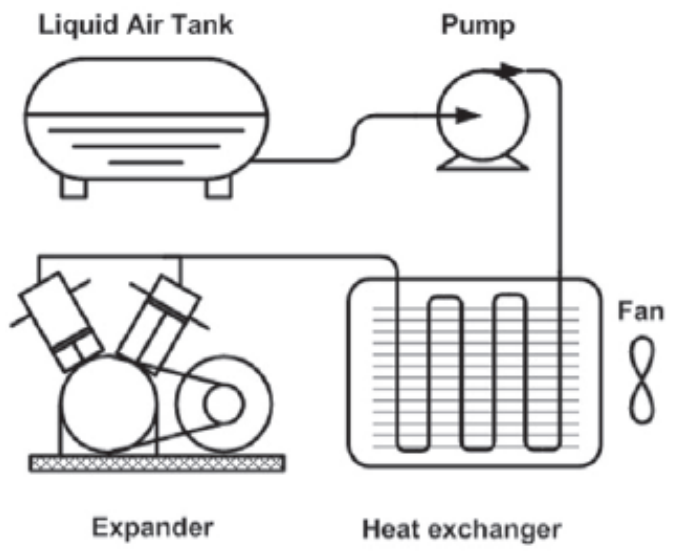

(a)

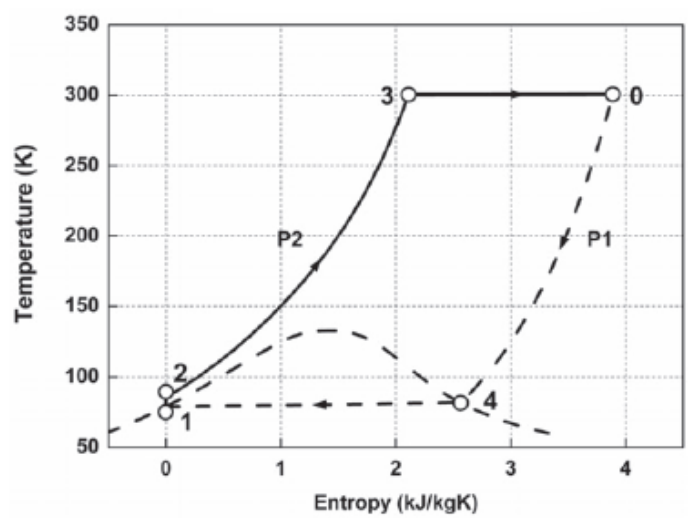

(b)

Fig. 10. Schematic of a direct expansion (open system) Cryogenic heat engine [17] 


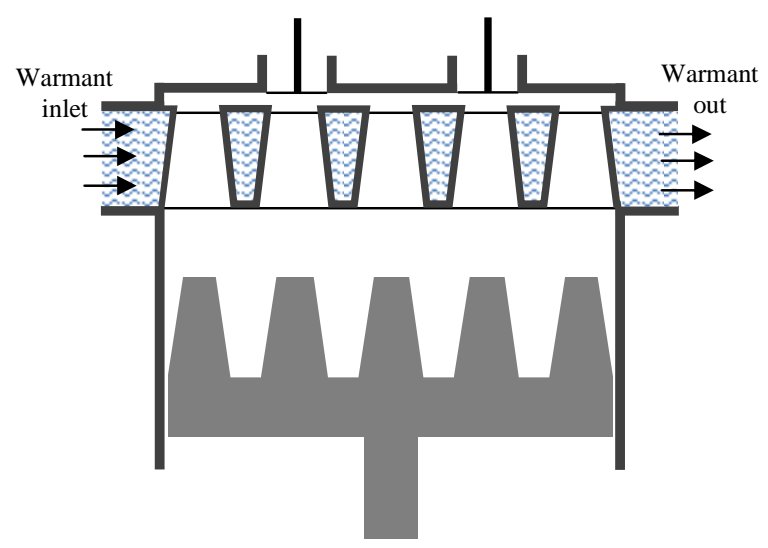

Fig. 11. Conical finned piston and heater core cylinder head [25]

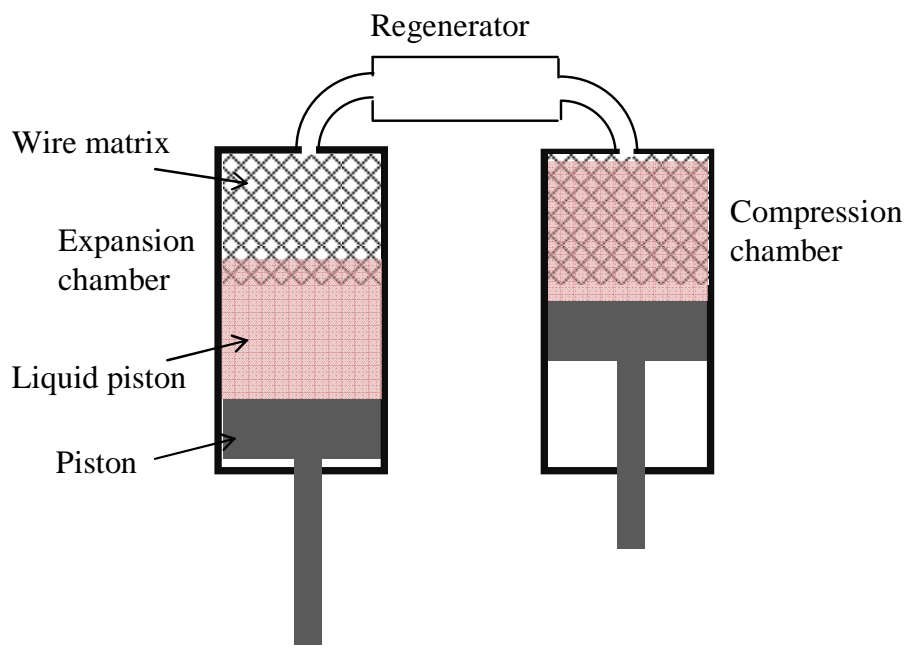

Fig. 12. Liquid piston Stirling engine [81] 


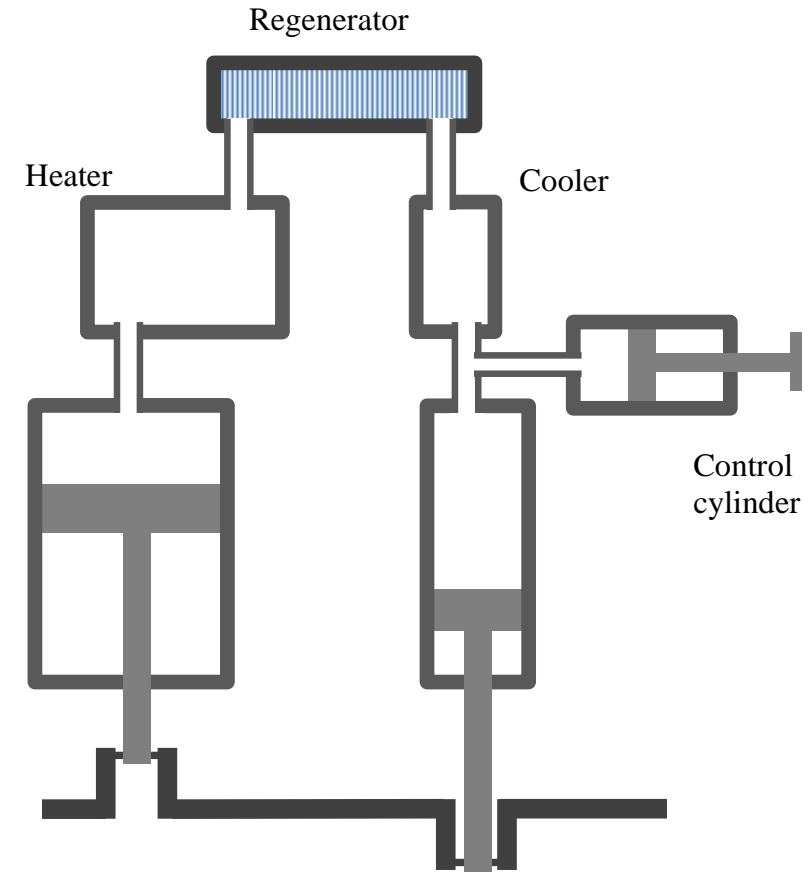

Fig. 13. Vapour Stirling engine [7]

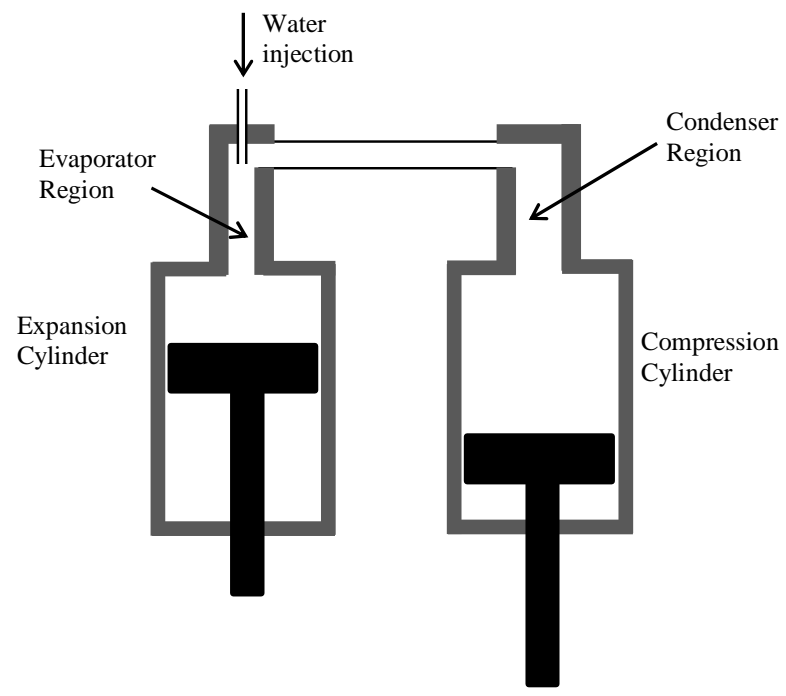

Fig. 14. Basic layout of the two-phase, two-component Stirling engine [26] 


\section{Tables}

Table 1. Heating methods and the applicable power cycles for quasi-isothermal operation, with relevant examples from the literature

\begin{tabular}{|c|c|c|}
\hline Applications & Secondary fluid heating & $\begin{array}{l}\text { Expander surface } \\
\text { heating }\end{array}$ \\
\hline $\begin{array}{l}\text { Rankine cycle engine } \\
\text { (section 3) }\end{array}$ & $\begin{array}{l}\text { Theoretical study of } \\
\text { liquid flooded scroll } \\
\text { turbine, using various } \\
\text { fluids [19] } \\
\text { Experimental study of the } \\
\text { effect of flooding liquid } \\
\text { quantity in scroll turbine } \\
\text { [20] }\end{array}$ & $\begin{array}{l}\text { Theoretical study of } \\
\text { surface heated scroll } \\
\text { turbine [21] } \\
\text { Experimental study of } \\
\text { surface heated } \\
\text { reciprocating cylinder } \\
\text { [22] }\end{array}$ \\
\hline $\begin{array}{l}\text { Cryogenic engine } \\
\text { (section } 4)\end{array}$ & $\begin{array}{l}\text { Experimental studies of } \\
\text { evaporating cryogenic } \\
\text { liquid in water }[23,24]\end{array}$ & $\begin{array}{l}\text { Theoretical studies of } \\
\text { surface heated } \\
\text { reciprocating cylinder } \\
{[23,25]}\end{array}$ \\
\hline $\begin{array}{l}\text { Stirling cycle engine } \\
\text { (section } 5)\end{array}$ & & $\begin{array}{l}\text { Theoretical studies of } \\
\text { controlled evaporation } \\
\text { in Stirling engine [26, } \\
27] \\
\text { Experimental study of } \\
\text { vapour Stirling engine } \\
\text { [27] }\end{array}$ \\
\hline
\end{tabular}

Table 2. Combinations of different working fluids and flooding liquid

\begin{tabular}{|c|c|c|c|c|}
\hline Working fluid & $\begin{array}{l}\text { Flooding } \\
\text { liquid }\end{array}$ & $\begin{array}{l}\text { Expansion } \\
\text { device }\end{array}$ & Ref. & $\begin{array}{l}\text { Study } \\
\text { type }\end{array}$ \\
\hline \multirow{2}{*}{$\begin{array}{l}\text { Ammonia (R717) } \\
\text { Carbon dioxide (R744) } \\
\text { R410A } \\
\text { R600a } \\
\text { n-pentane } \\
\text { R245fa }\end{array}$} & Water & \multirow{2}{*}{ Scroll } & \multirow[t]{2}{*}{ [19] } & \multirow[t]{2}{*}{$\mathrm{T}$} \\
\hline & Zerol 60 & & & \\
\hline R245fa & $\begin{array}{l}\text { Compressor } \\
\text { oil }\end{array}$ & Scroll & [20] & Ex \\
\hline Liquid air & Water & $\begin{array}{l}\text { Reciprocating } \\
\text { cylinder }\end{array}$ & $\begin{array}{l}{[23,} \\
24]\end{array}$ & Ex \\
\hline
\end{tabular}

T. Theoretical

Ex. Experimental 